\title{
Supplementary Information Greenhouse Gas Emission Mitigation Pathways for Urban Passenger Land Transport under Ambitious Climate Targets
}

Alexandre Milovanoff ${ }^{1 *}$, Laura Minet ${ }^{1}$, Lynette Cheah ${ }^{2}$, I. Daniel Posen ${ }^{1}$, Heather L. MacLean ${ }^{1}$, Rajasekhar Balasubramanian ${ }^{3 *}$

1: Civil \& Mineral Engineering, University of Toronto

2: Engineering Systems and Design, Singapore University of Technology and Design, Singapore

3: Civil \& Environmental Engineering, National University of Singapore

*: alexandre.milovanoff@mail.utoronto.ca; ceerbala@nus.edu.sg

This document complements the paper entitled "Greenhouse Gas Emission Mitigation Pathways for Urban Passenger Land Transport under Ambitious Climate Targets" published in Environmental Science and Technology. Section 1 presents all the data and assumptions used to apply the developed model to Singapore. Section 2 presents additional results. The developed model (CURTAIL) and case-study is also an open-source model that can be found in a Zenodo repository ${ }^{1}$.

47 pages; 23 figures; 21 tables 


\section{Table of Contents}

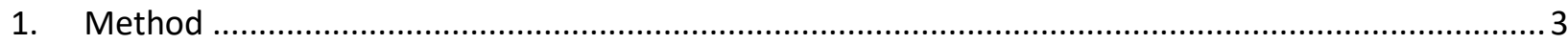

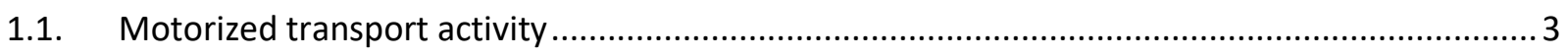

1.1.1. Historical motorized transport activity .................................................................... 3

1.2. Passenger transport fleet modelling................................................................................... 7

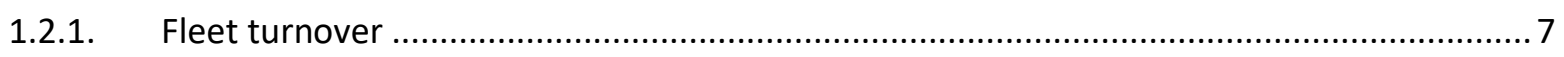

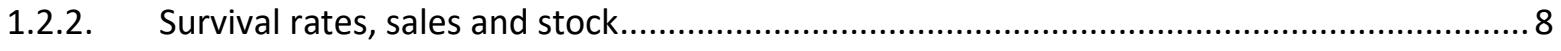

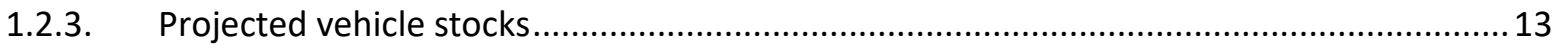

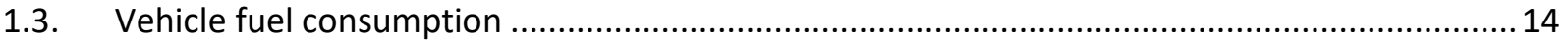

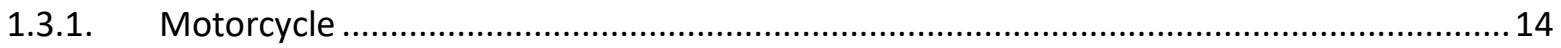

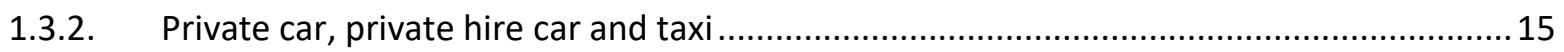

1.3.3. Public bus, private bus and school bus ................................................................... 18

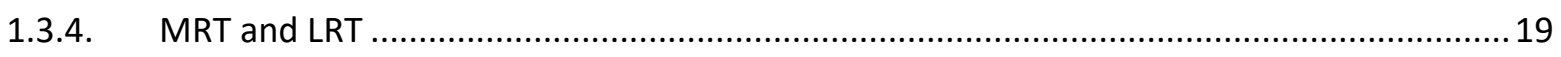

1.3.5. On-road degradation factors ............................................................................... 19

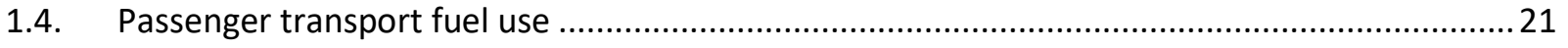

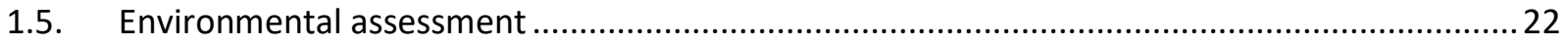

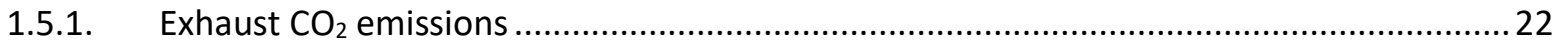

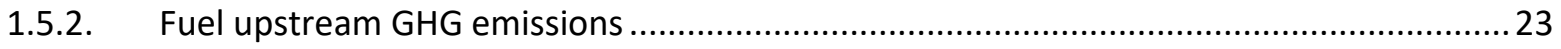

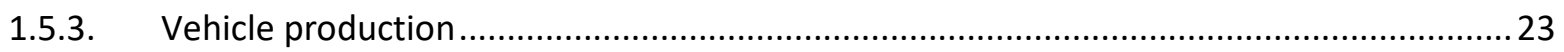

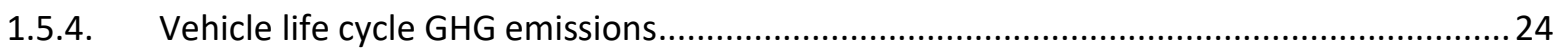

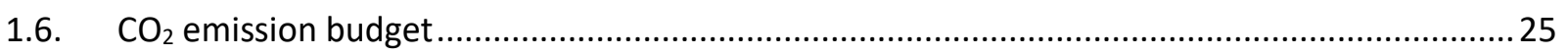

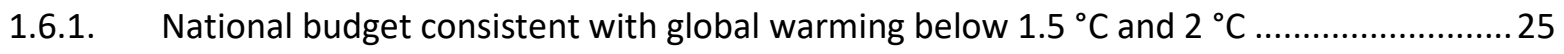

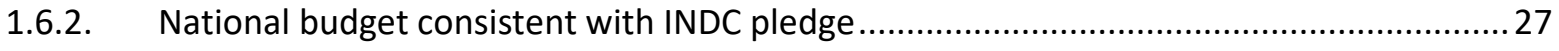

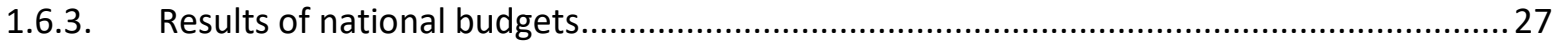

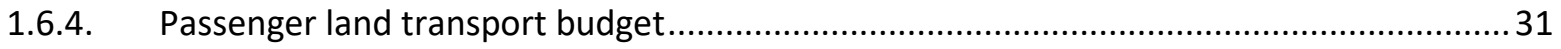

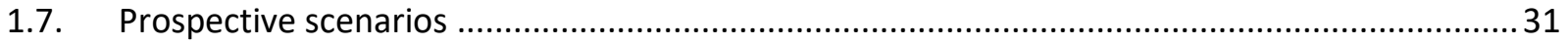

1.7.1. Avoid: Total motorized passenger transport activity .................................................. 31

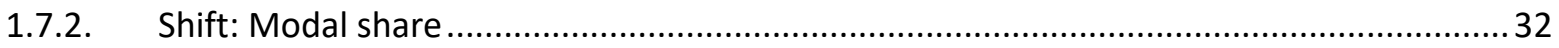

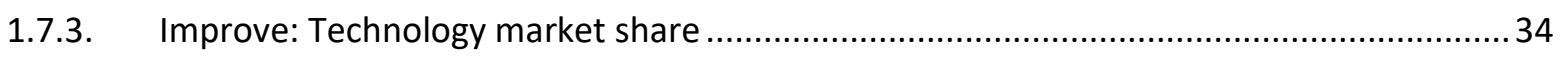

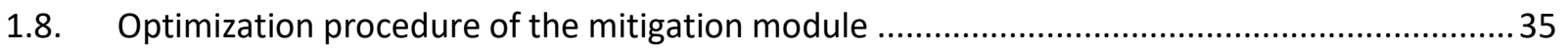

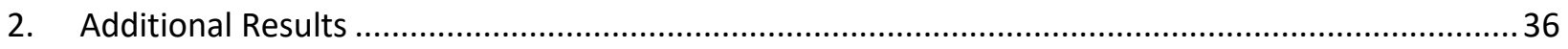

2.1. Historical passenger land transport life cycle GHG emission ..............................................36

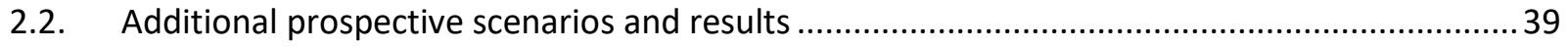


3. Recommendations to apply the CURTAIL model

4. References

\section{Method}

We develop a model, entitled CURTAIL (Climate change constrained URban passenger TrAnsport Integrated Life cycle assessment), to assess the GHG emissions of urban passenger land transport and to outline the set of mitigation strategies that are consistent with ambitious climate targets. The model comprises five modules: Passenger transport, Fleet, GHG emission, GHG emission budget and Mitigation modules. The Passenger transport module calculates the motorized passenger transport activity of the main transport modes. The Fleet module simulates the annual stocks and sales of the vehicles by transport mode, vehicle technology (e.g., internal combustion engine, electric vehicles) and vehicle age, and the resulting fuel use. The GHG emission module quantifies the life cycle GHG emissions of vehicle manufacturing, fuel production, and fuel use. The GHG emission budget module estimates the cumulative

GHG emission budgets for urban passenger land transport that are consistent with global warming below $2{ }^{\circ} \mathrm{C}$ and $1.5^{\circ} \mathrm{C}$ from global emission pathways developed by Integrated Assessment Models (IAM). Finally, the Mitigation module seeks the set of strategies to remain within the GHG emission budgets with a scenario-based prospective assessment. The mitigation strategies are categorized with the avoid-shitimprove approach.

In this section, we present all data and assumptions to apply the model to Singapore from 2005 to 2050 .

\subsection{Motorized transport activity}

We consider nine (9) modes of transport: Private car, Private hire car, Taxi, Motorcycle, Public bus, School bus, Private bus, Mass Rapid Transit (MRT), and Light Rail Transit (LRT). Private car includes privately owned, company and rental cars. Private hire car includes private hire cars with chauffeur or self-driven for ride-hailing. MRT refers to the heavy rail rapid transit system that covers Singapore owned by the Land Transport Authority and operated by SMRT Corporation. LRT refers to the series of automated light rail rapid transit systems that act as complementary services to MRT.

For each mode, we calculate four indicators: the passenger activity, the vehicle activity, the average annual distance travelled by vehicle, and the vehicle load factor. The passenger activity is calculated in passenger.km [pkt] and refers to 1 passenger travelling over 1 kilometer. The vehicle activity is calculated in vehicle.km [vkt] and refers to 1 vehicle travelling over 1 kilometer. The average annual distance travelled by vehicle is the distance travelled by one vehicle annually in $[\mathrm{km}]$. And the vehicle load factors represent the average number of passengers in a travelling vehicle in [passenger/vehicle].

\subsubsection{Historical motorized transport activity}

We calculate the indicators for each mode of transport from 2005 to 2019 by combining several data sources (Table 1) using Equations 1, 2 and 3.

Equation 1

$$
L F_{m, y}=\frac{R_{m, y} * T D_{m, y}}{V K T_{m, y}}
$$


Equation 2

$$
P K T_{m, y}=V K T_{m, y} * L F_{m, y}=R_{m, y} * T D_{m, y}
$$

Equation 3

$$
A V K T_{m, y}=\frac{V K T_{m, y}}{V e h P o p_{m, y}}
$$

With:

- $m$ the transport mode, $y$ the year,

- $L F_{m, y}$ the average vehicle load factor in [passenger/vehicle],

- $R_{m, y}$ the average ridership in [passenger.trip/year],

- $T D_{m, y}$ the average trip distance in [km/trip],

- $P K T_{m, y}$ the passenger activity in [passenger.km/year],

- $V K T_{m, y}$ the vehicle activity in [vehicle.km/year],

- $A V K T_{m, y}$ the average annual distance travelled by vehicle in [vehicle.km/vehicle.year],

- VehPop ${ }_{m, y}$ the vehicle population in [vehicle].

\begin{tabular}{|c|c|c|c|}
\hline Mode & Data & Source & $\begin{array}{l}\text { Equations } \\
\text { used }\end{array}$ \\
\hline Public bus & $\begin{array}{l}R_{m, y}(2005-2018) \\
V K T_{m, y}(2005-2014) \\
T D_{m, y}(2005-2014) \\
V_{e h P o p}, y(2005-2019)\end{array}$ & $\begin{array}{l}2 \\
3 \\
4 \\
5\end{array}$ & $(1,2,3)$ \\
\hline MRT & $\begin{array}{l}R_{m, y}(2005-2018) \\
V K T_{m, y}(2005-2018) \\
T D_{m, y}(2005-2014)\end{array}$ & $\begin{array}{l}2 \\
3 \\
4\end{array}$ & $(1,2)$ \\
\hline LRT & $\begin{array}{l}R_{m, y}(2005-2018) \\
V K T_{m, y}(2005-2018) \\
T D_{m, y}(2008-2014)\end{array}$ & $\begin{array}{l}2 \\
3 \\
4\end{array}$ & $(1,2)$ \\
\hline Taxi & $\begin{array}{l}R_{m, y}(2005-2018) \\
T D_{m, y}(2005-2014) \\
V e h P o p_{m, y}(2005-2019) \\
L F_{m, y}=1.75\end{array}$ & $\begin{array}{l}2 \\
4 \\
5 \\
\text { Own }\end{array}$ & $(1,2,3)$ \\
\hline Private car & $\begin{array}{l}\operatorname{VehPop}_{m, y}(2005-2019) \\
A V K T_{m, y}(2005-2018) \\
L F_{m, y}=1.75\end{array}$ & $\begin{array}{l}5 \\
6 \\
7\end{array}$ & $(2,3)$ \\
\hline Private hire car & $\begin{array}{l}\operatorname{VehPop}_{m, y}(2005-2019) \\
A V K T_{m, y}=2^{*} A V K T_{\text {Private car }, y} \\
L F_{m, y}=0.8\end{array}$ & $\begin{array}{l}5 \\
\text { Own } \\
8\end{array}$ & \\
\hline Motorcycle & $\begin{array}{l}\operatorname{VehPop}_{m, y}(2005-2019) \\
A V K T_{m, y}(2005-2018) \\
L F_{m, y}=1\end{array}$ & $\begin{array}{l}5 \\
6\end{array}$ & $(2,3)$ \\
\hline
\end{tabular}

Table 1: Data sources for historical motorized transport activity calculations. 


\begin{tabular}{|l|l|l|l|}
\hline School Bus & $\operatorname{VehPop}_{m, y}(2005-2019)$ & 5 & $(2,3)$ \\
& $A V K T_{m, y}(2005-2018)$ & 6 & \\
& $L F_{m, y}=9$ & 9 & $(2,3)$ \\
\hline Private bus & $\operatorname{VehPop}_{m, y}(2005-2019)$ & 5 & \\
& $A V K T_{m, y}(2005-2018)$ & 6 & \\
& $L F_{m, y}=15$ & Own & \\
\hline
\end{tabular}

Additional assumptions:

- Missing data for average trip distance $\left(T D_{m, y}\right)$ for MRT and LRT between 2015 and 2019. We calculate the load factors $\left(L F_{m, y}\right)$ from 2005 to 2014 using Equation 1, and assume it constant to the mean from 2015 to 2019. Then, we calculate the average trip distance ( $\left.T D_{m, y}\right)$ from 2015 to 2019 using Equation 1.

- Missing data for average trip distance $\left(T D_{m, y}\right)$ and historical vehicle activity $\left(V K T_{m, y}\right)$ for Public bus between 2015 and 2018. We calculate the load factors $\left(L F_{m, y}\right)$ from 2005 to 2014 using Equation 1, then assume the average trip distance $\left(T D_{m, y}\right)$ from 2015 to 2019 to stay at 2014 level, and calculate the historical vehicle activity $\left(V K T_{m, y}\right)$ from 2005 to 2019 using Equation 1.

- Missing data for average trip distance $\left(T D_{m, y}\right)$ and for historical vehicle activity $\left(V K T_{m, y}\right)$ between 2015 and 2019 for Taxi. We assume a constant load factor at 1.75, similar to the load factor in private cars ${ }^{7}$, assume $T D_{m, y}$ from 2015 to 2019 to be at 2014 level, and calculate $V K T_{m, y}$ from Equation 1.

- Missing data for average annual distance travelled by vehicle $\left(A V K T_{m, y}\right)$ in 2019. We assume $A V K T_{i, 2019}=A V K T_{i, 2018}$ for Private car, Motorcycle, Private bus and School bus.

- No information regarding Taxi load factors. We assume them equal to Private Car load factors.

- Average annual distance travelled by vehicle $\left(A V K T_{m, y}\right)$ for Private Hire Car derives from an article of The Straits Times that mentioned Private Hire Cars easily travel twice time "the distance clocked by a family car" ${ }^{10}$.

- The average load factor for School Bus derives from a private transport operator (Woodlands Transport) that estimates 6,200 students transported daily with 717 daily trips ${ }^{9}$.

- The average load factor for Private Bus derives from a vehicle occupancy rate of $75 \%$ provided by a private transport operator (Woodlands Transport) and an average capacity of 20 passengers ${ }^{11}$.

Table 2, Table 3, Figure 1, and Figure 2 present the historical values of average vehicle load factors, average annual distance travelled by vehicle, vehicle activity, and passenger activity from 2005 to 2019.

Table 2: Historical and assumed average vehicle load factors [passenger/vehicle] for all mode of transport in 2005, 2010, 2015 and 2019

\begin{tabular}{|l|l|l|l|}
\hline Mode & $\mathbf{2 0 0 5}$ & $\mathbf{2 0 1 0}$ & $\mathbf{2 0 1 5}$ \& 2019 \\
\hline LRT & 19.9 & 23.2 & 20.1 \\
\hline Motorcycle & \multicolumn{3}{|c|}{1} \\
\hline MRT & 367 & 384 & 374 \\
\hline Private bus & \multicolumn{3}{|c|}{15} \\
\hline Private car & \multicolumn{3}{|c|}{1.75} \\
\hline
\end{tabular}




\begin{tabular}{|l|c|c|c|}
\hline Private hire car & \multicolumn{2}{|c|}{0.8} \\
\hline Public bus & 18.3 & 18.3 & 18.4 \\
\hline School bus & & \multicolumn{2}{|c|}{9} \\
\hline Taxi & & \multicolumn{2}{|c|}{1.75} \\
\hline
\end{tabular}

Table 3: Historical average annual vehicle activity [thousand km/(vehicle.year)] for all modes of transport in 2005, 2010, 2015 and 2019

\begin{tabular}{|l|l|l|l|l|}
\hline Mode & $\mathbf{2 0 0 5}$ & $\mathbf{2 0 1 0}$ & $\mathbf{2 0 1 5}$ & $\mathbf{2 0 1 9}$ \\
\hline Motorcycle & 13.7 & 13.5 & 12.8 & 13.0 \\
\hline Private bus & 47.5 & 51.2 & 43.3 & 43.1 \\
\hline Private car & 20.6 & 19.1 & 17.3 & 17.5 \\
\hline Private hire car & 41.2 & 38.2 & 34.6 & 35.0 \\
\hline Public bus & 83.4 & 77.0 & 64.7 & 58.7 \\
\hline School bus & 46.3 & 48.4 & 52.1 & 44.8 \\
\hline Taxi & 80.4 & 67.9 & 74.6 & 67.0 \\
\hline
\end{tabular}

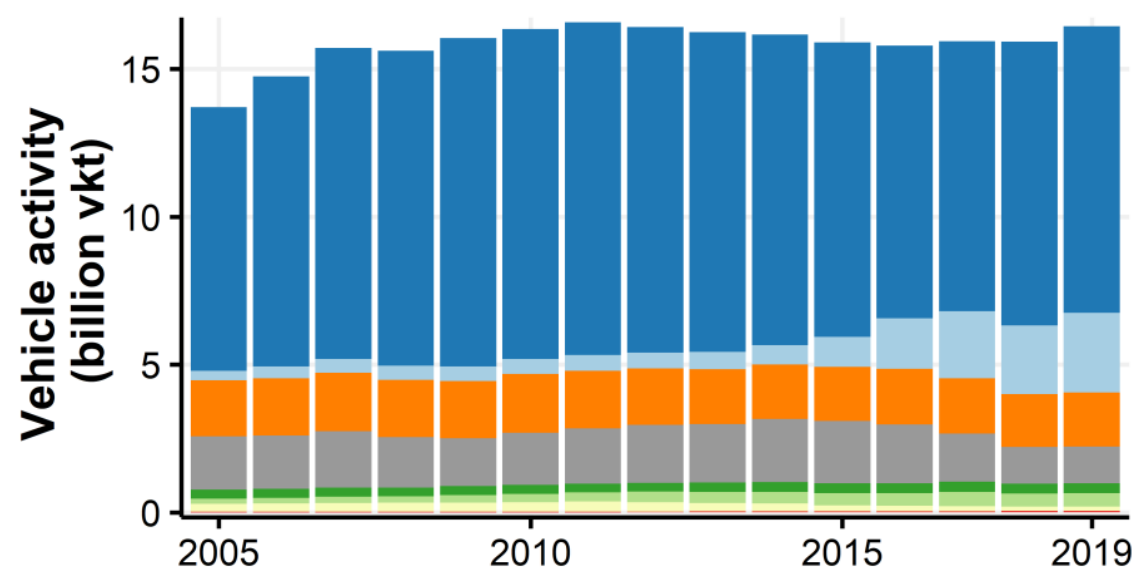

Tranport mode

- Private car

Private hire car

Motorcycle

Taxi

Public bus

School bus

Private bus

MRT

LRT

Figure 1: Historical vehicle activity by mode of transport

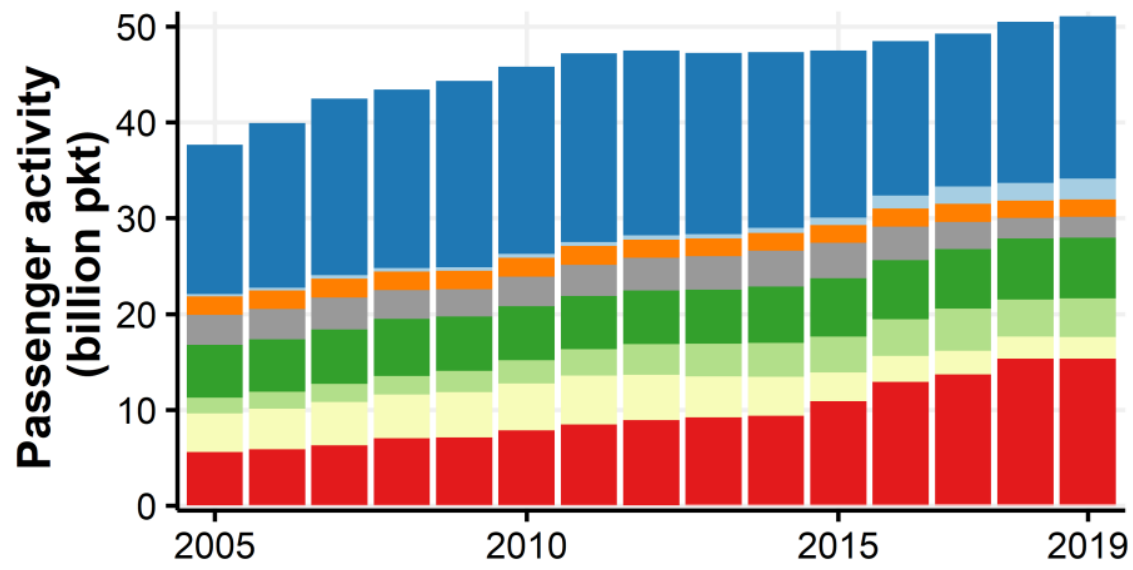

Tranport mode

- Private car

Private hire car

Motorcycle

Taxi

Public bus

School bus

Private bus

MRT

LRT

Figure 2: Historical passenger activity by mode of transport 


\subsection{Passenger transport fleet modelling}

The fleet module estimates the stock of vehicles by mode, technology and age and the resulting fuel use. It uses the outputs from the passenger transport module (average distance travelled by one vehicle and vehicle activity by transport mode) and uses other exogenous inputs. Figure 3 presents an overview of the module.

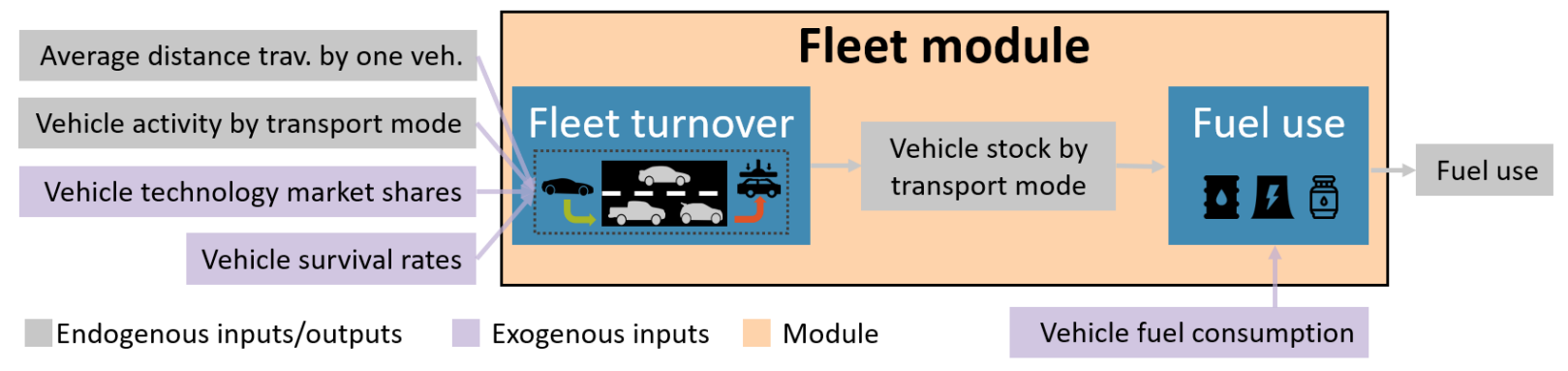

Figure 3: Overview of the fleet module

Table 4 presents the list of technologies considered for our case study of Singapore by transport mode.

Table 4: Technologies considered by transport mode

\begin{tabular}{|l|l|}
\hline Mode & List of technologies \\
\hline MRT \& LRT & Electric \\
\hline Motorcycle & $\begin{array}{l}\text { Internal combustion engine motorcycle using gasoline (ICEM-G), } \\
\text { electric motorcycle (EM) }\end{array}$ \\
\hline $\begin{array}{l}\text { Public bus, Private bus \& School } \\
\text { bus }\end{array}$ & $\begin{array}{l}\text { Internal combustion engine bus using diesel (ICEB-D), hybrid } \\
\text { electric bus using diesel (HEB-D), compressed natural gas bus } \\
\text { (CNGB), electric bus (EB) }\end{array}$ \\
\hline $\begin{array}{l}\text { Private car, Private hire car \& } \\
\text { Taxi }\end{array}$ & $\begin{array}{l}\text { Internal combustion engine vehicle using gasoline (ICEV-G), } \\
\text { Internal combustion engine vehicle using diesel (ICEV-D), hybrid } \\
\text { electric vehicle using gasoline (HEV-G), compressed natural gas } \\
\text { vehicle (CNG), plug-in hybrid electric vehicle using gasoline } \\
\text { (PHEV), battery electric vehicle (BEV) }\end{array}$ \\
\hline
\end{tabular}

\subsubsection{Fleet turnover}

Each year, the on-road stock of vehicles by technology for a transport mode is composed of all surviving vehicles from previous year and new incoming vehicles. Equation 4 illustrates the dynamics of the fleet turnover.

Equation 4

$$
\text { Stock }_{m, y, t}=\text { Stock }_{m, y-1, t}+\operatorname{In}_{m, y, t}-O u t_{m, y, t}
$$

With Stock $k_{m, y, t}$ the on-road stock of vehicles of mode " $m$ " and technology " $t$ " in year " $y$ ", I $n_{m, y, t}$ the new sales and $O u t_{m, y, t}$ the outgoing vehicles (i.e., scrapped vehicles).

We estimate 2005 vintage stocks for all modes of transport by technology and age from annual age distributions and on-road stock of vehicles by technology provided by the Land Transport Authority ${ }^{12-15}$.

Necessary assumptions due to missing data in 2005 are: 
- We assume the same annual age distributions for taxis, private cars and private hire cars, in the absence of data for each, and adjust the distribution to the total annual stock by mode.

- We assume the same annual age distributions for public, private and school buses, based on the distribution for buses, in the absence of specific data for each, and adjust the distributions to the total stock by mode.

Then from 2006 to 2019, we estimate the vintages stocks of all modes of transport by technology and age from the previous year vintage stocks, survival rates and the total on-road stock by technology provided by LTA ${ }^{15}$.

\subsubsection{Survival rates, sales and stock}

Survival rates $\left(S R_{m, a}\right)$ represent the probability for a vehicle to be operational in a given year knowing it was operational the previous year. Cumulative survival rates represent the probability for a vehicle to be operational after a given age. We calculate the survival rate distributions from 2006 to 2019 for private cars, buses and motorcycles from annual age distributions provided by the LTA ${ }^{12-14}$. Figure 4 presents the ranges of the cumulative survival rate distributions by mode of transport. Thick lines represent the default values used in the prospective scenarios based on the 2019 values.

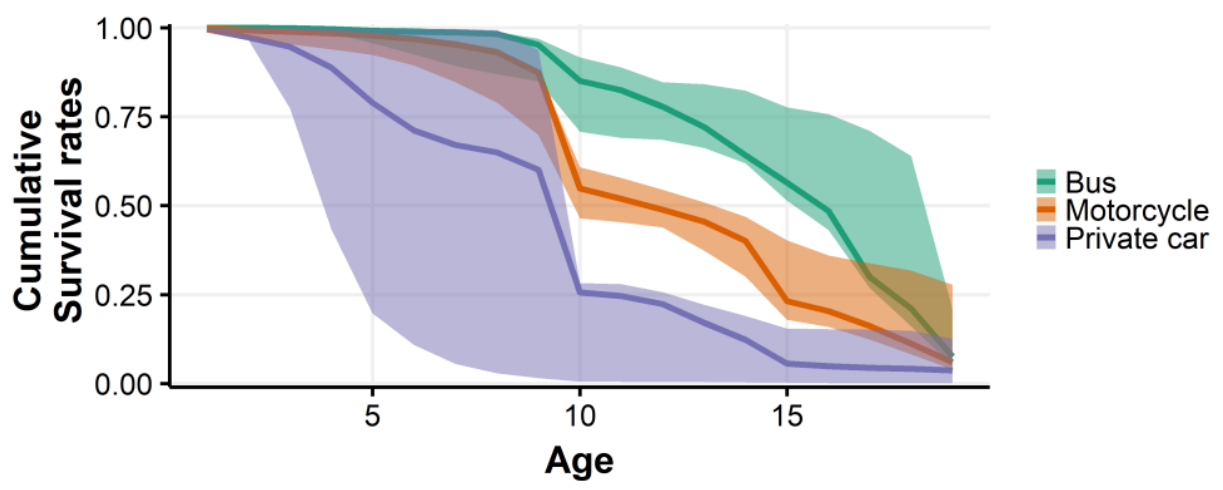

Figure 4: Empirical survival rates by mode of transport from 2006 to 2019

We note the unusual survival rate distribution and the short-lifetime of private cars in Singapore compared to other countries such as China ${ }^{16}$ or the United States ${ }^{17}$. Indeed, Singapore uses a Vehicle Quota System (VQS) to regulate the new registration of the vehicles and their lifetime ${ }^{18}$. The VQS was enacted in 1990 to control the increasing traffic flow in the city. It classifies the vehicles into several categories, depending on the engine capacity, and the LTA fixes quotas for each category every year (Figure 5). The would-be vehicle buyer must bid to obtain a license, the Certificate of Entitlement (COE), valid 10 years. After this period, the vehicle owner must renew the COE by paying a Prevailing Quota Premium. Consequently, most of the vehicles that are reaching 10 years of age in Singapore are deregistered, creating this unique survival rate distribution. 


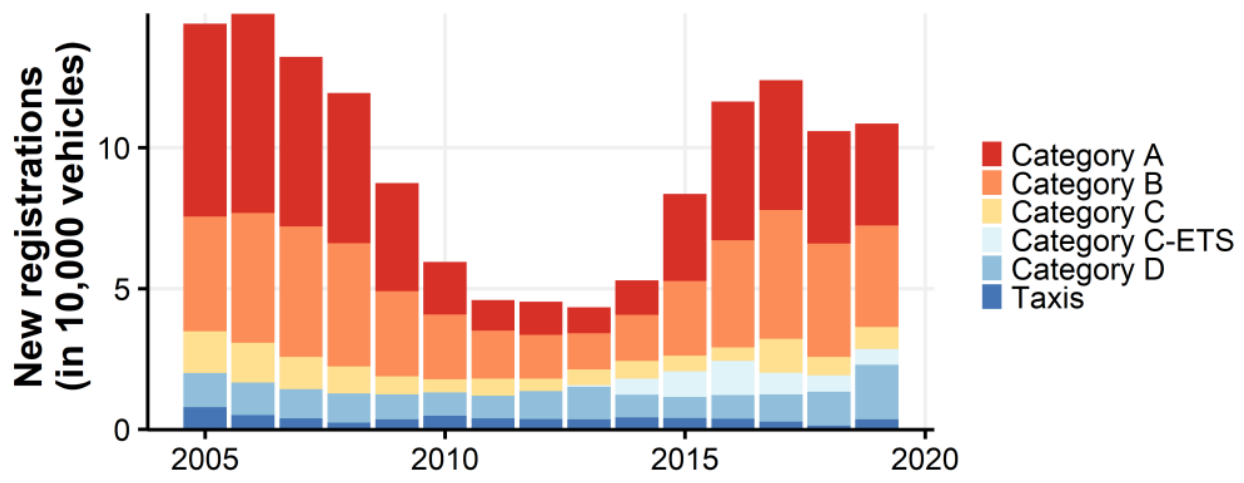

Figure 5: Annual new registrations under the Vehicle Quota System (VQS)

In our model, we use the estimated survival rate distributions from 2006 to 2019 with the following assumptions:

- All technologies within a mode have the same survival rate distributions,

- Taxis and private hire cars have the same survival rate distribution than private cars, in the absence of specific data,

- Public, private and school buses have the same survival rate distributions, derived from the bus category of Figure 4.

We estimate the number of scrapped vehicles per mode and technology in a given year from the previous year vintage stock and the survival rate distributions as presented in Equation 5.

Equation 5

$$
O u t_{m, y, t, a}=\left(1-S R_{m, y, a}\right) * S t o c k_{m, y-1, t, a} \& O u t_{m, y, t}=\sum_{a=a g e} O u t_{m, y, t, a}
$$

With Out $t_{m, y, t, a}$ the number of outgoing vehicles of mode " $\mathrm{m}$ ", technology " $\mathrm{t}$ ", age "a", at year " $\mathrm{y}$ ", $S R_{m, y, a}$ the survival rate, $S t o c k_{m, y-1, t, a}$ the previous year on-road stock and $O u t_{m, y, t}$ the total number of outgoing vehicles.

Combining Equation 4 and Equation 5 from 2006 to 2019, we calculate the sales and the vintage stock of vehicles by technology. We note that we adjust the estimated vintage stock from Equation 5 by proportionally scaling them up or down to reach the total on-road stock by technology provided by LTA ${ }^{15}$. Figure 6 and Figure 7 show the historical vehicle sales and on-road population by technology for all transport modes. Figure 8 presents an example of a vintage stock for private cars in 2019. 
a)

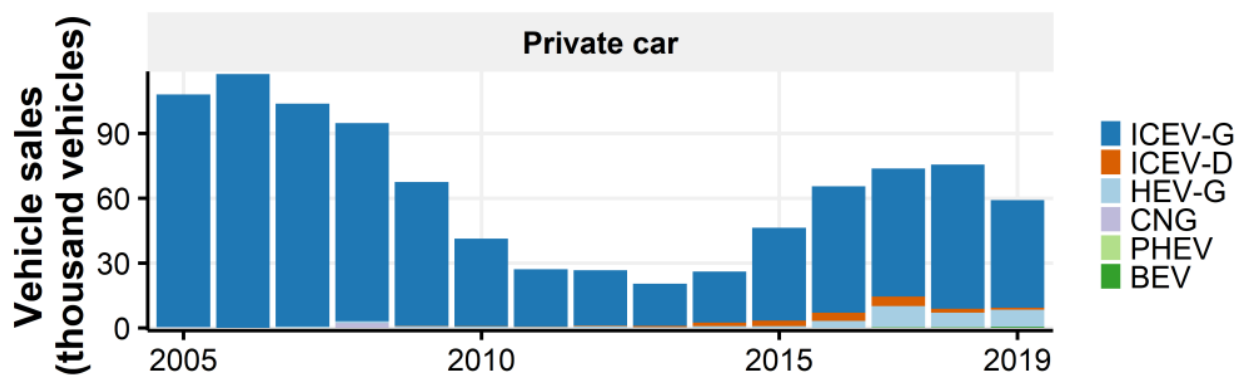

b)

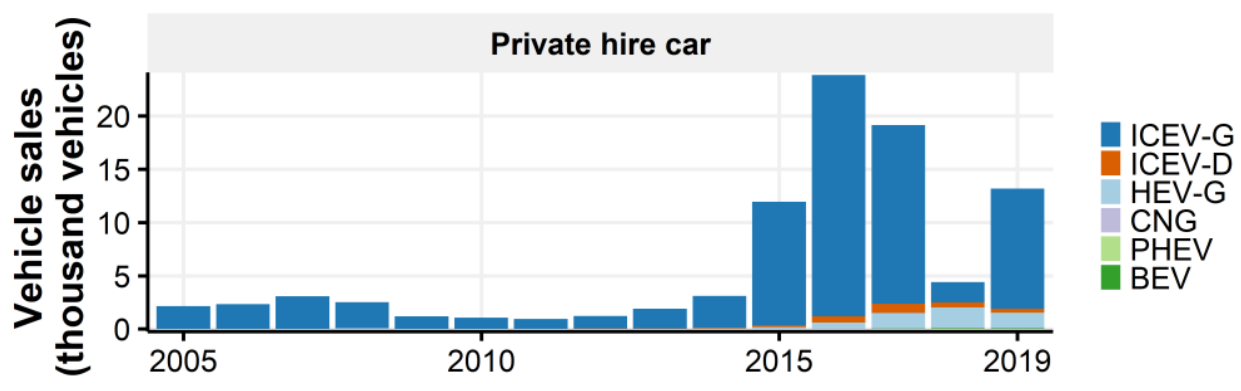

c)
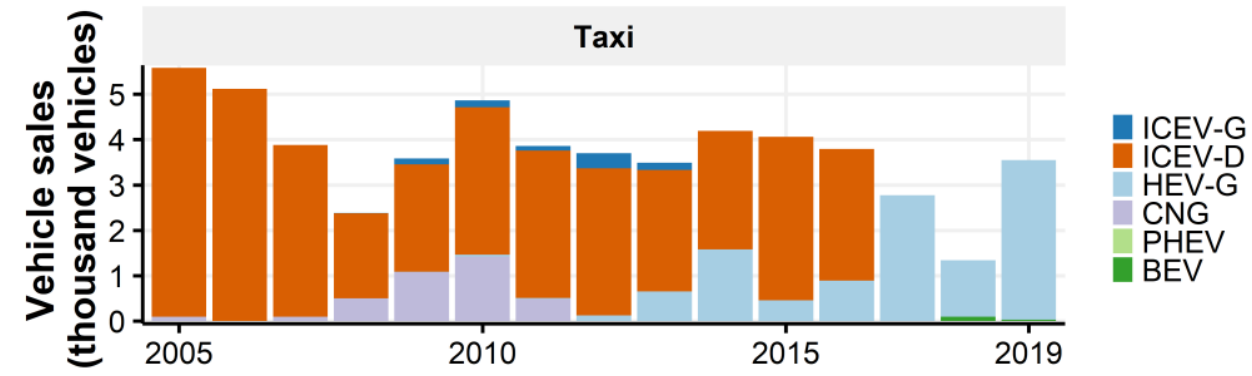

d)

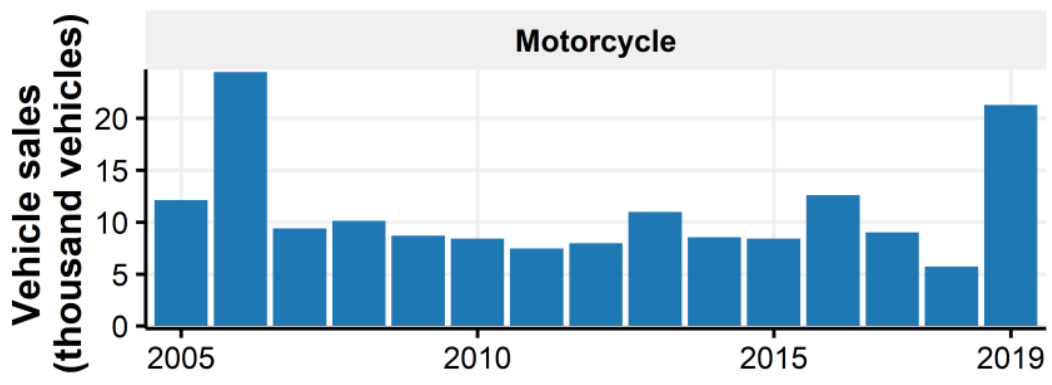

ICEM-G

EM 
e)

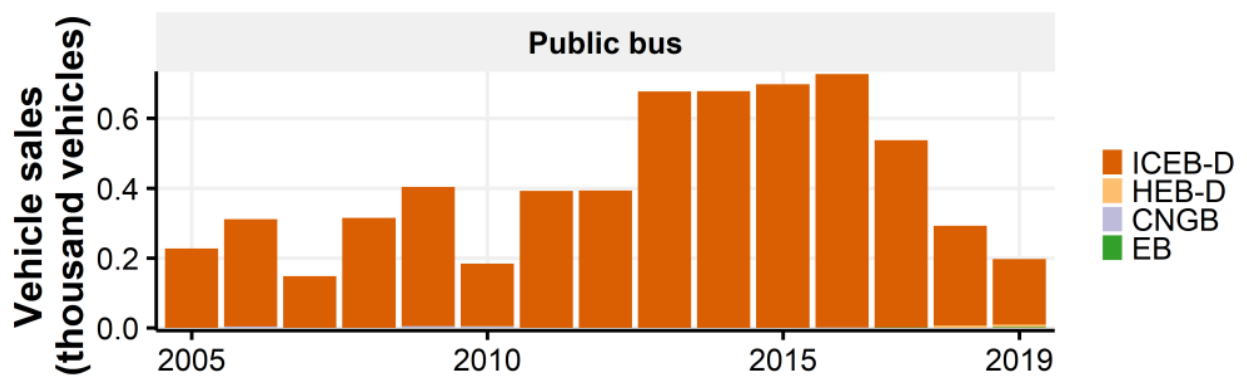

f)

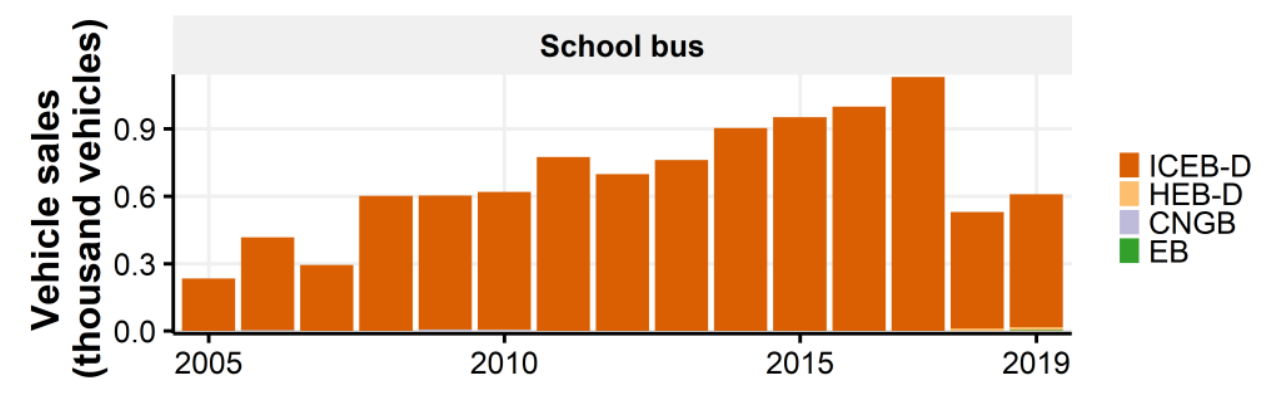

g)

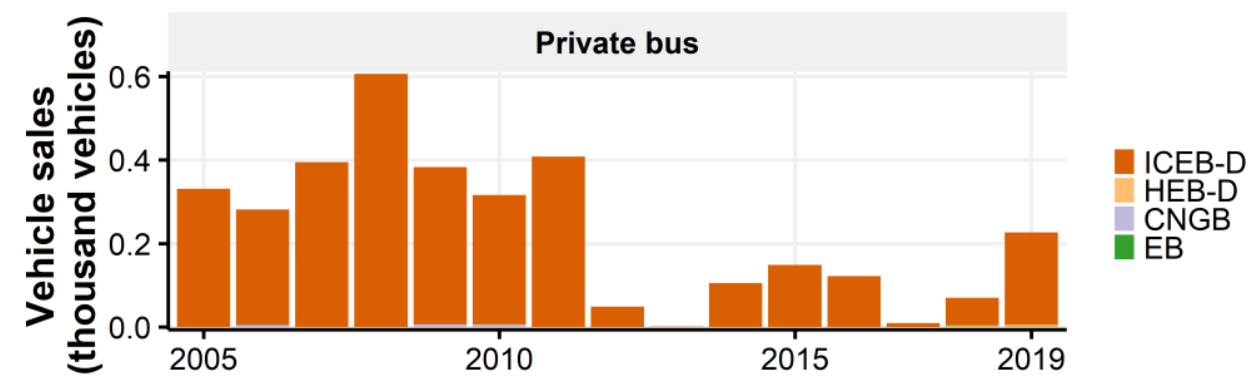

Figure 6: Historical vehicle sales by technology for all transport modes

a)

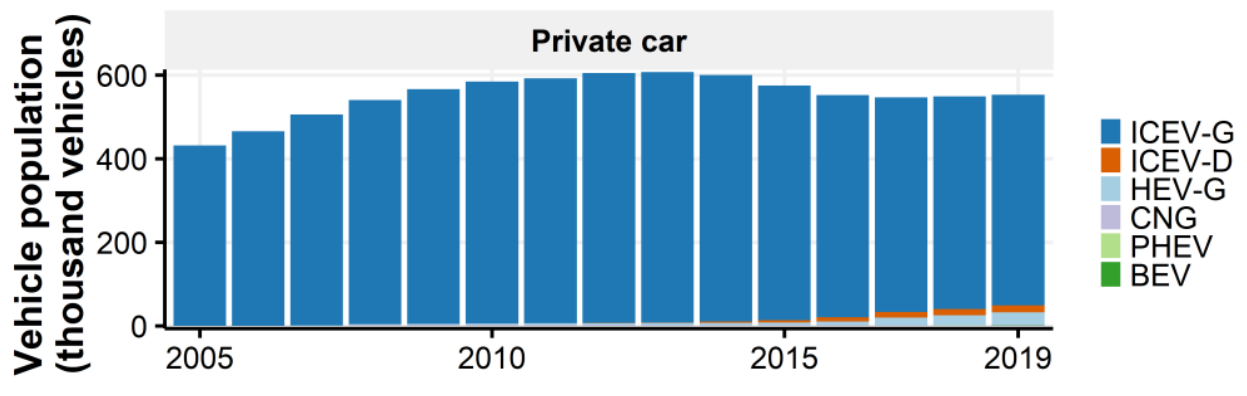


b)

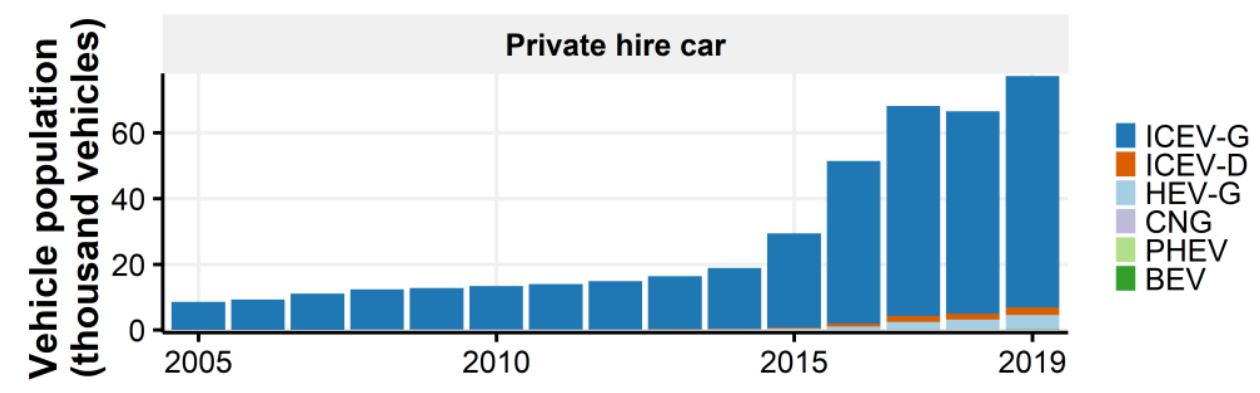

c)

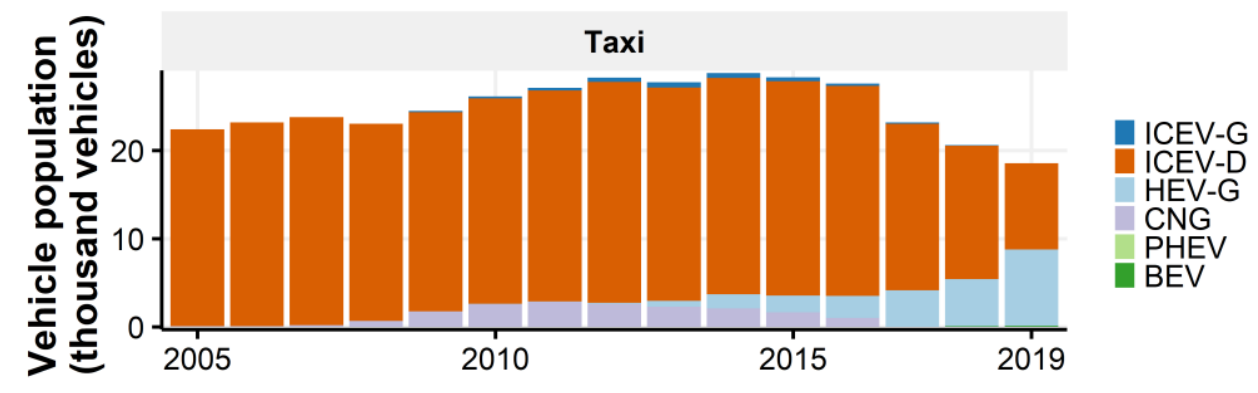

d)

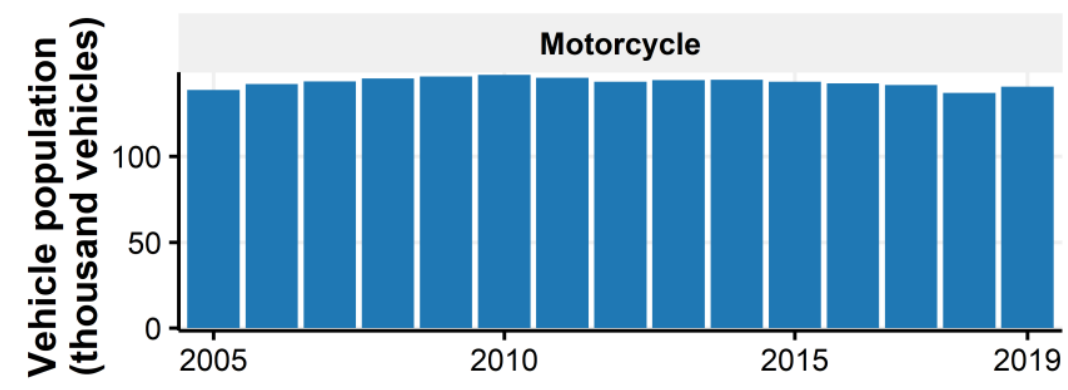

e)

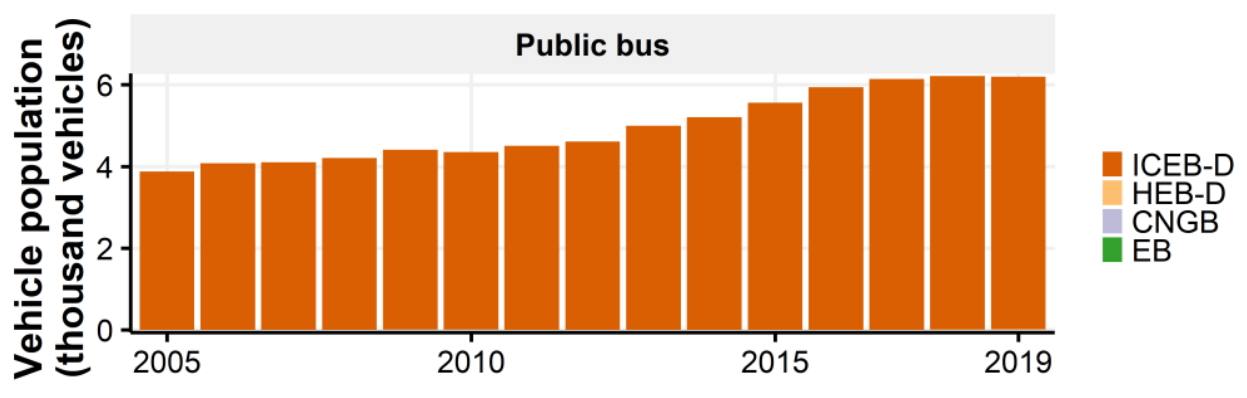


f)

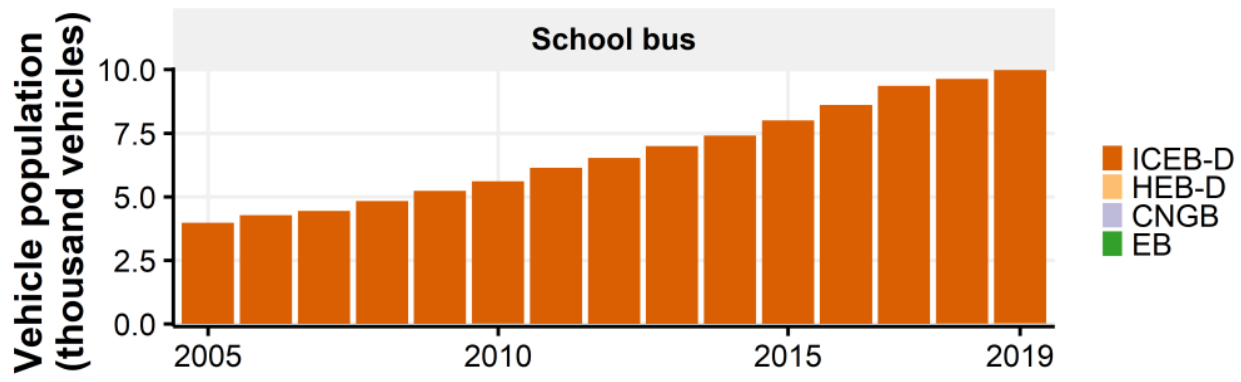

g)

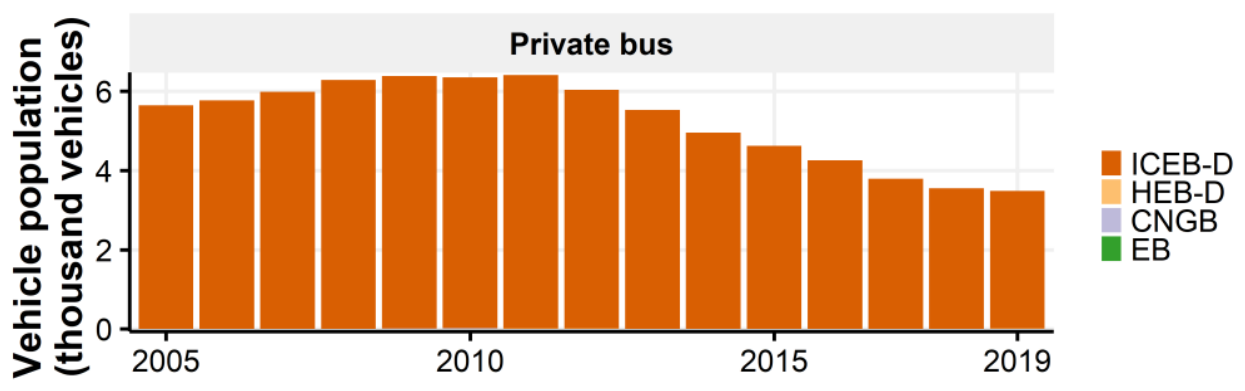

Figure 7: Historical vehicle population by technology for each mode of transport from 2005 to 2018.

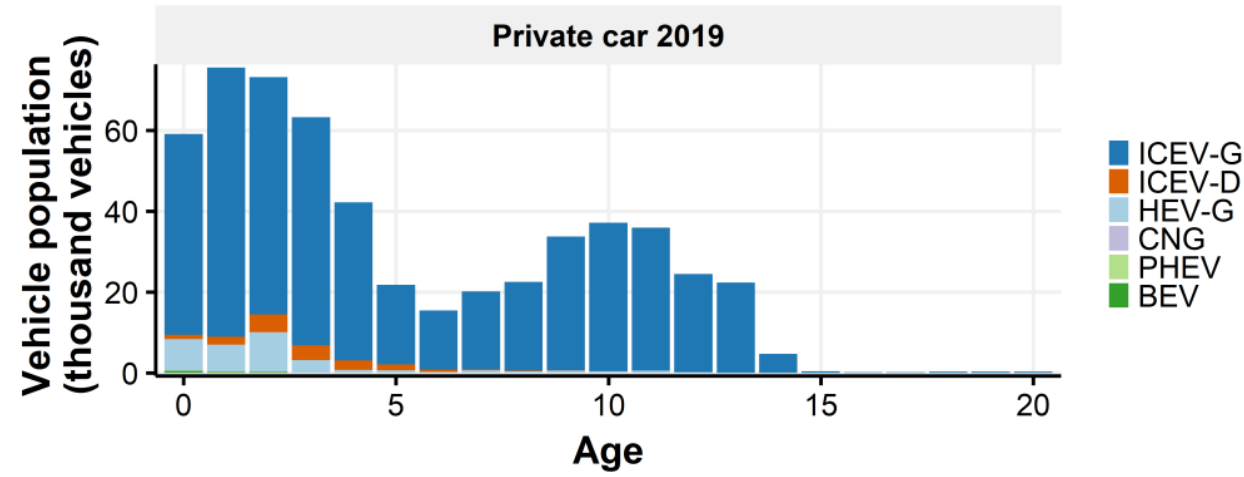

Figure 8: Age distribution of private cars in 2019 by technology

\subsubsection{Projected vehicle stocks}

From the prospective scenarios of the exogenous inputs (presented in section SI.1.7), we project the vehicle stocks by mode, technology, and model year from 2020 to 2050.

We first calculate the projected (at year $y$ ) total vehicle stock $\left(\operatorname{Stock}_{m, y}\right)$ by mode $(m)$ based on the prospective vehicle and passenger activities using equations 1,2 and 3 , as summarized in equation 6 .

Equation 6

$$
\text { Stock }_{m, y}=\frac{V K T_{m, y}}{A V K T_{m, y}}=\frac{P K T_{m, y}}{L F_{m, y} * A V K T_{m, y}}
$$


We then calculate the total number of new vehicles by mode from the projected total stock, the previous total stock and the estimated number of scrapped vehicles using equations 4 and 5 , as presented in equation 7.

Equation 7

$$
I n_{m, y}=\text { Stock }_{m, y}-\text { Stock }_{m, y-1}+\sum_{a=a g e} \sum_{t=\text { techno }}\left(1-S R_{m, y, a}\right) * \text { Stock }_{m, y-1, t, a}
$$

Finally, we calculate the resulting projected stock from the technology-specific $(t)$ vehicle sales $\left(T M_{m, y, t} * I n_{m, y}\right.$ with $T M_{m, y, t}$ being the technology market), the previous technology-specific stock, and the technology-specific number of scrapped vehicles.

Equation 8

$$
\text { Stock }_{m, y, t}=\text { Stock }_{m, y-1, t}+T M_{m, y, t} * I n_{m, y}-O u t_{m, y, t}
$$

\subsection{Vehicle fuel consumption}

We estimate for each mode, technology and model year the vehicle fuel consumption from 1985 to 2019.

We consider four (4) fuels in our model: Gasoline, diesel, compressed natural gas (CNG) and electricity. Table 5 presents the Lower Heating Values (LHVs) of gasoline, diesel and CNG assumed in our study ${ }^{19}$.

Table 5: Lower Heating Values (LDVs) of fuel considered in this study.

\begin{tabular}{|l|l|}
\hline Fuel & Lower Heating Value [MJ/L] \\
\hline Gasoline & 33.5 \\
\hline Diesel & 35.8 \\
\hline Compressed Natural Gas & 23.6 \\
\hline
\end{tabular}

We estimate the fuel consumption of all vehicle technologies by production year (model year). That is, from 1985 to 2050, each newly produced vehicle technology has an associated fuel consumption value. We use the unit L of fuel / 100km for vehicles using gasoline, diesel and CNG, and kWh of electricity $/ 100 \mathrm{~km}$ for vehicles using electricity. The following sections describe the assumptions, and sources to estimate the vehicle fuel consumption by transport mode.

\subsubsection{Motorcycle}

We estimate the fuel consumption of motorcycle technologies from 1985 to 2019 from an empirical study conducted by Koossalapeerom et al. ${ }^{20}$ as presented in Table 6.

Table 6: Fuel consumption of motorcycle technologies

\begin{tabular}{|l|l|l|l|l|}
\hline Mode & Technology & Fuel(s) & Fuel consumption & Source \\
\hline \multirow{2}{*}{ Motorcycle } & ICEM-G & Gasoline & $2.43(\mathrm{~L} / 100 \mathrm{~km})$ & 20 \\
\cline { 2 - 5 } & EM & Electricity & $2.8(\mathrm{kWh} / 100 \mathrm{~km})$ & 20 \\
\hline
\end{tabular}




\subsubsection{Private car, private hire car and taxi}

We calculate the fuel consumption for 1985 to 2019 model year vehicles for private cars, private hire cars and taxis using two different methods. For ICEVs-G and ICEVs-D, we calculate sales-weighted average fuel consumption. For all other technologies, we assign a representative vehicle model. We assume that private car, private hire car and taxi have the same fuel consumption per technology.

To calculate sales-weighted average fuel consumption by model years, we use fuel economy data by make, model, body type (i.e., Hatchback, Sedan, Wagon, Sports Utility Vehicle - SUV, Coupe), and fuel type approved for registration in Singapore derived from the LTA ${ }^{21}$. We use the combined fuel consumption as provided by the LTA and coming from the New European Driving Cycle (NEDC) and Japanese Driving Cycle (JC08) ${ }^{22}$, and adjust them to real-world driving. Then we use registration data of new ICEVs-G and ICEVs-D by make, body type and fuel type provided by the LTA ${ }^{23}$ from 2015 to 2019.

ICEV-D: For each vehicle make-body category (e.g., BMW Hatchback), we search all the corresponding diesel vehicle models in the fuel economy dataset ${ }^{21}$ and calculate the mean of their fuel consumption. Then, we calculate sales-weighted average from the new registration estimates by vehicle make-body category. Due to the low number of vehicle models by vehicle make-body category, this method provides low variations in the sales-weighted averages. We assume all vehicles prior to 2015 to be constant at 2015 levels. Table 7 shows the resulting sales-weighted average fuel consumption for new ICEVs-D from 2015 to 2019.

Table 7: Sales-weighted average fuel consumption of new ICEV-D from 2015 to 2019

\begin{tabular}{|l|l|}
\hline Model year & $\begin{array}{l}\text { Sales-weighted average } \\
\text { fuel consumption of ICEV-D [L of diesel/100 } \mathbf{k m} \text { ] }\end{array}$ \\
\hline Prior to 2015 & 4.43 \\
\hline 2016 & 4.59 \\
\hline 2017 & 4.79 \\
\hline 2018 & 4.89 \\
\hline 2019 & 4.72 \\
\hline
\end{tabular}

ICEV-G: The previous method is not applicable to gasoline-fueled vehicles because each vehicle make-body category contains many models, with often large variations in their fuel consumption. We therefore assign a representative model for each vehicle make-body category, estimate the fuel consumption of the category from the fuel economy dataset, and calculate the sales-weighted average from registration estimates by category from 2015 to 2019. To limit the number of categories, we consider the categories by increasing order of market share up to cumulative market shares around $90 \%$. We select the representative models from sales data gathered from multiple websites: The Business Times (https://www.businesstimes.com.sg/), The New Paper (https://www.tnp.sg/), SgCarMart (https://www.sgcarmart.com/) and CarBuyer (https://www.carbuyer.com.sg/).

Table 8 presents the representative vehicle models for the considered vehicle make-body categories, with the associated market shares and fuel consumption. We note that the fuel consumption for each representative vehicle model does not vary significantly by model year. 
Table 8: Market share by vehicle make, and body type, with representative model used in the sales-weighted average calculations and associated fuel consumption

\begin{tabular}{|c|c|c|c|c|c|c|c|c|}
\hline Make & Body type & Model & 2015 & 2016 & 2017 & 2018 & 2019 & $\begin{array}{l}\text { Fuel cons. } \\
\text { [L/100km] }\end{array}$ \\
\hline Mercedes Benz & Coupe & E200 coupe & $1.43 \%$ & $1.04 \%$ & $1.95 \%$ & $1.61 \%$ & $1.80 \%$ & 6.8 \\
\hline BMW & Hatchback & $\mathrm{X} 1$ & $0.76 \%$ & $0.08 \%$ & $0.06 \%$ & $0.73 \%$ & $2.67 \%$ & 6.8 \\
\hline Honda & Hatchback & Civic 1.5 & $1.99 \%$ & $2.36 \%$ & $1.49 \%$ & $3.99 \%$ & $7.56 \%$ & 6 \\
\hline Mazda & Hatchback & Mazda3 & $1.14 \%$ & $0.69 \%$ & $0.88 \%$ & $1.39 \%$ & $0.34 \%$ & 6.1 \\
\hline Mercedes Benz & Hatchback & A180 & $2.07 \%$ & $1.39 \%$ & $1.22 \%$ & $0.94 \%$ & $1.45 \%$ & 5.4 \\
\hline Nissan & Hatchback & Note 1.2 & $0.57 \%$ & $1.25 \%$ & $1.45 \%$ & $1.69 \%$ & $1.21 \%$ & 5.0 \\
\hline Volkswagen & Hatchback & Golf GTI 2.0 & $2.53 \%$ & $1.63 \%$ & $1.67 \%$ & $1.31 \%$ & $1.12 \%$ & 6.6 \\
\hline Honda & Wagon & Odyssey 2.4 & $2.72 \%$ & $4.18 \%$ & $3.64 \%$ & $3.51 \%$ & $3.12 \%$ & 8.1 \\
\hline Mazda & Wagon & Mazda6 & $2.08 \%$ & $1.65 \%$ & $2.14 \%$ & $0.23 \%$ & $0.03 \%$ & 7.2 \\
\hline Toyota & Wagon & Vellfire 2.5 & $5.43 \%$ & $7.99 \%$ & $6.47 \%$ & $4.71 \%$ & $3.84 \%$ & 8.4 \\
\hline Volkswagen & Wagon & Touran 1.4 & $0.26 \%$ & $0.43 \%$ & $0.55 \%$ & $0.98 \%$ & $0.95 \%$ & 5.6 \\
\hline Audi & Sedan & A4 2.0 & $2.53 \%$ & $2.04 \%$ & $2.00 \%$ & $2.14 \%$ & $1.50 \%$ & 6.2 \\
\hline BMW & Sedan & $520 i$ & $3.14 \%$ & $1.91 \%$ & $2.20 \%$ & $2.17 \%$ & $1.79 \%$ & 6.5 \\
\hline Honda & Sedan & Civic 1.5 & $1.48 \%$ & $2.28 \%$ & $4.15 \%$ & $4.74 \%$ & $3.67 \%$ & 5.9 \\
\hline Hyundai & Sedan & Elantra & $2.71 \%$ & $2.70 \%$ & $3.75 \%$ & $7.49 \%$ & $7.93 \%$ & 6.4 \\
\hline Kia & Sedan & Cerato & $2.32 \%$ & $2.28 \%$ & $3.51 \%$ & $4.09 \%$ & $4.87 \%$ & 6.6 \\
\hline Mazda & Sedan & Mazda3 & $6.09 \%$ & $6.26 \%$ & $7.94 \%$ & $4.76 \%$ & $2.21 \%$ & 6.1 \\
\hline Mercedes Benz & Sedan & C200 & $6.04 \%$ & $4.14 \%$ & $5.03 \%$ & $4.95 \%$ & $5.07 \%$ & 6.4 \\
\hline Mitsubishi & Sedan & Attrage 1.2 & $1.06 \%$ & $3.51 \%$ & $3.29 \%$ & $2.39 \%$ & $2.36 \%$ & 4.9 \\
\hline Nissan & Sedan & Sylphy 1.6 & $4.26 \%$ & $1.85 \%$ & $0.57 \%$ & $1.63 \%$ & $1.65 \%$ & 6.2 \\
\hline Toyota & Sedan & Corolla altis & $12.11 \%$ & $9.53 \%$ & $7.30 \%$ & $5.19 \%$ & $7.18 \%$ & 6.4 \\
\hline Volkswagen & Sedan & Passat b8 & $2.24 \%$ & $1.16 \%$ & $0.59 \%$ & $0.61 \%$ & $0.41 \%$ & 5.9 \\
\hline Audi & SUV & Q5 sport 2.0 & $0.72 \%$ & $0.52 \%$ & $0.84 \%$ & $1.02 \%$ & $1.21 \%$ & 7.4 \\
\hline BMW & SUV & $\mathrm{X} 4$ & $0.91 \%$ & $1.12 \%$ & $1.64 \%$ & $2.53 \%$ & $3.42 \%$ & 7.8 \\
\hline Honda & SUV & CRV 1.5 & $8.47 \%$ & $12.91 \%$ & $6.05 \%$ & $4.70 \%$ & $5.07 \%$ & 7 \\
\hline Hyundai & SUV & Tucson 2.0 & $0.36 \%$ & $0.45 \%$ & $1.00 \%$ & $0.74 \%$ & $0.46 \%$ & 7.9 \\
\hline Kia & SUV & Sportage 2.0 & $0.38 \%$ & $0.08 \%$ & $0.13 \%$ & $0.00 \%$ & $1.46 \%$ & 7.9 \\
\hline Mazda & SUV & $C x-52.0$ & $0.52 \%$ & $0.39 \%$ & $0.41 \%$ & $1.28 \%$ & $1.27 \%$ & 6.9 \\
\hline Mercedes Benz & SUV & AMG GLA45 & $0.32 \%$ & $1.11 \%$ & $1.69 \%$ & $2.28 \%$ & $3.23 \%$ & 7.4 \\
\hline Mitsubishi & SUV & Outlander 2.0 & $1.51 \%$ & $1.13 \%$ & $1.30 \%$ & $1.95 \%$ & $2.53 \%$ & 6.6 \\
\hline Nissan & SUV & Qashqai 2.0 & $5.34 \%$ & $5.72 \%$ & $4.94 \%$ & $2.33 \%$ & $0.67 \%$ & 6.9 \\
\hline Subaru & SUV & Forester 2.0 & $2.61 \%$ & $3.14 \%$ & $3.34 \%$ & $4.12 \%$ & $1.80 \%$ & 7.4 \\
\hline Toyota & SUV & Fortuner & $4.03 \%$ & $4.03 \%$ & $3.97 \%$ & $3.37 \%$ & $3.72 \%$ & 10.7 \\
\hline Volvo & SUV & Xc60 t5 & $0.60 \%$ & $0.41 \%$ & $0.57 \%$ & $1.02 \%$ & $0.97 \%$ & 6.7 \\
\hline \multicolumn{3}{|c|}{ Sum of market share represented } & $90.74 \%$ & $91.39 \%$ & $87.71 \%$ & $86.62 \%$ & $88.53 \%$ & \\
\hline
\end{tabular}

Table 9 presents the estimated sales-weighted average from 2015 to 2019 for new ICEVs-G. We note that the sales-weighted averages have been stable in the past 5 years. This is due to a relative stable size market share. 
Table 9: Sales-weighted average fuel consumption of new ICEV-G from 2015 to 2019

\begin{tabular}{|l|l|}
\hline Model year & $\begin{array}{l}\text { Sales-weighted average } \\
\text { fuel consumption of ICEV-G [L of gasoline/100km] }\end{array}$ \\
\hline 2015 & 6.90 \\
\hline 2016 & 6.95 \\
\hline 2017 & 6.89 \\
\hline 2018 & 6.82 \\
\hline 2019 & 6.85 \\
\hline
\end{tabular}

In the absence of data prior to 2015, we use a top-down approach to estimate the fuel consumption of new ICEVs-G from 1985 to 2015. We note that only private cars, private hire cars and motorcycle use motor gasoline (see Figure 7) in Singapore. Therefore, we estimate the on-road gasoline consumption of ICEVs-G in Singapore from the total annual motor gasoline consumption in Singapore of the IEA's Oil Information ${ }^{24}$, and the total stock of private cars and motorcycles. Then, we assess the trends in historical changes to estimate fuel consumption of new ICEVs-G from 1985 to 2015. Our steps are:

1. Extract total motor gasoline volumes in Singapore $\left(V_{\text {total,gasoline, } y}\right)$ from 1990 to 2017 from the IEA's Oil Information $2019^{24}$,

2. Estimate the motor gasoline volumes of the motorcycles $\left(V_{\text {moto,gasoline,y }}\right)$ from the motorcycle activity $\left(V K T_{m o t o, y}\right.$ in Equation 3), and the motorcycle fuel consumption of Table $6\left(F C_{m o t o}\right)$.

$$
V_{\text {moto,gasoline,y }}=\frac{F C_{\text {moto }}}{100} * V K T_{\text {moto }, y}
$$

3. Estimate the total vehicle activity of private and private hire cars $\left(V K T_{\text {car, } y}\right.$ in Equation 3),

4. Calculate the on-road fuel consumption of ICEVs-G.

$$
F C_{\text {on-road }, I C E V-G}=\frac{\left(V_{\text {total,gasoline }, y}-V_{\text {moto }, \text { gasoline }, y}\right)}{V K T_{\text {car }, y}} * 100
$$

Figure 9 presents the estimated total motor gasoline use by ICEVs-G and the resulting on-road fuel consumption.

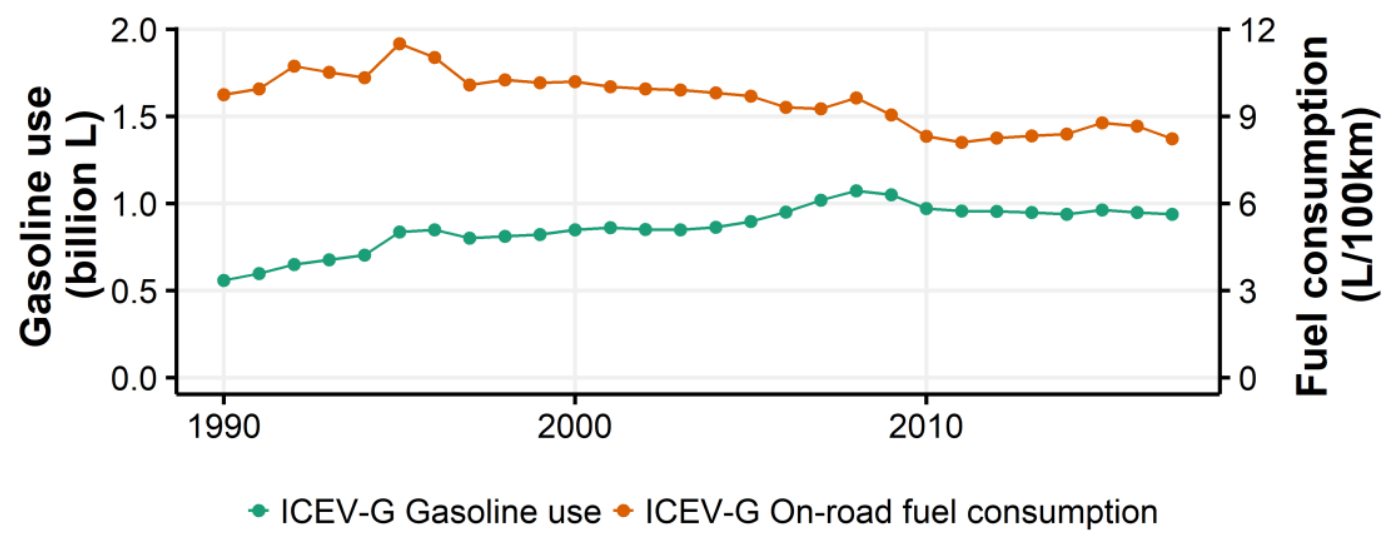

Figure 9: Gasoline use and on-road fuel consumption of ICEV-G for private cars, private hire cars and taxis from 1990 to 2017 
We note that the on-road fuel consumption of ICEVs-G from 2015 to 2017 are higher than the calculated sales-weighted average fuel consumption of new ICEVs-G presented in Table 9 for two mains reasons. First, the on-road fuel consumption comprises all operating vehicles and therefore include older vehicles with potentially higher fuel consumption. Second, the fuel consumption data calculated from the fuel economy dataset provided by LTA ${ }^{21}$ are derived from in-lab testing and are often lower than real-world fuel consumption ${ }^{25}$. Section 1.3.5 discusses in great length on-road degradation factors.

We, therefore, adjust the fuel consumption of new ICEVs-G from 1985 to 2015 based on the on-road fuel consumption changes. We assume that fuel consumption of new ICEVs-G was 15\% lower in 2015 than in 2000 (i.e., $8.1 \mathrm{~L} / 100 \mathrm{~km}$ in 2000). It represents average fuel consumption improvements of $0.95 \%$ per year over this period, which is aligned with a recent analysis from the IEA that reported annual improvement rates in fuel consumption around $1 \%$ in countries with no fuel consumption regulations (as in Singapore) ${ }^{26}$. We linearly interpolate the fuel consumption of new ICEVs-G between 2000 to 2015 and assume that fuel consumption of new ICEVs-G prior to 2000 are constant at 2000 level.

From 2020 onwards, we assume in our study that annual sales-weighted average fuel consumption values of new conventional cars remain constant. This assumption comes for stable fuel consumption of new cars between 2015 and 2019 and a clear focus in Singapore on electric vehicles. We nonetheless simulate a case assuming $1 \%$ annual improvements in new conventional car fuel consumption over the period 2020 and 2050 and we find no appreciable changes to the results and figures presented in this current study. Only a case assuming increasing model shares of private cars and no technology market share changes (also called PC-Constant in the manuscript) would see a 5\% reduction in 2018-2050 cumulative GHG emissions resulting from the new conventional car annual improvements. This low reduction comes from the slow fleet turnover of private cars. In this study, most of our discussions revolved around a scenario that assumes continued trends in public transit deployment and complete electrification of vehicles by 2040 (also called PT-EV in the manuscript) and this scenario is not affected (less than $1 \%$ in 2018-2050 cumulative GHG emissions) by $1 \%$ annual improvements in new conventional car fuel consumption.

Other technologies: We consider the representative vehicle models described in Table 10. CD-mode refers to Charge Depleting mode, and CS-mode refers to Charge Sustaining mode for PHEV. We consider a utility factor of 0.5 for PHEV, meaning that $50 \%$ of the vehicle activity for PHEV is in CD-mode, and $50 \%$ in CS-mode ${ }^{27}$. We note that the values in Table 10 are not corrected by on-road degradation factors and Section 1.3.5 discusses corrections.

Table 10: Fuel consumption of private car, private hire car and taxi technologies

\begin{tabular}{|l|l|l|l|}
\hline Technology & Fuel(s) & Fuel consumption & Representative vehicles \\
\hline HEV-G & Gasoline & $3.9 \mathrm{~L} / 100 \mathrm{~km}$ & Toyota Prius C Hybrid $1.5 \mathrm{~L}$ \\
\hline CNG & CNG & $14.2 \mathrm{~L} / 100 \mathrm{~km}$ & Toyota Camry CNG \\
\hline PHEV & $\begin{array}{l}\text { Gasoline } \\
\text { Electricity }\end{array}$ & $\begin{array}{l}\text { CS-mode: } 6.0 \mathrm{~L} / 100 \mathrm{~km} \\
\text { CD-mode: } 20.8 \mathrm{kWh} / 100 \mathrm{~km}\end{array}$ & Chevrolet Volt \\
\hline BEV & Electricity & $17.1 \mathrm{kWh} / 100$ & Nissan Leaf \\
\hline
\end{tabular}

\subsubsection{Public bus, private bus and school bus}

We base the fuel consumption of the bus technologies on a study by Zhang et al. ${ }^{28}$ who estimated realworld fuel consumption of urban buses in the city of Beijing, China. They included ICEB-D, CNGB and HEBD. For EB, Singapore contracted 60 new electric buses in 2018, among them 20 are from BYD. Their single- 
deck electric buses have an electrical consumption of $130 \mathrm{kWh} / 100 \mathrm{~km}{ }^{29}$. Table 11 presents the fuel consumption by bus technologies. We assume that public bus, private bus and school bus have the same fuel consumption by technology, and that the fuel consumption values apply to all model years.

Table 11: Fuel consumption of bus technologies

\begin{tabular}{|l|l|l|l|}
\hline Technology & Fuel & Fuel consumption & Source \\
\hline ICEB-D & Diesel & $32.6 \mathrm{~L} / 100 \mathrm{~km}$ & 28 \\
\hline HEB-D & Diesel & $24.3 \mathrm{~L} / 100 \mathrm{~km}$ & 28 \\
\hline CNGB & CNG & $68 \mathrm{~L} / 100 \mathrm{~km}$ & 28 \\
\hline EB & Electricity & $130 \mathrm{kWh} / 100 \mathrm{~km}$ & 29 \\
\hline
\end{tabular}

\subsubsection{MRT and LRT}

We estimate the MRT and LRT electrical consumption from two reports of the SMRT Corporation ${ }^{30,31}$. We obtain the total electricity consumption from 2013 to 2016 of the trains operated by the SMRT Corporation ${ }^{31}$ and divide them by the total car-kilometres operated ${ }^{30}$. Table 12 presents the calculated values.

Table 12: MRT and LRT electrical consumption from 2013 to 2016 calculated from SMRT Corporation

\begin{tabular}{|l|l|l|l|l|}
\hline & 2013 & 2014 & 2015 & 2016 \\
\hline MRT \& LRT electrical consumption (kWh/100 km) & 421 & 495 & 496 & 497 \\
\hline
\end{tabular}

For comparison, the Transportation Energy Databook (TEDB) of the Oak Ridge National Laboratory in the U.S. ${ }^{32}$ reports national average energy intensity at $360 \mathrm{kWh} / 100 \mathrm{~km}$ for transit rail and up to 978 $\mathrm{kWh} / 100 \mathrm{~km}$ for commuter rail. Our calculated values are in the range of values obtained from literature. We note that air conditioning load undoubtedly play an important part of the energy consumption in the Singaporean context, and could explain the higher energy intensity of the transit rail in Singapore compared to the U.S. In this work, we assume a value of $497 \mathrm{kWh} / 100 \mathrm{~km}$ from 2017 onwards for both MRT and LRT.

\subsubsection{On-road degradation factors}

Some of the vehicle fuel consumptions previously presented are extracted from fuel economy dataset ${ }^{21}$ or manufacturer websites ${ }^{29}$. However, real-world vehicle fuel consumptions are often higher than values from certification tests ${ }^{25,33}$. Reasons could include aggressive driving with frequent acceleration and braking, excessive idling, nonoptimal environment for engines (e.g., cold weather generally reduces engine efficiency), heavy load, air conditioning, or mountainous terrain. In the context of Singapore, air conditioning represents undoubtedly the most significant auxiliary loads ${ }^{34}$. Therefore, we consider onroad degradation factors for some vehicle fuel consumptions to adjust for real-world conditions and fuel use.

Car: We calculate historical on-road degradation factors for ICEVs-G in private car, private hire car and taxi with a top-down approach. We use the historical motor gasoline consumption of ICEVs-G in Singapore from 2005 to $2017^{24}$, as calculated in section 1.3.2, and estimates of gasoline consumption from on-road vintage stock and new vehicle fuel consumption. Table 13 presents the results. We note that the average on-road degradation factor over this period is $+20 \%$, which is similar to values found in the literature (e.g., 
between $+10 \%$ and $+35 \%$ degradations in $\mathrm{CO}_{2}$ emissions for a study in Europe ${ }^{25}$; between $+17 \%$ to $+40 \%$ in fuel consumption for the U.S. EPA ${ }^{35}$ ). We assume that from 2018 onwards, the on-road degradation factors of ICEVs-G is $+20 \%$. We assume similar degradation factors for HEV-G, ICEV-D, PHEV and CNG for private car, private hire car and taxi.

Table 13: Historical on-road degradation factors of ICEVs-G

\begin{tabular}{|l|l|l|l|l|l|l|l|l|l|l|l|l|l|}
\hline Year & 2005 & 2006 & 2007 & 2008 & 2009 & 2010 & 2011 & 2012 & 2013 & 2014 & 2015 & 2016 & 2017 \\
\hline Factor & 1.24 & 1.21 & 1.21 & 1.27 & 1.20 & 1.11 & 1.09 & 1.11 & 1.13 & 1.15 & 1.22 & 1.23 & 1.20 \\
\hline
\end{tabular}

Regarding BEV, in addition to driving behaviors, battery performances are highly affected by the outside temperature ${ }^{36}$. For example, under cold weather conditions, the battery efficiency may decrease, and the battery internal resistance may increase. Under warm weather conditions, the battery may degrade faster requiring increasing thermal management. Hao et al. ${ }^{37}$ estimated that average real-world electrical consumption of BEVs in an urban area (Beijing) in summer is about $18 \%$ higher than predicted by the European drive cycles. As Singapore has a warmer and more humid weather than Beijing, we assume a degradation factor of $+20 \%$ for BEVs, consistent with the degradation factors of the other technologies.

Bus: In our study, we derive the bus fuel consumption from empirical values found in Beijing. However, we did not adjust for the air conditioning loads. As Singapore is significantly warmer than Beijing, we assume that air conditioning will be all the time at maximum capacity. Zhang et al. ${ }^{28}$ reported that it would increase the fuel consumption by $+22.8 \%$ for ICEB-D, $+9 \%$ for CNGB, and $+48.2 \%$ for HEB-D. Regarding EB, we conduct a small literature review of real-world electrical consumption of electric buses and find values between $135{ }^{38}$ and $172{ }^{39} \mathrm{kWh} / 100 \mathrm{~km}$ (compared to $130 \mathrm{kWh} / 100 \mathrm{~km}$ from the manufacturer website ${ }^{29}$ ). For the same reasons than before, we consider the high range of the values in our work and therefore consider a degradation factor of $+30 \%$ (resulting in $172 \mathrm{kWh} / 100 \mathrm{~km}$ ) for EB. Table 14 summarize the on-road degradation factors adopted in our study.

We note that we do not adjust fuel consumption of motorcycles as the initial value was derived from realworld driving ${ }^{20}$, and there is no air conditioning load in motorcycles. We do not adjust electrical consumption for MRT and LRT as calculations are based on real-world estimates.

Table 14: On-road degradation factors of fuel consumption for bus and cars

\begin{tabular}{|c|c|c|c|c|}
\hline Mode & Technology & Fuel(s) & $\begin{array}{l}\text { On-road } \\
\text { degradation factors }\end{array}$ & Source \\
\hline \multirow{6}{*}{$\begin{array}{l}\text { Private car, Private } \\
\text { hire car \& Taxi }\end{array}$} & ICEV-G & Gasoline & $+20 \%$ & Own calculations \\
\hline & ICEV-D & Diesel & $+20 \%$ & \multirow{4}{*}{$\begin{array}{l}\text { Assumed same than ICEV-C } \\
\text { with validation from }{ }^{25}\end{array}$} \\
\hline & HEV-G & Gasoline & $+20 \%$ & \\
\hline & CNG & CNG & $+20 \%$ & \\
\hline & PHEV & $\begin{array}{l}\text { Gasoline } \\
\text { Electricity }\end{array}$ & $+20 \%$ & \\
\hline & BEV & Electricity & $+20 \%$ & 37 \\
\hline \multirow{4}{*}{$\begin{array}{l}\text { Public bus, Private } \\
\text { bus \& School bus }\end{array}$} & ICEB-D & Diesel & $+22.8 \%$ & \multirow[t]{3}{*}{28} \\
\hline & HEB-D & Diesel & $+48.2 \%$ & \\
\hline & CNGB & CNG & $+9 \%$ & \\
\hline & EB & Electricity & $+30 \%$ & 39 \\
\hline
\end{tabular}




\subsection{Passenger transport fuel use}

We calculate the passenger transport fuel use from the vehicle activity (vkt) by mode, technology and vehicle age, the vehicle fuel consumption, and the on-road degradation factors.

Equation 9

$$
V_{y, f}=\sum_{m} \sum_{t}\left(\sum_{a} V K T_{y, m, t, a} *\left(F C_{y-a, m, t, f} * U F_{m, t, f}\right)\right) * D F_{m, t, f}
$$

With:

- $\quad y$ the year, $f$ the fuel type, $m$ the transport mode, $t$ the vehicle technology, $a$ the vehicle age

- $V K T_{y, m, t, a}$ the vehicle activity in [vehicle.km/year],

- $F C_{y-a, m, t, f}$ the vehicle fuel consumption of model year $y-a$ in [L or $\mathrm{kWh} / \mathrm{km}$ ]

- $U F_{m, t, f}$ the utility factors. 0.5 for PHEV and 1 for other technologies.

- $D F_{m, t, f}$ the on-road degradation factor.

Figure 10 presents the historical passenger transport fuel use estimated by our model from 2005 to 2019.

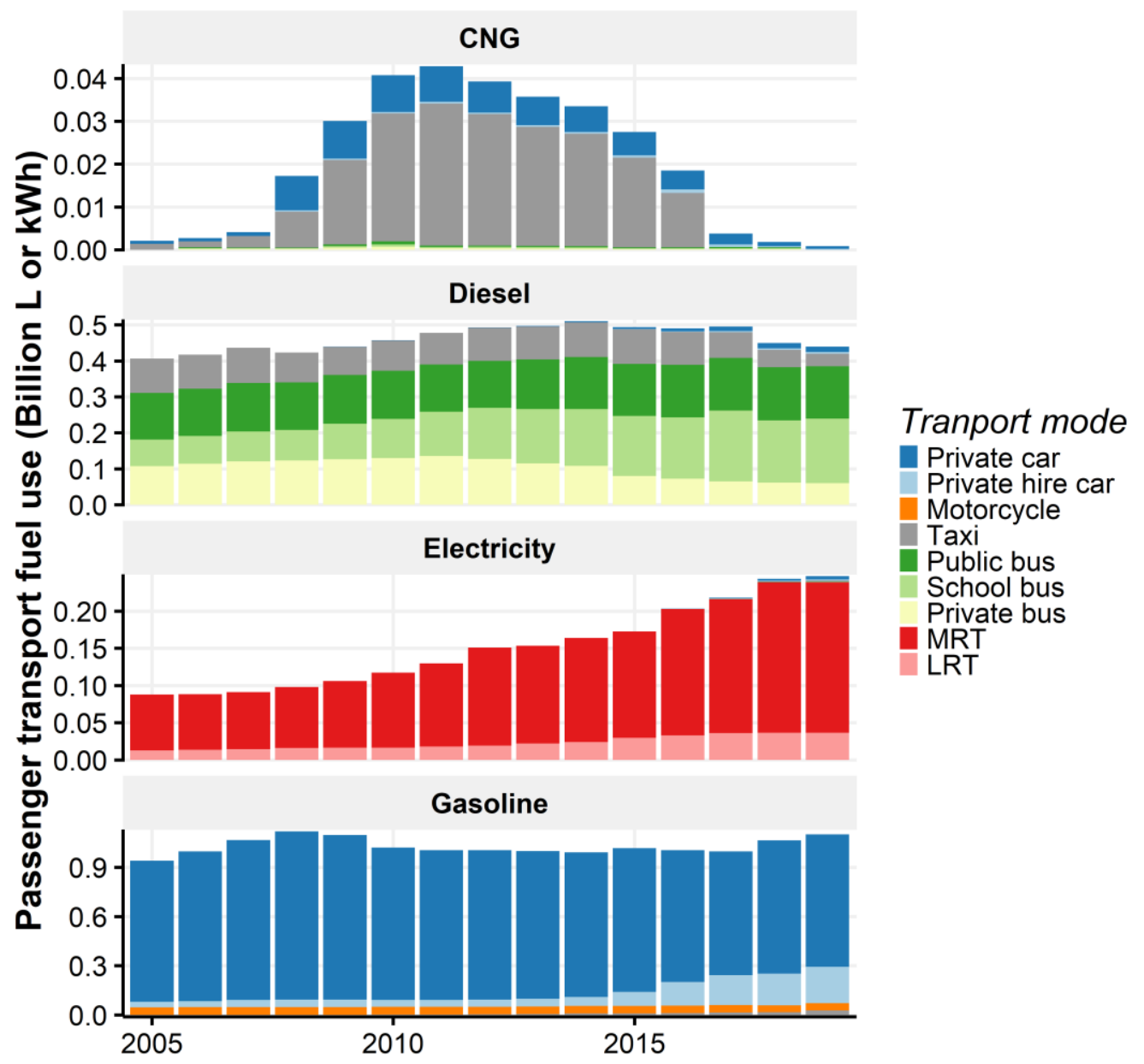

Figure 10: Historical passenger transport fuel use from 2005 to 2019 by transport mode and fuel type 


\subsection{Environmental assessment}

We estimate the life cycle GHG emissions of passenger transport in Singapore. Our system boundary comprises vehicle exhaust, fuel upstream, and vehicle production emissions as represented in Figure 11. We include all potential GHG emissions, when possible, and pay careful attention to carbon dioxide $\left(\mathrm{CO}_{2}\right)$, methane $\left(\mathrm{CH}_{4}\right)$ and nitrous oxide $\left(\mathrm{N}_{2} \mathrm{O}\right)$. We aggregate the GHG emissions using the Global Warming Potential (GWP) values of the fifth assessment report (AR5) of the International Panel on Climate Change (IPCC) over a 100-year time horizon with no climate-carbon feedbacks for non- $\mathrm{CO}_{2}$ emissions ${ }^{40}$. The climate-carbon feedback refers to the feedback between the carbon-cycle and the climate system that may amplify or reduce the global warming effects of GHGs. We do not consider them due to substantial uncertainties associated with the indirect radiative forcing estimates ${ }^{40}$. We, therefore, use a GWP of 30 kg CO 2 eq. / $\mathrm{kg} \mathrm{CH}_{4}$ for fossil $\mathrm{CH}_{4}$ and of $265 \mathrm{~kg} \mathrm{CO}$ eq. / $\mathrm{kg} \mathrm{N} 2 \mathrm{O}$ for $\mathrm{N}_{2} \mathrm{O}$.

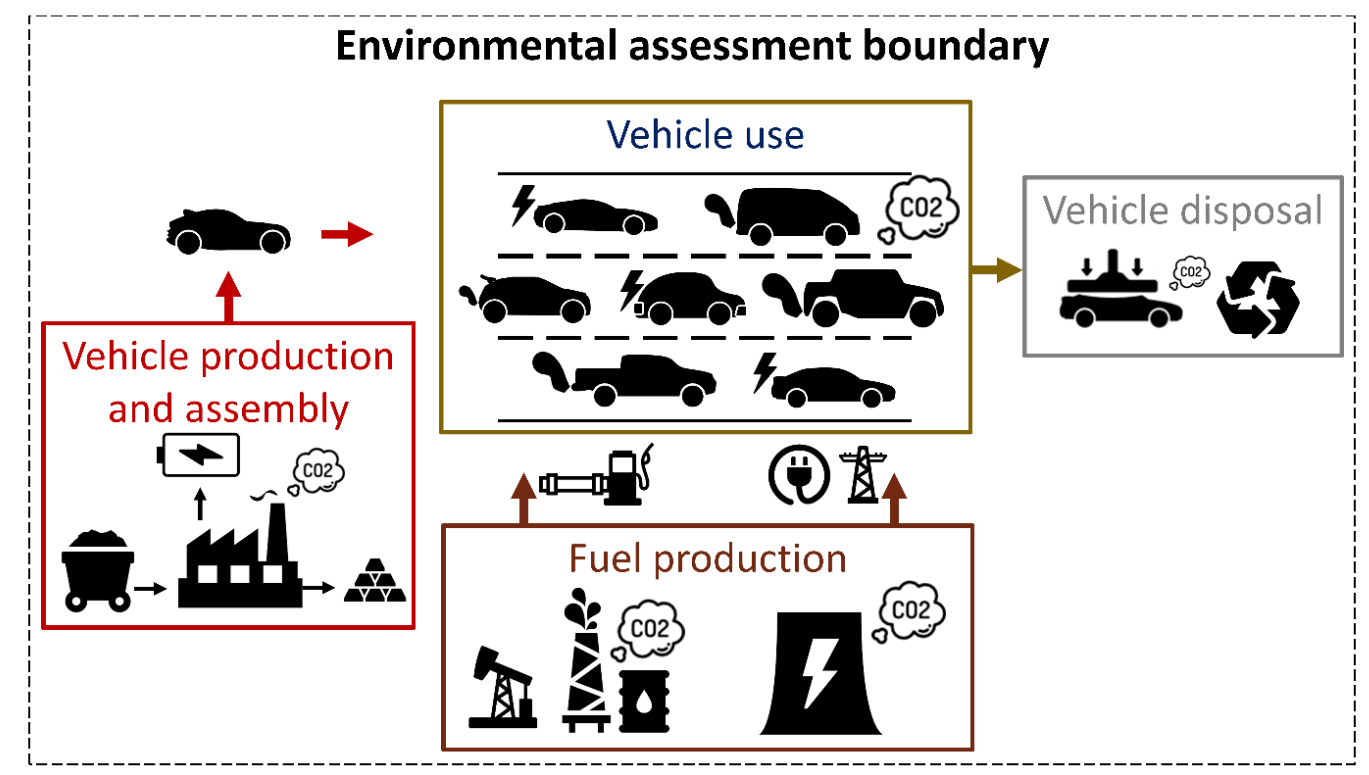

Figure 11: Environmental assessment boundary

\subsubsection{Exhaust $\mathrm{CO}_{2}$ emissions}

We estimate the vehicle $\mathrm{CO}_{2}$ exhaust emissions of passenger transport from $\mathrm{CO}_{2}$ combustion emission factors recommended by the IPCC (2006) and presented in Table 15. We neglect the exhaust emissions of other GHGs, such as $\mathrm{CH}_{4}$ and $\mathrm{N}_{2} \mathrm{O}$, as they usually have very low contributions to the GWP of vehicle exhaust emissions. The GWP contribution of $\mathrm{CH}_{4}$ exhaust emissions is about $0.3-0.4 \%$ of the GWP of $\mathrm{CO}_{2}$ exhaust emissions for conventional vehicles ${ }^{42}$, and $\mathrm{N}_{2} \mathrm{O}$ emissions about $1-3 \%{ }^{43}$. Recent analyses even reported lower emission rates for both GHGs, potentially due to improvements in catalytic converter technology ${ }^{44}$.

Table 15: Vehicle $\mathrm{CO}_{2}$ exhaust emissions of fuel combustion

\begin{tabular}{|l|l|l|}
\hline Fuel & Exhaust $\mathrm{CO}_{2}$ Emission Factors $\left[\mathrm{kg} \mathrm{CO}_{2} / \mathrm{TJ}\right]$ & Exhaust $\mathrm{CO}_{2}$ Emission Factors $[\mathbf{k g ~ C O} / \mathbf{L}]$ \\
\hline Gasoline & $69.3 \times 10^{3}$ & 2.17 \\
\hline Diesel & $74.1 \times 10^{3}$ & 2.65 \\
\hline CNG & $56.1 \times 10^{3}$ & 1.33 \\
\hline Electricity & 0 & 0 \\
\hline
\end{tabular}




\subsubsection{Fuel upstream GHG emissions}

We estimate the upstream GHG emissions of gasoline, diesel and CNG from the GREET model assuming U.S. averages ${ }^{45}$. These estimates may not be entirely representative of the Singaporean context as energy sources and production processes differ, but are our best estimates given the lack of data. We note that $\mathrm{CO}_{2}$ emissions are the major contributors to the GWP of gasoline, diesel and CNG production, at $71 \%, 73 \%$ and $55 \%$ respectively, $\mathrm{CH}_{4}$ had the second highest contributions at $25 \%, 26 \%$ and $43 \%$ respectively, and $\mathrm{N}_{2} \mathrm{O}$ had the lowest contributions at $4 \%, 1 \%$ and $2 \%$ respectively.

Regarding electricity generation, Singapore has derived more than $95 \%$ of its electricity from natural gas since $2014{ }^{46}$. The Singaporean Energy Market Authority (EMA) estimates that average $\mathrm{CO}_{2}$ emission factors of electricity generation have decreased from $0.5255 \mathrm{~kg} \mathrm{CO} / \mathrm{kWh}$ in 2005 to $0.4085 \mathrm{~kg} \mathrm{CO} / \mathrm{kWh}$ in $2019{ }^{46}$. In addition to the $\mathrm{CO}_{2}$ emissions from fuel combustion, upstream fugitive methane emissions occur during the drilling, extraction, and transportation processes of natural gas. The EMA estimates these emissions between 0.00198 and $0.00228 \mathrm{~kg} \mathrm{CH}_{4} / \mathrm{kWh}^{46}$, or between 0.0594 and $0.0684 \mathrm{~kg} \mathrm{CO}$ eq. $/ \mathrm{kWh}$ using the GWP value reported above. An LCA of a gas fired combined cycle plant in Singapore conducted in 2005 estimated that direct combustion emissions and fugitive emissions represented more than $96 \%$ of the GWP of electricity generation ${ }^{47}$. We therefore omit the GHG emissions associated with other upstream processes, such as plant construction and decommissioning. We consider a value of $0.472 \mathrm{~kg}$ $\mathrm{CO}_{2}$ eq./kWh from 2019 onward and explore changes in electricity sources as prospective scenarios.

Table 16: Upstream GHG emissions of fuel

\begin{tabular}{|l|l|l|}
\hline Fuel & $\begin{array}{l}\text { Upstream GHG } \\
\text { Emission Factors }\end{array}$ & Source \\
\hline Gasoline & $0.611 \mathrm{~kg} \mathrm{CO}$ eq./L & GREET: Baseline Gasoline ${ }^{45}$ \\
\hline Diesel & $0.658 \mathrm{~kg} \mathrm{CO}_{2}$ eq./L & GREET: Baseline Conventional and LS Diesel ${ }^{45}$ \\
\hline CNG & $0.416 \mathrm{~kg} \mathrm{CO}_{2}$ eq./L & GREET: Compressed Natural Gas ${ }^{45}$ \\
\hline Electricity & $0.472 \mathrm{~kg} \mathrm{CO} 2$ eq./kWh & 46 \\
\hline
\end{tabular}

\subsubsection{Vehicle production}

We estimate the production emissions of cars (Private car, Private hire car, Taxi), buses (Public bus, Private bus and School bus), and motorcycles. We use a simplistic approach by estimating the vehicle production emissions without battery for all vehicle technologies, and then adding the battery production emissions for technologies with batteries.

GHG emissions of bus and motorcycle productions derive from the ecoinvent v3.6 life cycle inventory database ${ }^{48}$ simulated through the Brightway software ${ }^{49} \cdot \mathrm{CO}_{2}$ emissions represented $91 \%$ and $93 \%$, respectively, of the GWP of the motorcycle and bus production processes and $\mathrm{CH}_{4}$ emissions represented the other $9 \%$ and $7 \%$, respectively. We estimate the car production without battery emissions from a recent LCA study ${ }^{50}$ using Japanese data, Japan being the primary producer of private vehicles in Singapore. Table 17 presents the emission factors of vehicle production without battery for cars, buses and motorcycles. 
Table 17: Life cycle emission factors of vehicle production without battery

\begin{tabular}{|l|l|l|l|}
\hline Mode & $\begin{array}{l}\text { GHG Emission factor }\left[\mathbf{k g ~ C O}_{2}\right. \\
\text { eq. / functional unit] }\end{array}$ & $\begin{array}{l}\text { Functional } \\
\text { unit }\end{array}$ & Source \\
\hline $\begin{array}{l}\text { Private car, Private } \\
\text { hire car, Taxi }\end{array}$ & $5.49 \times 10^{3}$ & 1 car & 50 \\
\hline $\begin{array}{l}\text { Public bus, Private bus, } \\
\text { School bus }\end{array}$ & $32.0 \times 10^{3}$ & 1 bus & $\begin{array}{l}\text { Ecoinvent: Bus production, } \\
\text { RoW }\end{array}$ \\
\hline Motorcycle & 392 & 1 motorcycle & $\begin{array}{l}\text { Ecoinvent: } \text { motor scooter } \\
\text { production, RoW }\end{array}$ \\
\hline
\end{tabular}

We add the battery production emissions to the vehicle production without battery emissions. We estimate battery capacity by mode and vehicle technology from representative vehicle models (see Table 18). Then, we multiply the battery capacity by a battery production emission factors of $140 \mathrm{~kg} \mathrm{CO} 2$ eq./kWh obtained from Kim et al. ${ }^{51}$.

Table 18: Battery capacity by mode and technology

\begin{tabular}{|l|l|l|l|}
\hline Mode & Technology & $\begin{array}{l}\text { Battery capacity } \\
{[\mathbf{k W h}]}\end{array}$ & Source \\
\hline \multirow{2}{*}{$\begin{array}{l}\text { Private car, } \\
\text { Private hire } \\
\text { car, Taxi }\end{array}$} & HEV-G & 0.9 & Based on Toyota Prius C Hybrid ${ }^{52}$ \\
\cline { 2 - 4 } & PHEV & 18.4 & Based on Chevrolet Volt \\
\cline { 2 - 4 } & BEV & 40 & Based on Nissan Leaf \\
\cline { 2 - 4 } & HEB-D & 4.8 & Based on Volvo B5LH \\
\cline { 2 - 4 } & EB & 324 & Based on BYD K9 ${ }^{29}$ \\
\hline Motorcycle & EM & 1.2 & 20 \\
\hline
\end{tabular}

One major limitation of our approach is that we only differentiate the vehicle production emissions of the technologies if they have a battery. However, other components are changing for different technologies. For example, battery electric vehicles do not have an internal combustion engine, but have an electric motor. Hybrid vehicles may have both a combustion engine and an electric motor. Overall, this simplification may lead to under- or over- estimations, but is a common assumption found in the literature (see ${ }^{54}$ for example) in the absence of detailed data.

\subsubsection{Vehicle life cycle GHG emissions}

Figure 12 and Figure 13 show the vehicle life cycle GHG emissions with all previous parameters for all technologies in private car, motorcycle and public bus. The parameters are taken for the 2018 model year vehicles, with an assumed lifetime of $150,000 \mathrm{~km}$ for private car and motorcycle, and 500,000 km for public bus. In Figure 12, the functional unit is per vehicle activity (vkt), and the results are comparable only between technologies within the modes, as the transport modes have different load factors. In Figure 13 , the functional unit is per passenger activity (pkt), which allows for comparison between the modes. 


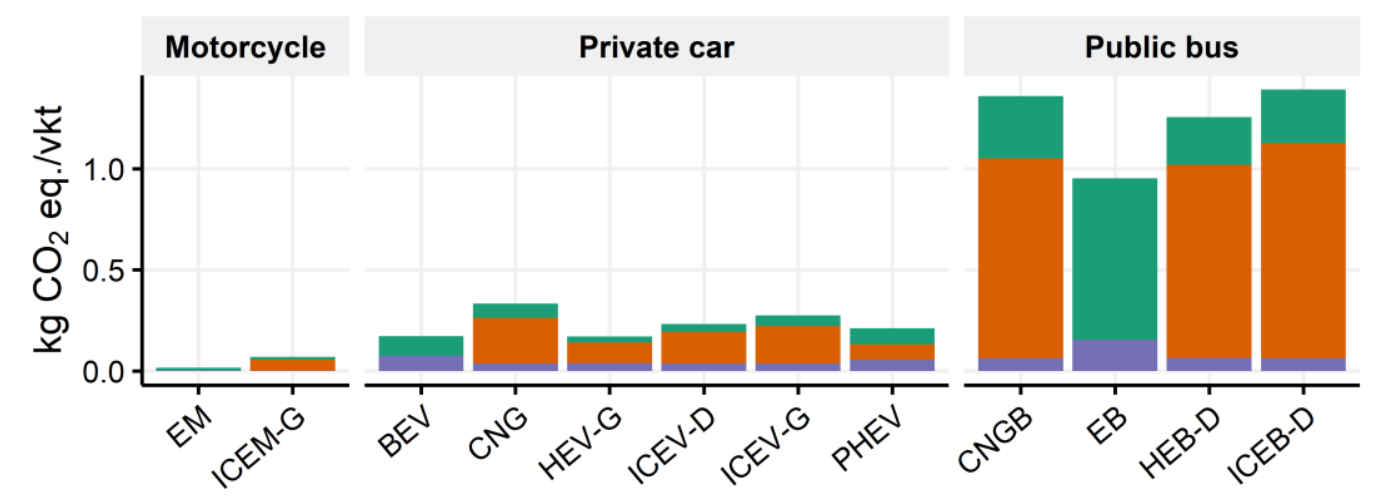

Fuel Production — Fuel Use 1 Vehicle production

Figure 12: Vehicle life cycle GHG emissions for motorcycle, private car and public bus per vehicle activity

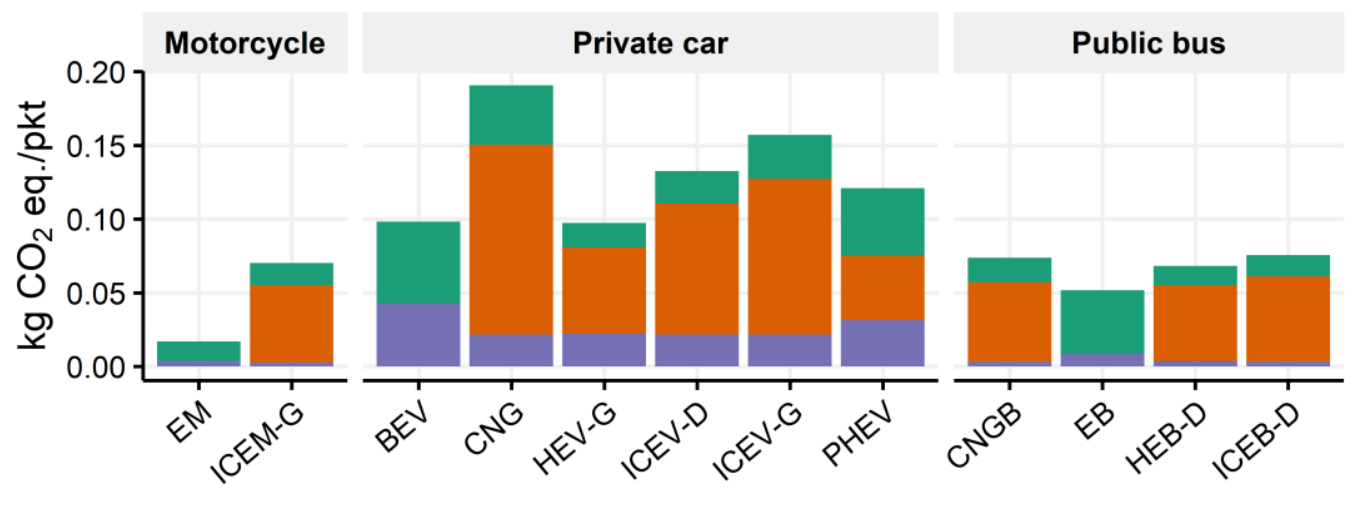

Fuel Production 1 Fuel Use $\square$ Vehicle production

Figure 13: Vehicle life cycle GHG emissions for motorcycle, private car and public bus per passenger activity

\section{6. $\mathrm{CO}_{2}$ emission budget}

We calculate $\mathrm{CO}_{2}$ emission budgets for passenger land transport in Singapore that are consistent with global warming below $1.5{ }^{\circ} \mathrm{C}$ and $2{ }^{\circ} \mathrm{C}$ and compare them with the national pledge under the Paris agreement ${ }^{55}$.

\subsubsection{National budget consistent with global warming below $1.5^{\circ} \mathrm{C}$ and $2{ }^{\circ} \mathrm{C}$}

A commonly agreed objective regarding climate change mitigation is to limit the global mean temperature change relative to pre-industrial era "well below $2{ }^{\circ} \mathrm{C}$ ", and ideally below $1.5^{\circ} \mathrm{C}{ }^{56}$. These temperatures targets are often converted into global cumulative emission budgets of $\mathrm{CO}_{2}$, as cumulative emissions of $\mathrm{CO}_{2}$ are almost proportional to global mean temperature changes ${ }^{57}$. The exact value of this budget is however highly uncertain, but Meinshausen et al. ${ }^{58}$ estimated a global cumulative $\mathrm{CO}_{2}$ emission budget from 2000 to 2050 between $1,000 \mathrm{Gt} \mathrm{CO}_{2}$ to $1,440 \mathrm{Gt} \mathrm{CO}_{2}$ for a $25 \%$ and $50 \%$ probability of limiting global mean temperature below $2{ }^{\circ} \mathrm{C}$.

To estimate national and sectoral $\mathrm{CO}_{2}$ emission budgets in Singapore that are consistent with global warming below $1.5{ }^{\circ} \mathrm{C}$ and $2{ }^{\circ} \mathrm{C}$, we use global $\mathrm{CO}_{2}$ emission pathways developed for different 
socioeconomic scenarios, called Shared Socioeconomic Pathways (SSP) ${ }^{59}$, and simulated through Integrated Assessment models (IAMs). These emission pathways, describe realistic temporal and spatial distributions of $\mathrm{CO}_{2}$ emissions that are consistent with global warming below $1.5^{\circ} \mathrm{C}$ and $2{ }^{\circ} \mathrm{C}$. We use the scenarios developed for four SSPs (i.e., 1, 2, 4 and 5) by six IAMs (i.e., AIM, IMAGE, GCAM, MESSAGE, REMIND-MAGPIE, WITCH) with the $1.9 \mathrm{~W} \cdot \mathrm{m}^{2}$ and $2.6 \mathrm{~W} \cdot \mathrm{m}^{2}$ radiative forcing levels in 2100 , as representative of global warming below $1.5{ }^{\circ} \mathrm{C}$ and $2{ }^{\circ} \mathrm{C}{ }^{60,61}$. We do not use SSP 3 as the narrative does not provide emission pathways consistent with the $1.9 \mathrm{~W} \cdot \mathrm{m}^{2}$ and $2.6 \mathrm{~W} \cdot \mathrm{m}^{2}$ radiative forcing levels in 2100. The emission pathways are however not refined at the country-level for Singapore, but at regional levels, and need to be downscaled.

There are many approaches to downscale emission pathways and budgets. In chapter 6 (section 6.3.6.6) of its fifth assessment report, the IPCC provides an overview of seven different allocation methods based on three equity principles: responsibility, capability and equality ${ }^{62}$. The responsibility principle uses historical emissions to derive emission goals and allocates high mitigation for countries with high historical emissions. The capability principle uses economic or human development indicators and allocates high mitigation for countries with high development. The equality principle uses population data and argues for convergence towards equal per capita emissions. Some of the suggested allocation methods use a mix of equity principles, such as the "Responsibility, capability, and need" method that relies on the responsibility and capability principles. The IPCC reports that the most common approaches are based on the equality principle and on the idea of emissions per person convergence. These approaches are indeed simple to apply with few input parameters, such as population data and current emission shares, and have a transparent mathematical model ${ }^{63}$. Methods based on the responsibility and capability principles require more input data (e.g., human development index, wealth distribution within countries, GDP) and have more complex mathematical models, as they need to translate the inputs into differentiated mitigation efforts ${ }^{64}$.

Gignac and Matthews ${ }^{63}$ describes two extreme approaches based on the equality principle. At one end of the spectrum is the strict non-application of the equality principle in an approach entitled "grandfathering" that assumes reduction goals based on current emission shares. This approach is based on a status quo and is criticized in the literature ${ }^{65}$ as it does not respect the statement of the Paris agreement: "mitigation, adaptation [...] in the light of equity and the best available science" ${ }^{56}$. On the other end of the spectrum is the allocation of future $\mathrm{CO}_{2}$ emissions strictly based on equal projected per capita emissions (also called Complete Equality approach in the sections below). In this approach, $\mathrm{CO}_{2}$ emission budgets are allocated based on projected population share. This extreme does not provide a transition between current emission shares and equal per capita emissions. A solution to acknowledge both the current state of emission shares and an equitable convergence toward equal per capita emissions is the approach of contraction \& convergence developed by Meyer ${ }^{66}$ and applied by Gignac and Matthews 63. This approach consists in sharing a carbon budget amongst nations while allowing the least economically developed nations for emission expansions. It consists in two phases. First, the national per capita emissions increase/decrease until they converge to a point of equal per capita emissions across all countries at a given year. After the convergence year, all countries follow the same annual per capita emissions ${ }^{63}$.

For our case study of Singapore, we extract from the SSP datasets the regional $\mathrm{CO}_{2}$ emission pathways for Asia (as defined by the harmonized CMIP6 emissions data set ${ }^{61}$ ) from 2010 to 2100 for scenarios consistent with global warming below $1.5^{\circ} \mathrm{C}$ and $2{ }^{\circ} \mathrm{C}$. We use the historical country-level $\mathrm{CO}_{2}$ emissions 
of the Asian nations from the IEA database on $\mathrm{CO}_{2}$ emissions from fuel consumption ${ }^{67}$, the Global Carbon Budget of Le Quéré et al. ${ }^{68}$, and the Community Emission Data System ${ }^{69}$ to calculate country-level fractional share of emissions in 2017. Then, we calculate the country-level fractional share of emissions based on population distribution at the convergence year, considering two convergence years (2040 and 2050). We assume linear transitions from the current fractional share of emissions to the convergence year and assume the fractional share to stay constant after the convergence year. Finally, we multiply the annual fractional shares with the $\mathrm{CO}_{2}$ emission pathways of Asian nations of the SSP database from 2018 to 2050, adjusted to the $2017 \mathrm{CO}_{2}$ emissions. It is important to note that all available simulations from all IAMs and SSPs are used with two convergence years each, meaning that 26 different budgets are calculated for the $1.5^{\circ} \mathrm{C}$ target and 38 for the $2{ }^{\circ} \mathrm{C}$ target. We consider the mean of each distribution as default in our model. Figure 14 shows an overview of the GHG emission budget module.

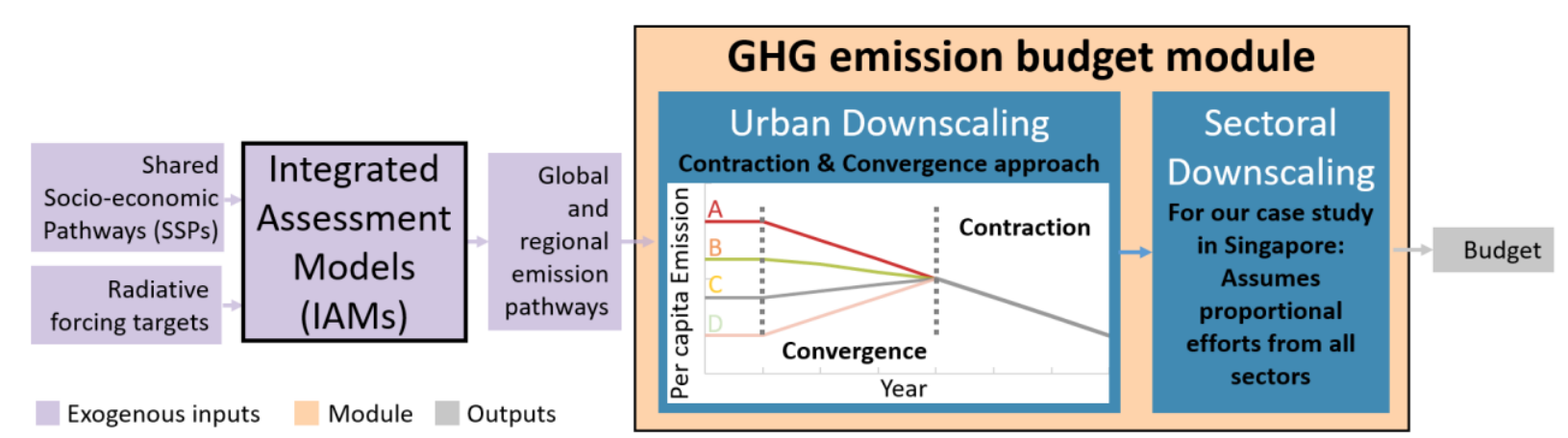

Figure 14: Overview of the GHG emission budget module

\subsubsection{National budget consistent with INDC pledge}

Singapore pledged to reduce its national emission intensity by $36 \%$ from 2005 levels by 2030 with an Intended nationally determined contribution (INDC) ${ }^{55}$. We assume emission intensity to refer to $\mathrm{CO}_{2}$ emissions per unit of GDP using purchasing power parities (PPP). Between 2005 and 2017, emission intensity in Singapore decreased from 0.142 to $0.101 \mathrm{~kg} \mathrm{CO}_{2} / 2010$ US\$ ${ }^{67}$. Therefore, emission intensity target for 2030 should be around $0.0909 \mathrm{CO}_{2} / 2010$ US\$. To estimate the resulting national $\mathrm{CO}_{2}$ emissions, we use the GDP growth of the SSP1 scenario of CMIP6, that assumes an increase of $32 \%$ in GDP (PPP) between 2017 and 2030 for Singapore ${ }^{61}$, and obtain approximately $55.6 \mathrm{Mt} \mathrm{CO}_{2}$ of national emissions in 2030, from $47 \mathrm{Mt} \mathrm{CO}_{2}$ in $2017^{67}$.

\subsubsection{Results of national budgets}

Figure 15 shows the estimated national $\mathrm{CO}_{2}$ emission pathways from 2005 to 2050 in Singapore that are consistent with global warming below $1.5^{\circ} \mathrm{C}$ and $2{ }^{\circ} \mathrm{C}$ using three allocation methods: The contraction \& convergence approach as described above, the grandfathering approach based on constant emission shares and the complete equality approach based on equal per capita emissions and future population shares. The figure also shows the INDC emissions. The ranges of the pathways from the various input data (i.e., simulation results for multiple SSPs and IAMs) and methodological choices (i.e., convergence year) are represented with shadowed areas and the means with lines.

The results presented in Figure 15 show that the INDC emissions up to 2030 are almost always above the $\mathrm{CO}_{2}$ emission pathways that are consistent with ambitious climate targets, even the ones based on the Grandfathering approach. When we calculate the cumulative emissions of the INDC over the period 2018- 
2030, we obtain a value of $710 \mathrm{Mt} \mathrm{CO}_{2}$. Despite the shorter time period, this value is still above the 2018$2050 \mathrm{CO}_{2}$ emission budgets calculated using the Complete Equality and Contraction \& Convergence approaches for $1.5{ }^{\circ} \mathrm{C}$ and $2{ }^{\circ} \mathrm{C}$ targets. The Grandfathering approach over the period 2018-2030 gives budgets between $510 \mathrm{Mt} \mathrm{CO} 2\left(1.5^{\circ} \mathrm{C}\right.$ target) and $571 \mathrm{Mt} \mathrm{CO}_{2}\left(2{ }^{\circ} \mathrm{C}\right.$ target $)$, or $28 \%$ and $20 \%$, respectively, lower than the INDC emissions. Therefore, our findings corroborate the claim of the Climate Action Tracker that Singapore's INDC is 'highly insufficient' and incompatible with a $2^{\circ} \mathrm{C}$ goal ${ }^{70}$.

Figure 15 shows also clearly how the contraction \& convergence approach offers a trade-off between current emission shares (grandfathering) and equal per capita emissions (complete equality).

\section{a) National $\mathrm{CO}_{2}$ emission pathways}

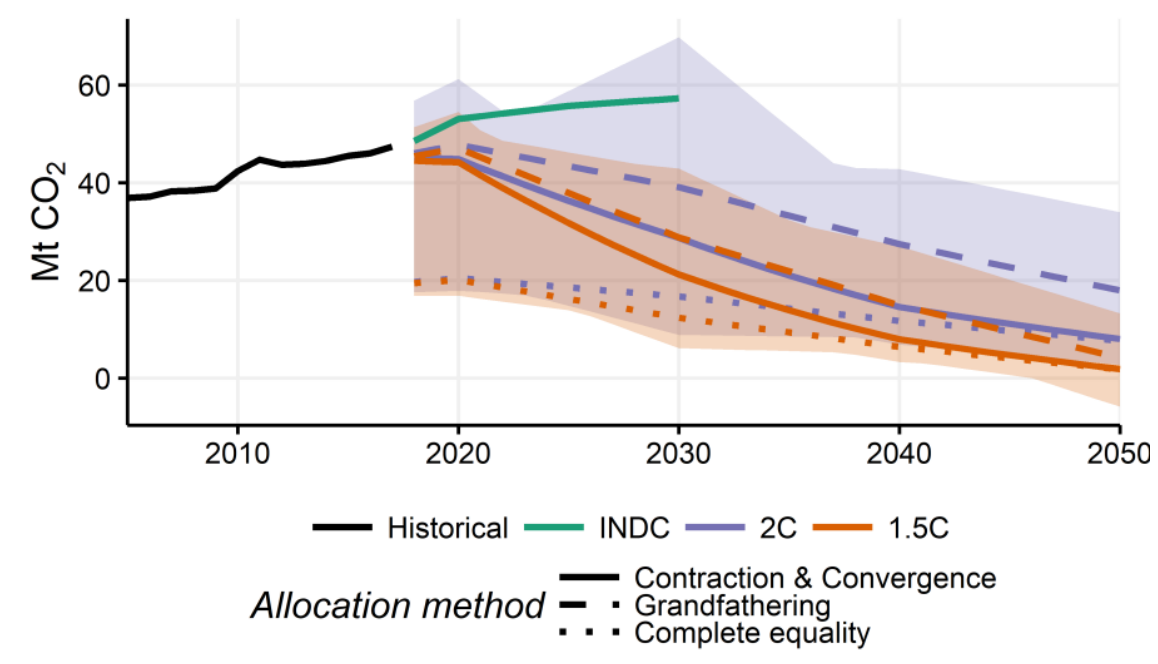

\section{b) 2018-2050 National $\mathrm{CO}_{2}$ emission budgets}

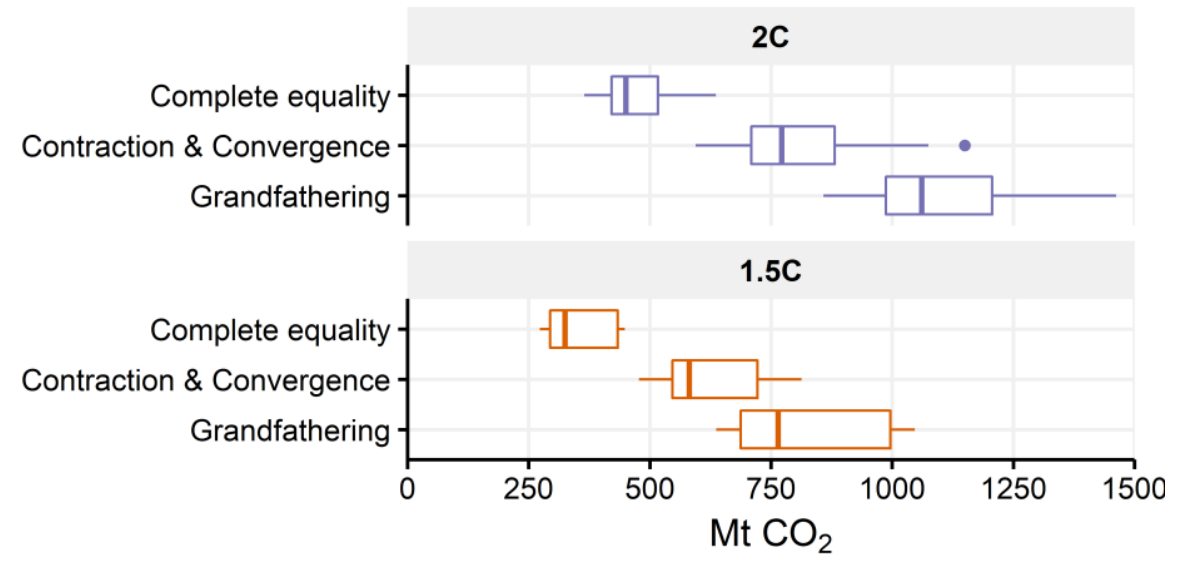

Figure 15: a) National $\mathrm{CO}_{2}$ emission pathways for Singapore under current INDC, and consistent with $1.5^{\circ} \mathrm{C}$ and $2{ }^{\circ} \mathrm{C}$ using three allocation methods, b) Boxplots of 2018-2050 $\mathrm{CO}_{2}$ emission budgets consistent with $1.5{ }^{\circ} \mathrm{C}$ and $2{ }^{\circ} \mathrm{C}$ with three allocation methods.

Note: In the boxplot, upper hinge represents $75 \%$ quantile, lower hinge $25 \%$ quantile, and the thick horizontal line in-between the median ( $50 \%$ quantile).

In Figure 16, the distributions of 2018-2050 $\mathrm{CO}_{2}$ emission budgets based on the contraction \& convergence approach are presented aggregated and disaggregated by parameters to show the variability across the 
multiple parameters included in the estimates (i.e., SSP, IAM, convergence year). We note that distributions across SSP is substantial, as SSP5 generally provides higher estimates than others. This is explained by the socio-economic and technological assumptions embedded within the different SSPs. For example, SSP5 assumes high technological advances and the intensive use of carbon capture and storage (CCS) technologies ${ }^{71}$, while SSP2 does not rely on CCS technologies ${ }^{72}$. Similar variations are found for the IAMs, as GCAM generally provides higher estimates than the other IAMs. This disparity comes from the modelling methods and choices embedded in the IAMs, such as their economic models (e.g., general vs. partial equilibrium models), cost assumptions or mitigation strategies ${ }^{73}$. Finally, it can be noted that earlier convergence year returns lower budgets for Singapore as Singapore currently possesses high emissions per capita.

\section{a)Distributions of $2018-2050 \mathrm{CO}_{2}$ emission budgets}

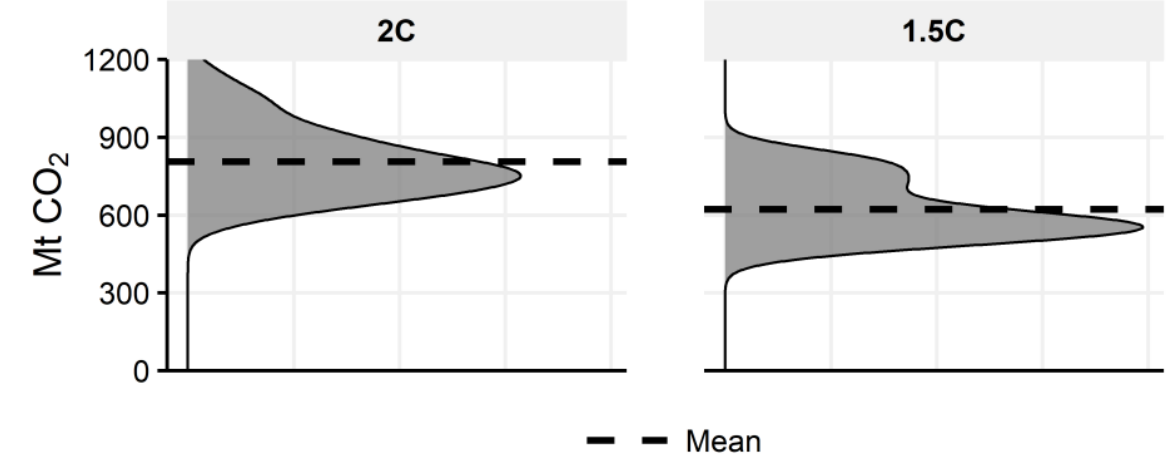

\section{b) Disaggregated by SSP}

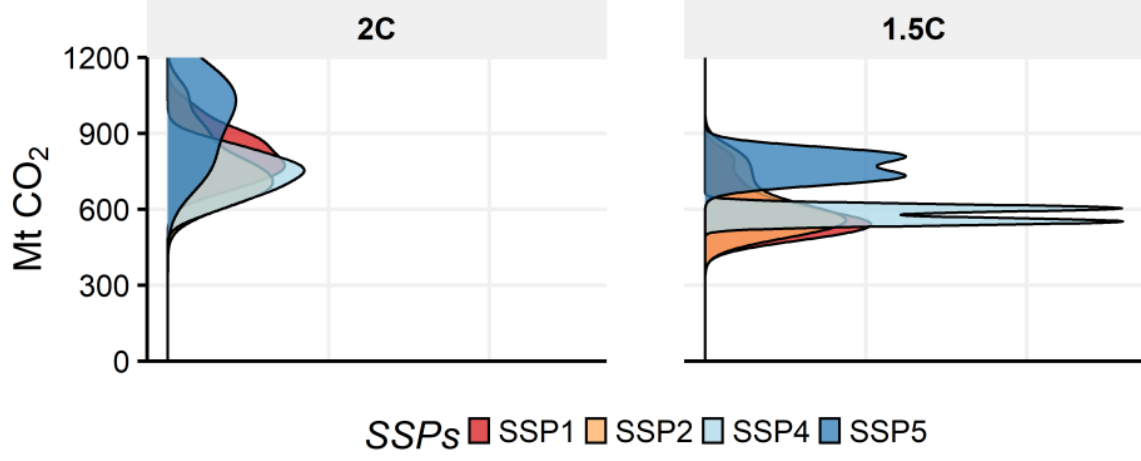

\section{c) Disaggregated by IAM}
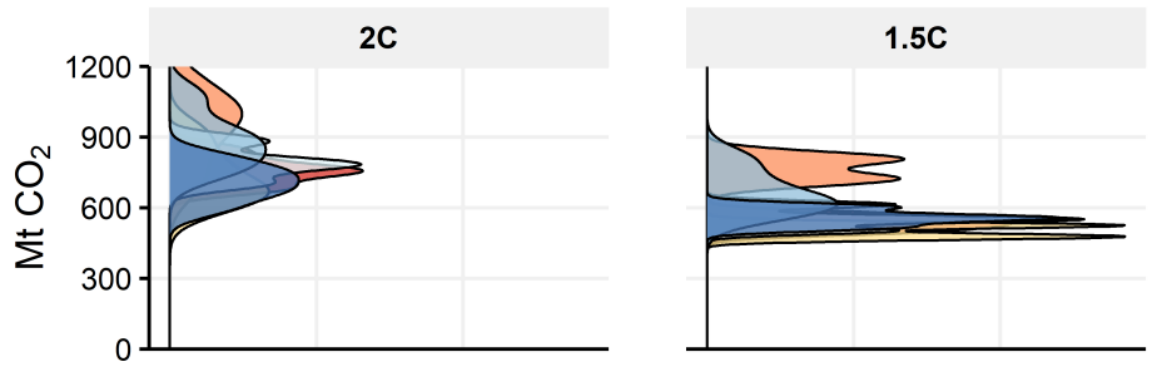

Model $\mathrm{D}$ AIM/CGE $\mathrm{GIMAGE}$ 


\section{d) Disaggregated by convergence year}

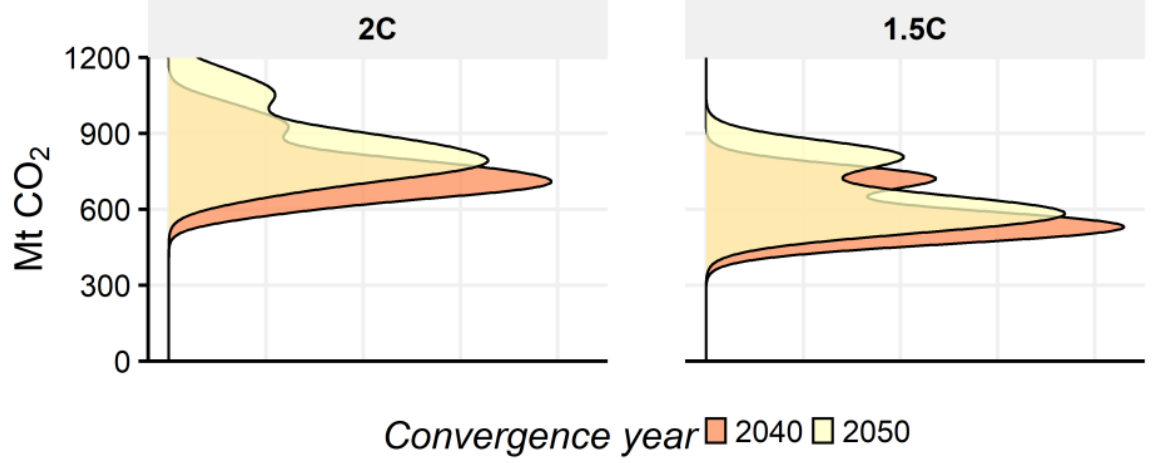

Figure 16: Distributions of 2018-2050 CO $\mathrm{CO}_{2}$ emission budgets a) aggregated, b) disaggregated by SSP, c) disaggregated by IAM, d) disaggregated by convergence year

Robiou du Pont et al. ${ }^{65}$ estimated country-level 2010-2050 GHG emission budgets based on the IPCC principles presented in section 1.6.1. They used five approaches: Capability (CAP) that assumes high mitigation for countries with high GDP per capita; Equal per capita (EPC) that assumes converging emissions per person; Greenhouse development rights (GDR) that assumes high mitigation for countries with high GDP per capita and high historical per capita emissions; Equal cumulative per capita (CPC) that assumes high mitigation for countries with high historical per capital emissions; and constant emissions ratio (CER) that assumes constant emission ratios (grandfathering). We extract their estimates of Singapore GHG emission budgets for 2010-2050 in Table 19 and compare them with our estimates.

Table 19: Singapore GHG emission budgets for 2010-2050 that are consistent with $1.5^{\circ} \mathrm{C}$ and $2{ }^{\circ} \mathrm{C}$ climate change targets from Robiou du Pont et al. ${ }^{65}$ and our study

\begin{tabular}{|c|c|c|c|}
\hline \multirow[t]{2}{*}{ Source } & \multirow[t]{2}{*}{ Allocation method } & $1.5^{\circ} \mathrm{C}$ & $2{ }^{\circ} \mathrm{C}$ \\
\hline & & \multicolumn{2}{|c|}{$\mathrm{Mt} \mathrm{CO} 2$} \\
\hline \multirow{5}{*}{ Robiou du Pont et al. (2017) } & CAP & 485 & 578 \\
\hline & EPC & 856 & 1146 \\
\hline & $\mathrm{CPC}$ & 664 & 1071 \\
\hline & GDR & -1174 & -619 \\
\hline & CER & 871 & 1171 \\
\hline \multirow[t]{3}{*}{ This study } & Complete equality & 705 & 837 \\
\hline & Contraction \& convergence & 980 & 1164 \\
\hline & Grandfathering & 1170 & 1478 \\
\hline
\end{tabular}

Their budgets are lower than our budgets, even though difficult to compare. First, they use different and older global emission pathways that probably do not amount to the same global GHG emission budgets. Second, their estimates are based on data up to 2010 (our estimates include historical emissions up to 2017). Therefore, population data, GDP and emission shares are different than the ones we considered. Taking that into account, we can still comment that our estimates based on the contraction \& convergence approach are relatively similar to their budgets based on the Equal per Capita (EPC) approach (our estimates are $15 \%$ and $1.6 \%$ higher for $1.5{ }^{\circ} \mathrm{C}$ and $2{ }^{\circ} \mathrm{C}$, respectively). It is important to note that their EPC approach is similar to our contraction \& convergence approach, as it assumes a transition from current emission shares to equal per capita emissions, contrarily to our complete equality approach that assumes 
strict equal per capita emissions. Our budgets based on the grandfathering approach are however higher that their estimates (about $34 \%$ and $26 \%$ higher for $1.5^{\circ} \mathrm{C}$ and $2{ }^{\circ} \mathrm{C}$, respectively). We also note that their budgets associated with the Greenhouse development rights (GDR) approach are negative, meaning that Singapore has, according to this approach, exceeded its budget allowance and needs to be a net absorber of GHGs in the decades to come.

In this study, we use the budgets estimated from the contraction \& convergence approach to be conservative. Any other budgets based on the estimates of Robiou du Pont et al. ${ }^{65}$ would create far greater mitigation efforts.

\subsubsection{Passenger land transport budget}

We finally calculate the sectoral budgets for passenger land transport in Singapore from the previously calculated national $\mathrm{CO}_{2}$ emission budgets based on the contraction \& convergence approach. We assume that the share of passenger land transport of national emissions remains constant from 2018 to 2050 . This assumption implicitly asserts that all sectors participate similarly to the reductions.

\subsection{Prospective scenarios}

We construct prospective scenarios for urban passenger land transport in Singapore and outline GHG emission mitigation measures that are consistent with the GHG emission budgets.

In our prospective scenarios, we simulate separately three drivers of GHG emissions: total motorized passenger transport activity, modal share, and technology market share. These three drivers are representative of the avoid, shift and improve framework ${ }^{74}$.

\subsubsection{Avoid: Total motorized passenger transport activity}

We create one prospective business-as-usual scenario for total motorized passenger transport activity from historical trends.

From 2005 to 2019, we calculate the total motorized passenger transport activity per capita in Singapore (transport intensity in Figure 17) ${ }^{75}$. The ratio was quite stable below 9,000 pkt/person from 2005 to 2016 and increased in 2019 at 9,130 pkt/person. Then, we assume the ratio of 2019 to hold until 2050. Figure 17 presents the total motorized passenger activity from 2005 to 2050 in our business-as-usual scenario. 


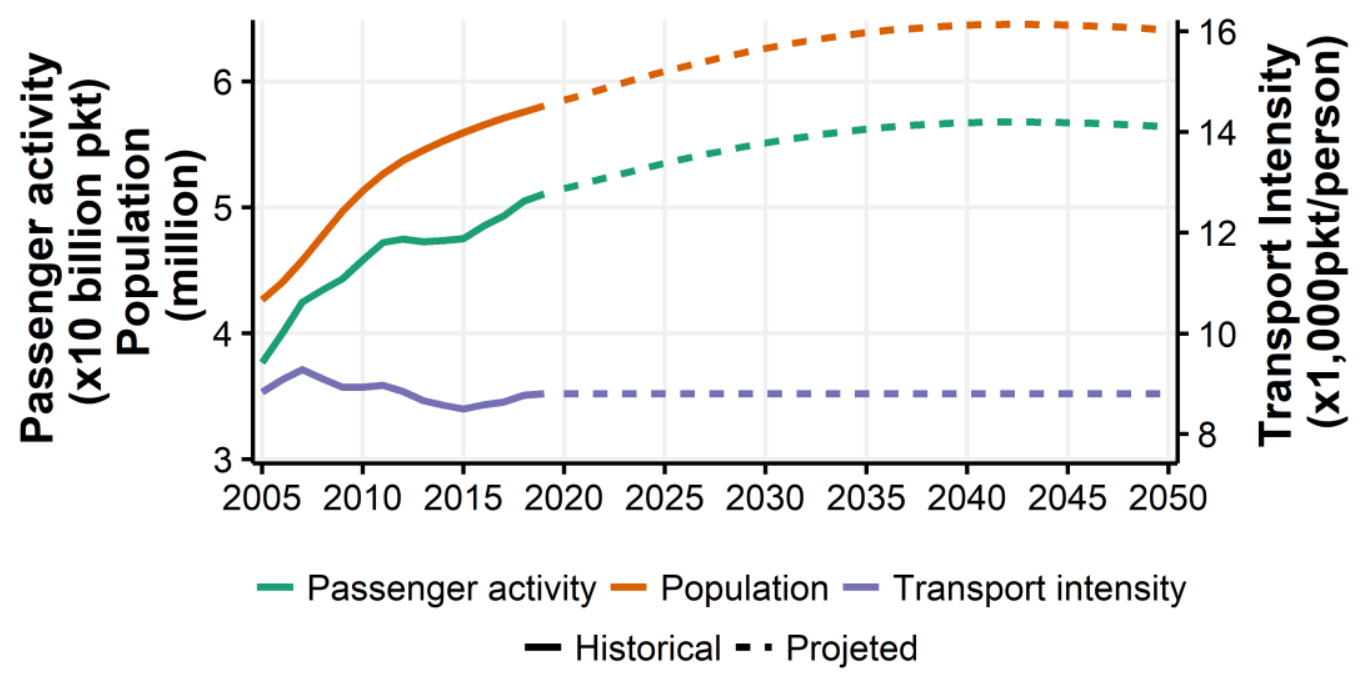

Figure 17: Historical and prospective motorized passenger activity and population in Singapore.

\subsubsection{Shift: Modal share}

We construct two scenarios of prospective modal share of passenger transport: private car ubiquity (PC), and public transit development (PT).

For both scenarios, we assume that load factors and average annual distance travelled by one vehicle for all modes stay constant from 2019 onwards.

\subsubsection{Private car ubiquity (PC)}

We create a pessimistic scenario from an environmental standpoint, entitled "private car ubiquity" (PC in the figures), that simulates an increase in private car activity from 2020 onwards. In this scenario, we postulate that the current policies and private car control measures are revoked, and private car modal share increases following opposite historical trends from 2020 onward. Between 2009 and 2019, modal share of private cars reduced from $45 \%$ to $36 \%$ with an annual percentage point change of $-0.9 \%$ per year. We assume that revoking the private car control measures implies an increase in private car modal share at an opposite linear change, or $+0.9 \%$ per year. All other modes are being reduced proportionally. We assume the increase to stop in 2030, meaning that 2030 modal share of private car equals 2009 level, and keep the modal shares constant between 2030 and 2050 for all modes. Figure 18 shows the resulting passenger, vehicle activities and vehicle sales and populations in the PC scenario. 
a)

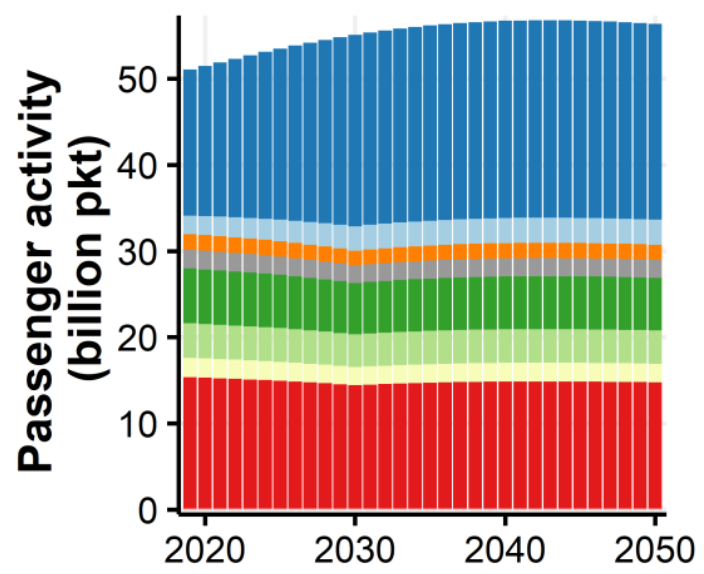

c)

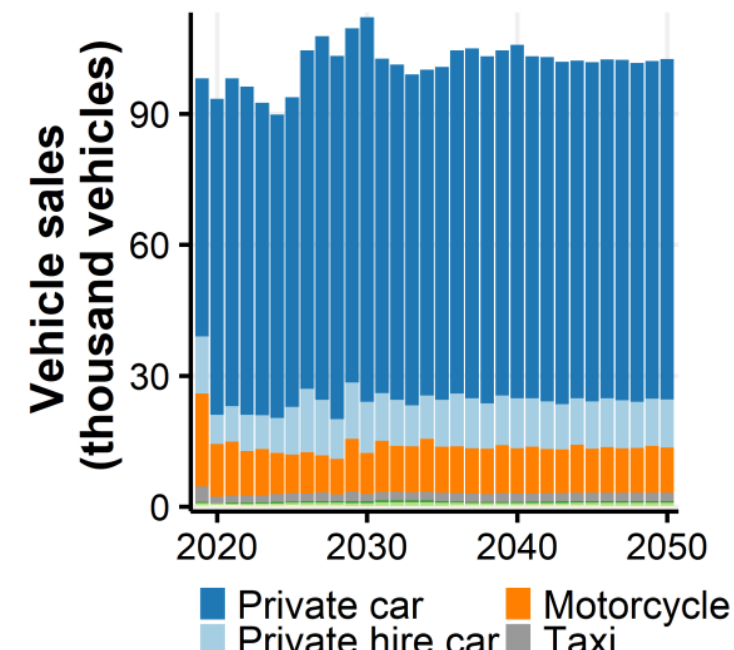

b)

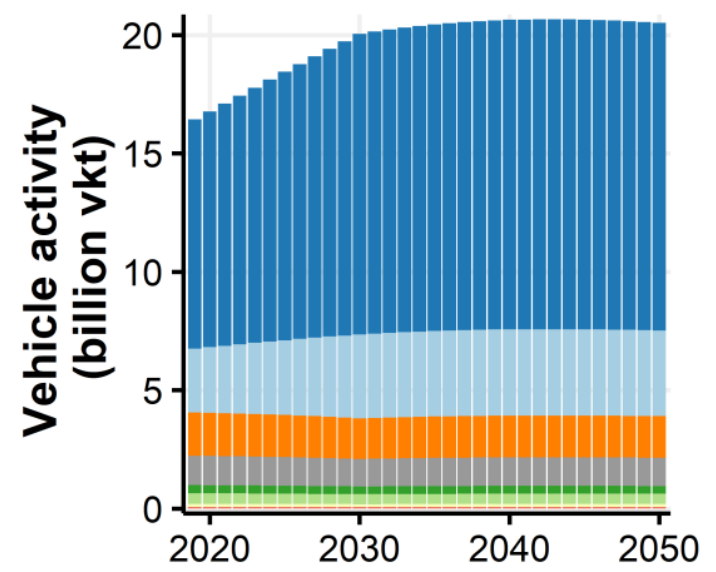

d)

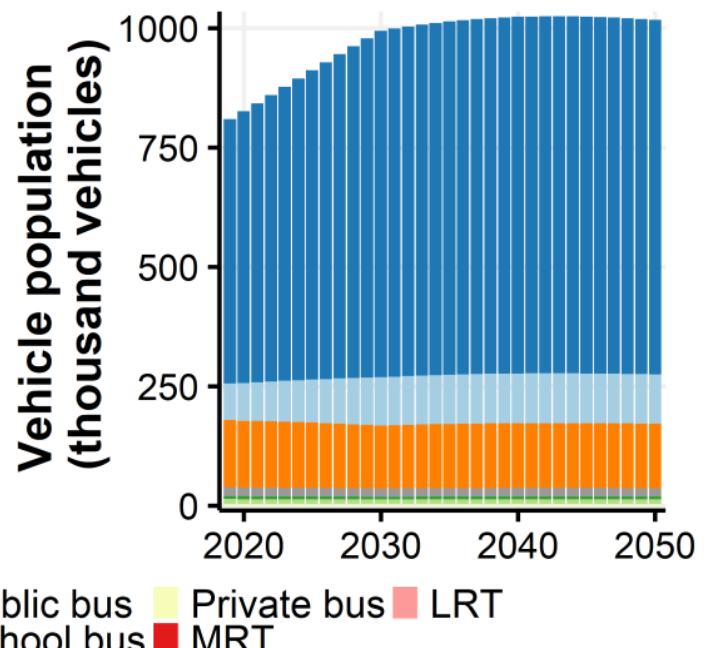

Figure 18: a) Passenger activity, b) vehicle activity, c) vehicle sales, and d) vehicle population in the Private Car Ubiquity (PC) scenario

\subsubsection{Public Transit development (PT)}

Singapore enacted a series of policies to limit private car usage, with electronic road pricing, and private car ownership with a vehicle quota system ${ }^{76}$. These measures are planned to be reinforced in the near future ${ }^{77}$. In addition, Singapore is committed to continue its public transit development with large investments in mass public transport to increase the number of public buses and trains, and expand the rail and bus networks ${ }^{78}$. In the PT scenario, we assume an increasing modal share of public transit (i.e., MRT, LRT and Public bus) following the historical trends between 2009 and 2019, and decreasing modal shares for all other modes. Modal shares of public buses, LRT and MRT were $11.7 \%, 0.1 \%$ and $18.4 \%$ in 2009 and $12.0 \%, 0.3 \%$ and $28.7 \%$ in 2019 , respectively, with annual percentage point changes of $+0.05 \%$, $+0.02 \%$ and $+1.5 \%$ per year. We assume the annual percentage point changes to hold between 2020 and 2030 and modal shares of all modes to be constant from 2030 onward. Figure 19 shows the resulting passenger, vehicle activities and vehicle sales and populations in the PT scenario. 
a)

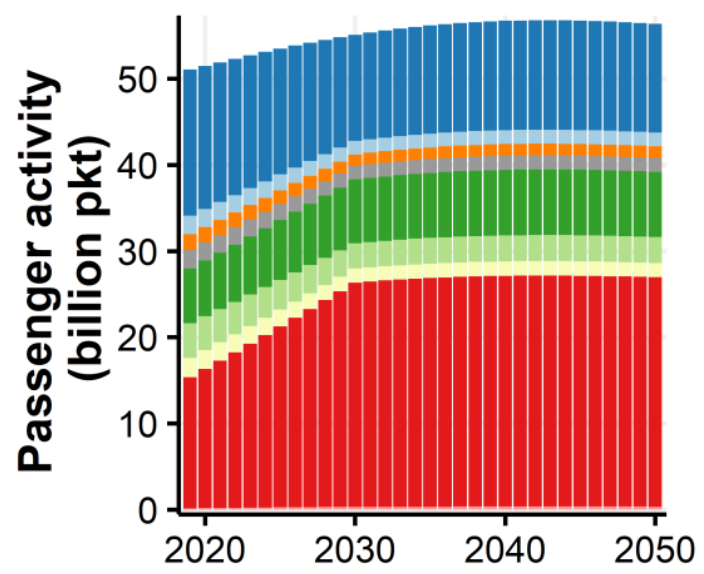

c)

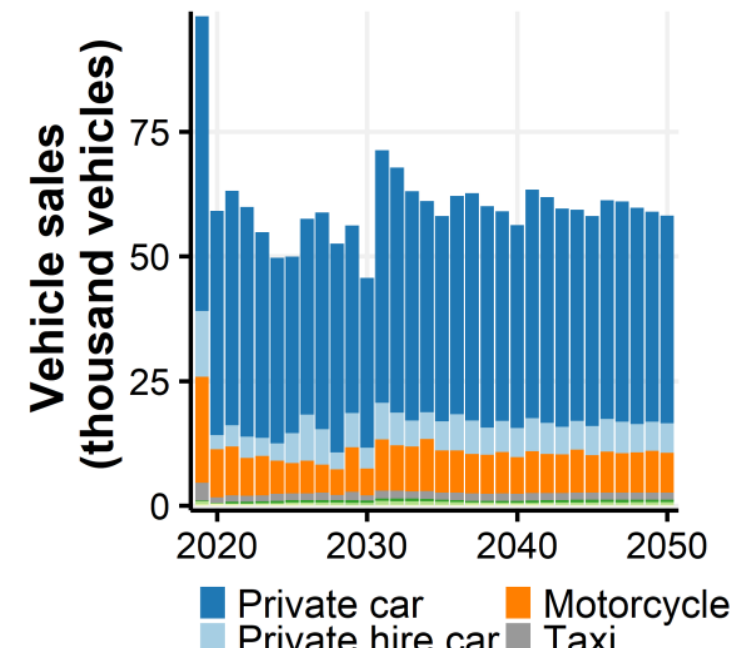

b)

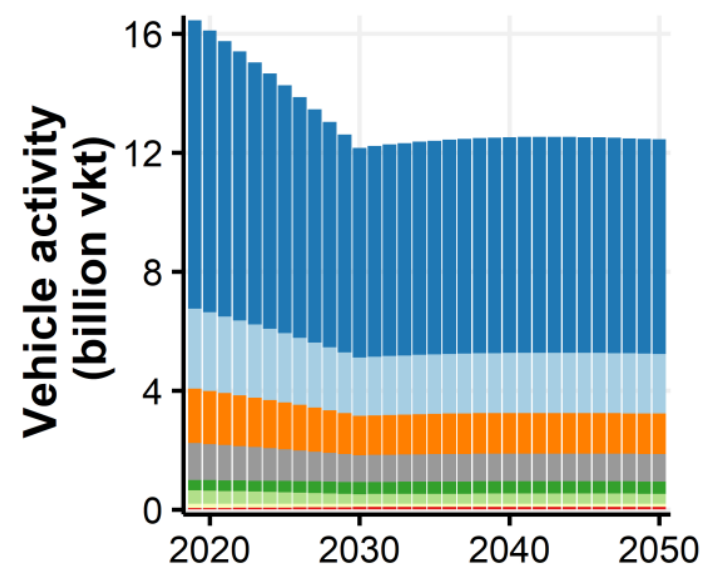

d)

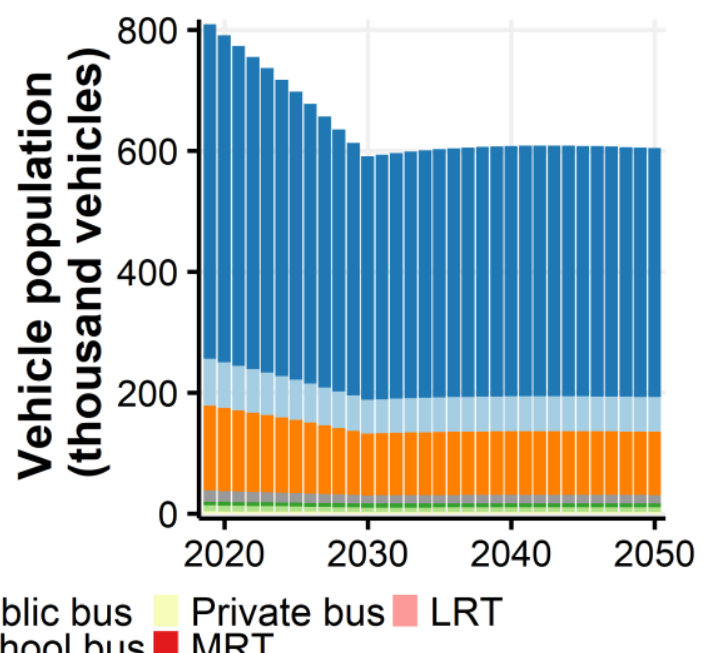

Figure 19: a) Passenger activity, b) vehicle activity, c) vehicle sales, and d) vehicle population in the Public Transit development (PT) scenario

\subsubsection{Improve: Technology market share}

We create two scenarios of prospective technology market shares: Constant and Electrification.

\subsubsection{Constant}

In the Constant scenario, we assume that technology market share for all transport modes stay constant from 2020 onwards.

\subsubsection{Electrification (EV)}

Singapore envisions to phase out all internal combustion engine vehicles by $2040{ }^{77}$. In the EV scenario, we assume a complete electrification of buses, taxis and private cars by 2040 . To achieve a complete electrification of private cars and taxis by 2040 , we assume that all new vehicles starting in 2030 are BEVs, and an increasing market share from 2020 to 2030. Regarding buses, it is assumed in the EV scenario that all newly introduced buses starting 2021 are electric buses. Figure 20 shows the prospective stock by transport mode and vehicle technology for the two prospective modal share scenarios: PC and PT. 


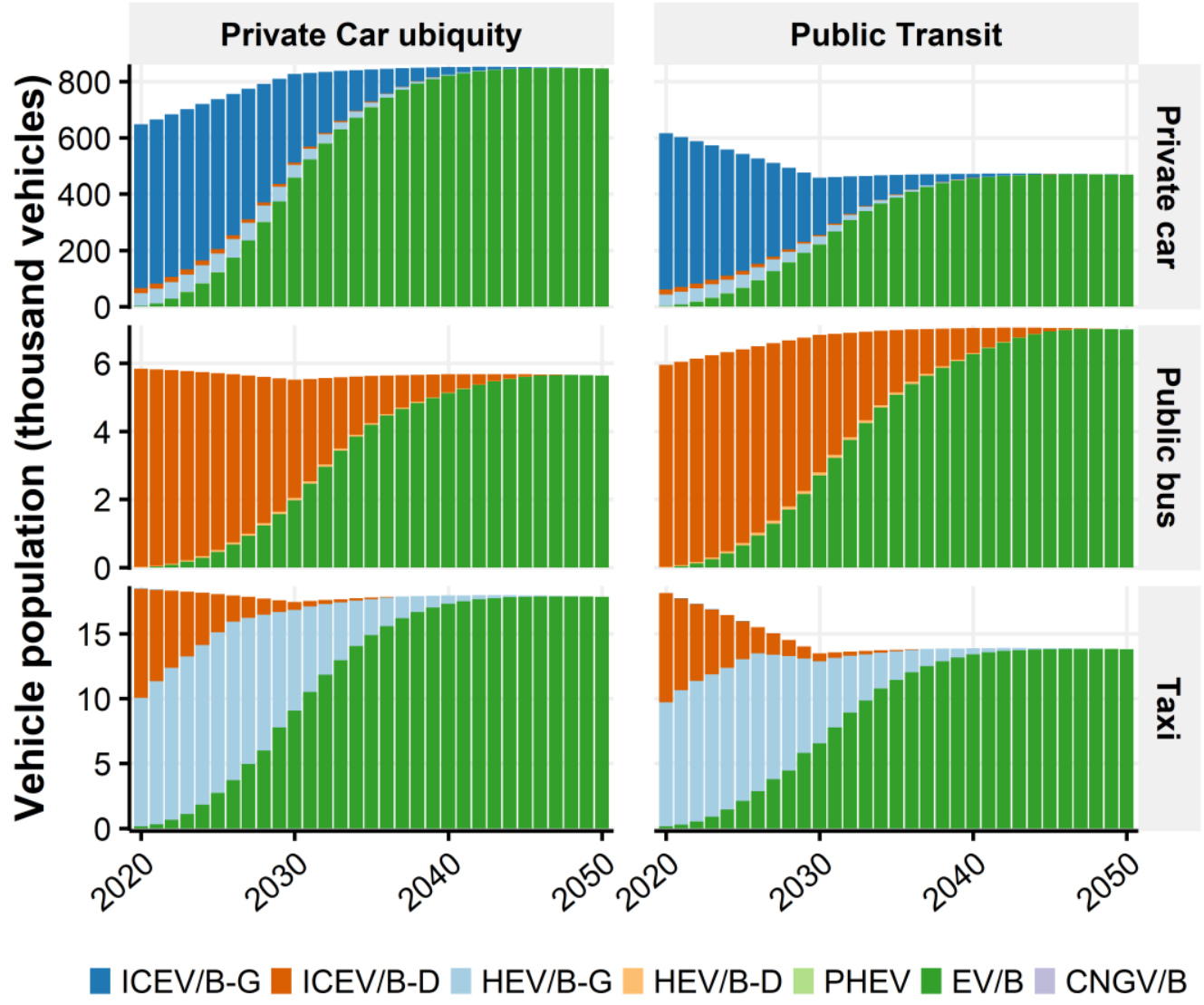

Figure 20: Vehicle population by technology from 2020 to 2050 for private cars, taxis and public buses in the Private Car ubiquity, and Public Transit development scenarios

\subsection{Optimization procedure of the mitigation module}

The mitigation module seeks the set of strategies that balances the GHG emissions with the GHG emission budgets. For our case study of Singapore, we have defined three mitigation variables: the total motorized travel activity (avoid), the public transit modal share (shift), and the electric vehicle share in new vehicles (improve). For each of the mitigation variable, we apply an optimization procedure with all other inputs and variables defined by the prospective scenarios.

The objective function of the optimization model is to minimize the changes for the decision variable from the baseline value of the considered prospective scenario. For the sake of modelling, we transform the mitigation variables into decision variables as presented in Table 20.

Table 20: Mitigation variables, decision variables and default values for the optimization procedure of the case study

\begin{tabular}{|l|l|l|l|}
\hline Mitigation variable & Decision variable & Default value & $\begin{array}{l}\text { Incremental } \\
\text { change }\end{array}$ \\
\hline $\begin{array}{l}\text { Total motorized travel } \\
\text { activity }\end{array}$ & $\begin{array}{l}\text { Annual relative decrease in total } \\
\text { motorized travel activity }\end{array}$ & $\begin{array}{l}0 \% \text { in all baseline } \\
\text { scenarios }\end{array}$ & $0.01 \%$ \\
\hline $\begin{array}{l}\text { Public transit modal } \\
\text { share }\end{array}$ & $\begin{array}{l}\text { Annual percentage point increase in } \\
\text { public transit modal share }\end{array}$ & $\begin{array}{l}1.5 \% \text { in the PT } \\
\text { scenario }\end{array}$ & $0.01 \%$ \\
\hline $\begin{array}{l}\text { Electric vehicle share } \\
\text { in new vehicles }\end{array}$ & $\begin{array}{l}\text { Decrease in electrification target } \\
\text { year }\end{array}$ & $\begin{array}{l}2040 \text { in the EV } \\
\text { scenario }\end{array}$ & 1 year \\
\hline
\end{tabular}


The constraint of our optimization model is to have cumulative GHG emissions of passenger transport from 2018 to 2050, as simulated by the GHG emission module, lower or equal than the cumulative budget over the same period for the given climate target (i.e., $1.5^{\circ} \mathrm{C}$ or $2{ }^{\circ} \mathrm{C}$ ), as simulated by the GHG emission budget module. Our model is not a linear or a formulated mathematical model and uses a search-and-try process. The model first simulates the cumulative emissions with no changes to the default value of the considered mitigation variable (as presented in column "Default value" of Table 20) and compare them with the budget. If the cumulative emissions are lower, then the decision variable is increased with an incremental change (as presented in column "Incremental change" of Table 20). The model seeks the lowest total incremental change for the decision variable that respects the constraint.

\section{Additional Results}

This section shows some additional results.

\subsection{Historical passenger land transport life cycle GHG emission}

Figure 21 presents the historical life cycle passenger transport GHG emissions from 2005 to 2019 aggregated by mode of transport.

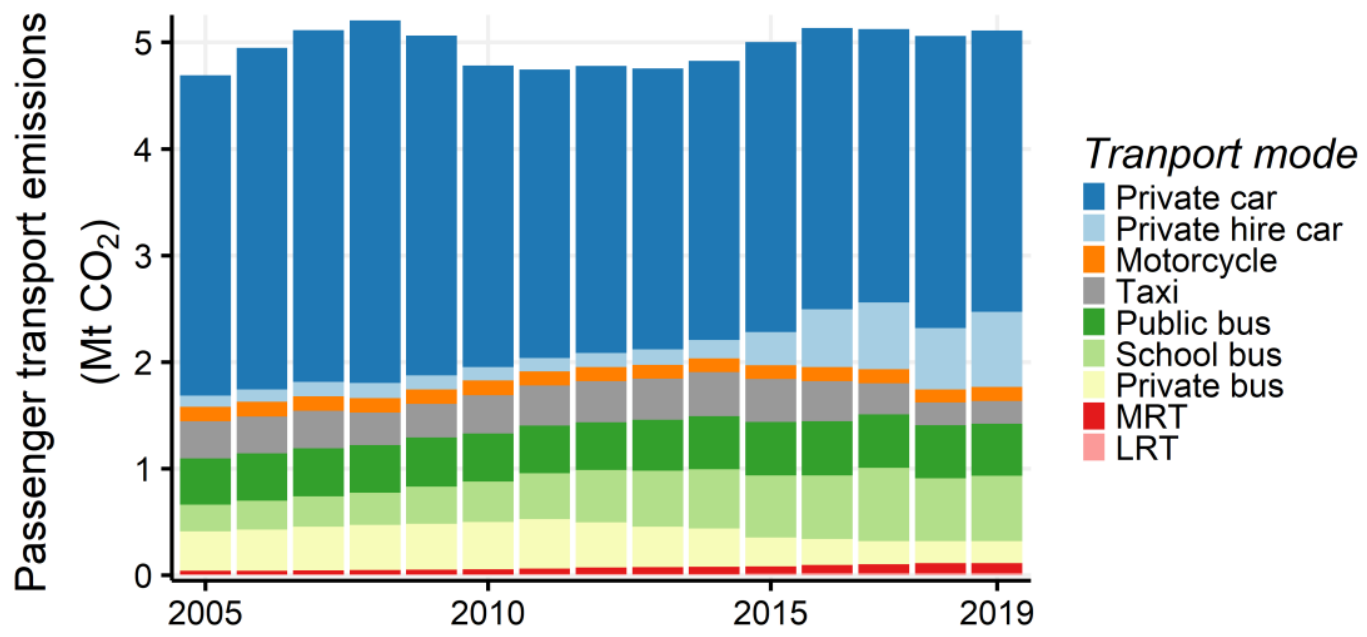

Figure 21: Historical passenger transport GHG emissions from 2005 to 2019 by transport mode

Figure 22 presents the historical life cycle GHG emissions for all transport modes by life cycle stage. We note that fuel upstream and exhaust emissions are aggregated in the figure.

a)

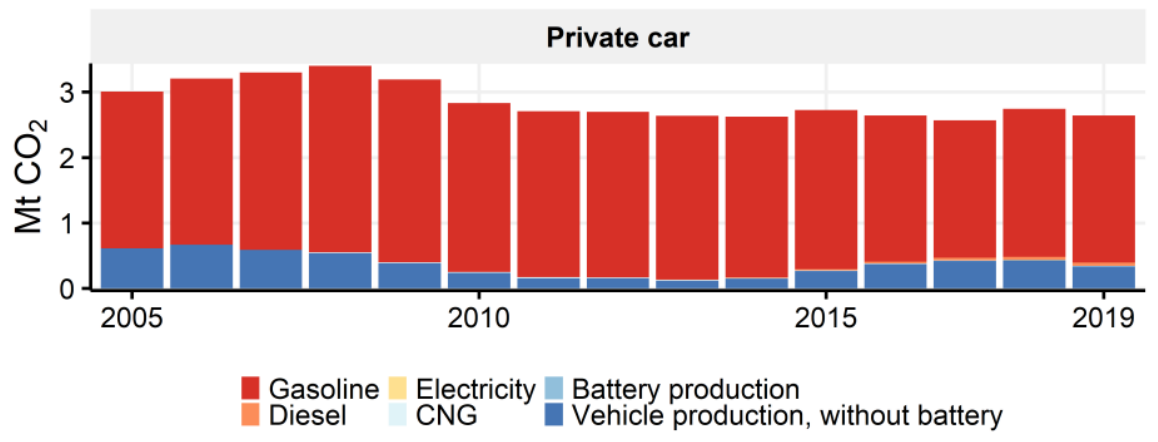


b)

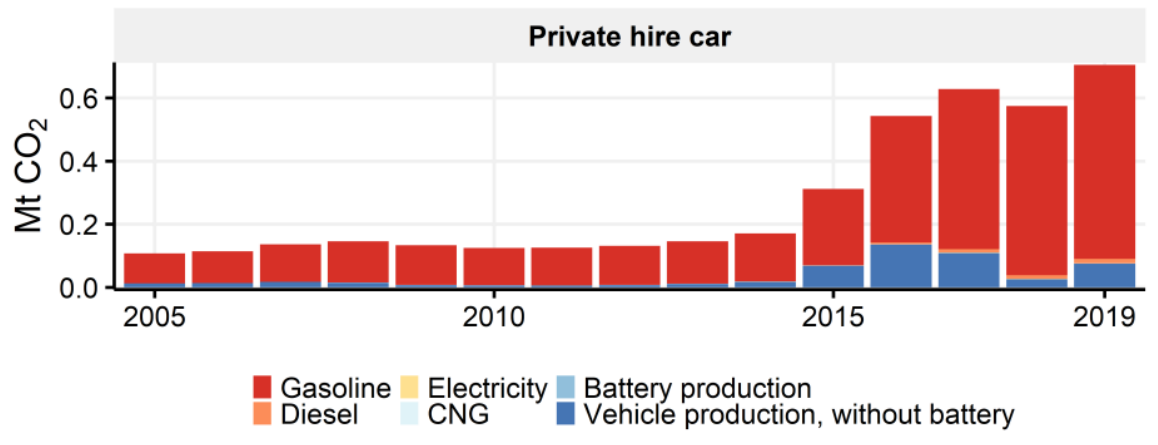

c)

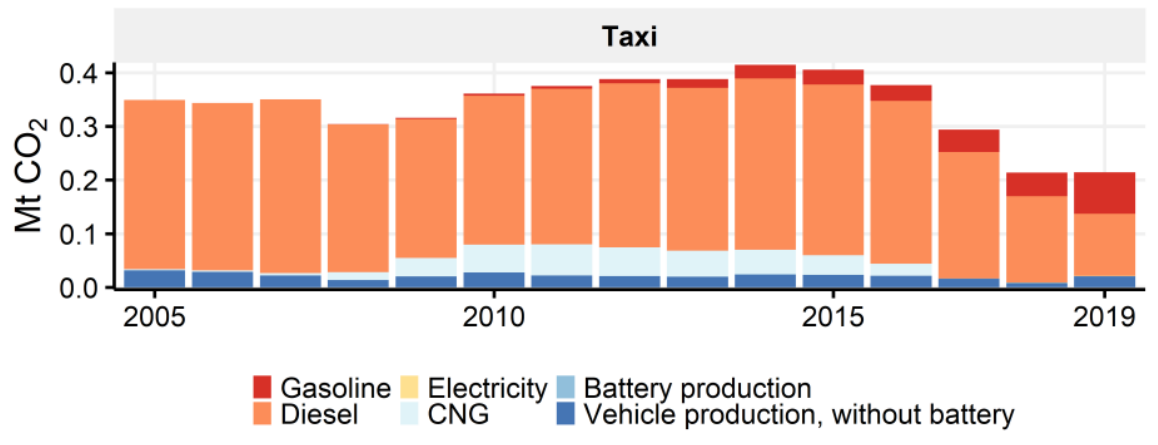

d)

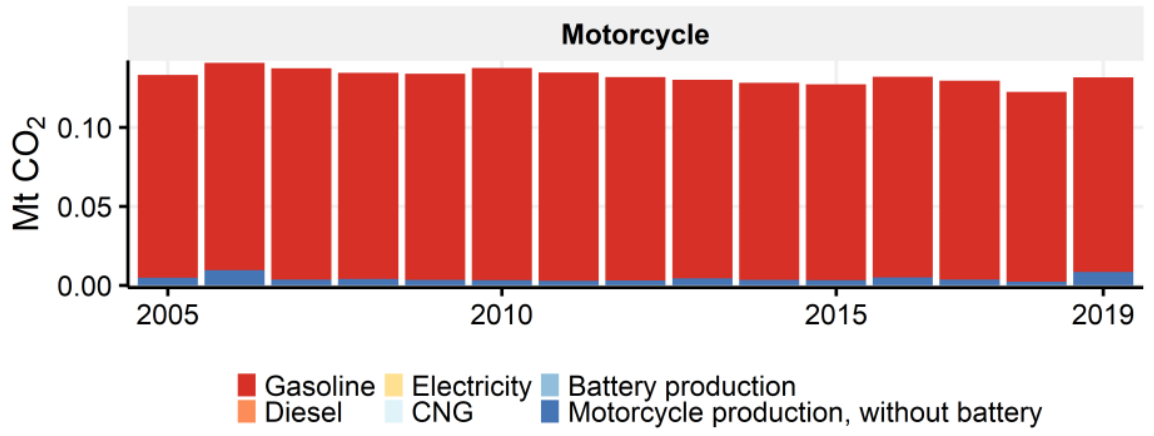

e)

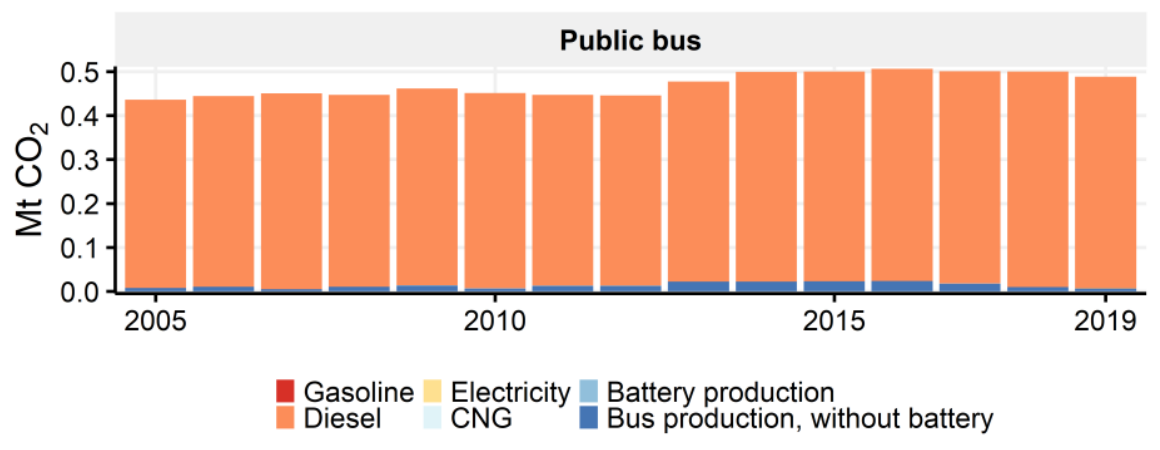

f) 


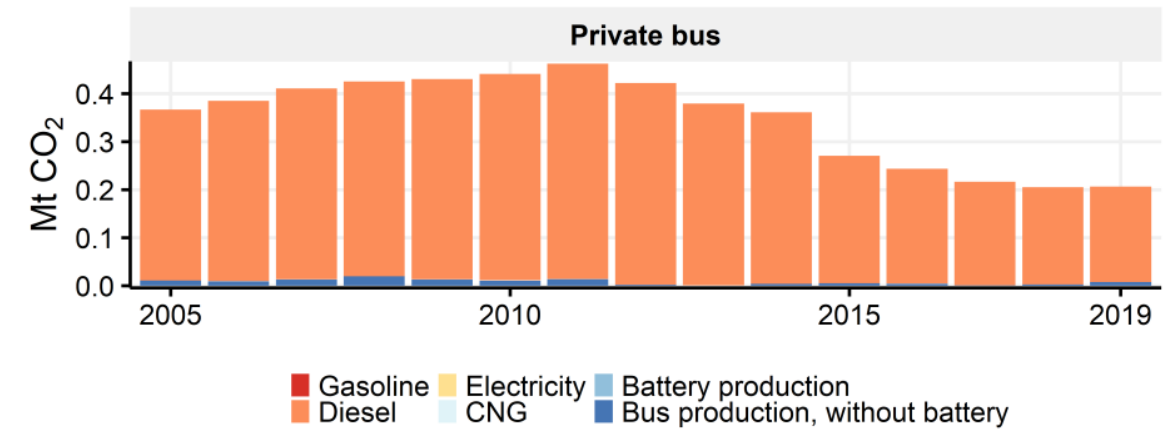

g)

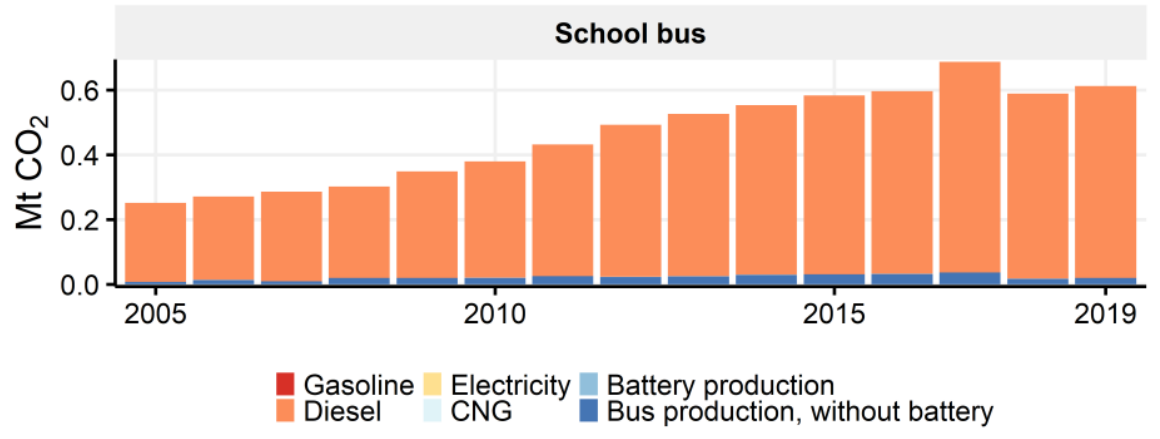

h)

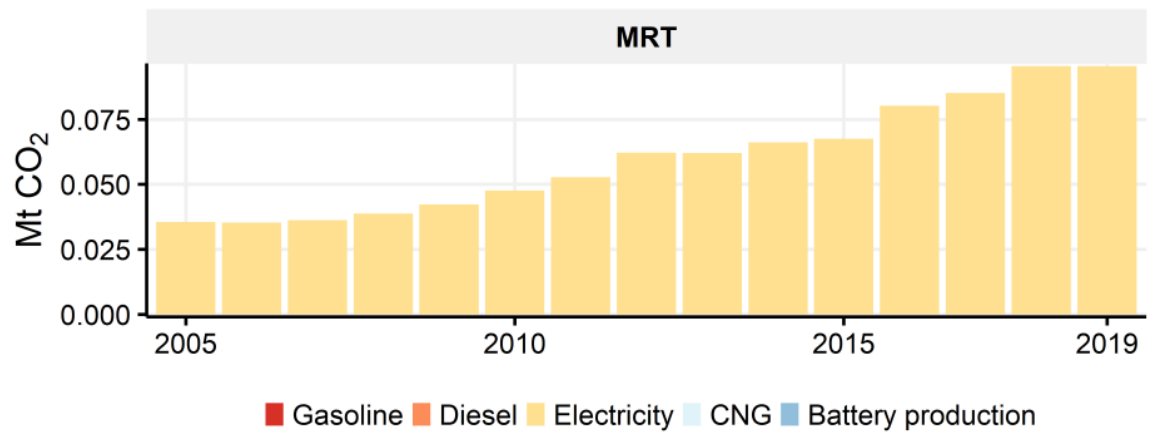

i)

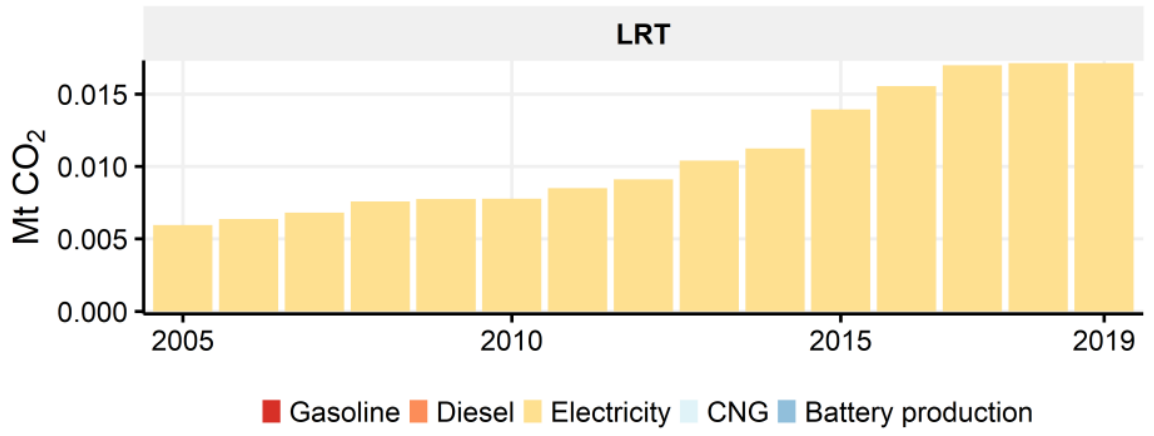

Figure 22: Fleet life cycle GHG emissions by life cycle phase for all the transport mode from 2005 to 2019 


\subsection{Additional prospective scenarios and results}

In this section, we simulate additional prospective scenarios that pertain to public transit deployment and electrification.

In Figure 23, we estimate the 2018-2050 cumulative GHG emissions of passenger transport in Singapore under different scenarios of public transit deployment ( $\mathrm{Y}$-axis of each panel), public electrification target year (X-axis of each panel) and electricity decarbonization scenarios (two panels). This figure is similar to Figure 5 of the manuscript but assumes that all non-bus transport modes have constant technology market shares from 2020 onward.

One of the key critical elements that can be noted from Figure 23 is that public transit electrification has a substantial lower GHG emission reduction potential than all passenger fleet electrification. Indeed, $68 \%$ of the GHG emission reductions associated with the complete electrification of all passenger fleets in the PT scenario comes from private car electrification. Therefore, under business-as-usual deployment for public transit (i.e., $+1.6 \%$ point change in public transit modal share), the $1.5{ }^{\circ} \mathrm{C}$ and $2{ }^{\circ} \mathrm{C}$ budgets are not achievable with the sole electrification of public transit, even if the electricity completely derives from renewable energy.

In addition, the public transit electrification target year has only a substantial influence under large deployments of public transit. Indeed, reduction potentials between the 2030 and 2050 target years are minimal for annual \% point changes in public transit modal share between $0 \%$ and $2 \%$. Therefore, it means that it is more critical, on the short term, to deploy public transit and reduce private car usage rather than electrify it. A deeper assessment should examine the costs of the different strategies and the potential co-benefits. For example, bus electrification might be a strategy to increase bus ridership and the capital costs associated with electric buses might benefit public transit ridership (see an example of rail electrification and associated impact on ridership in ${ }^{79}$ ). 


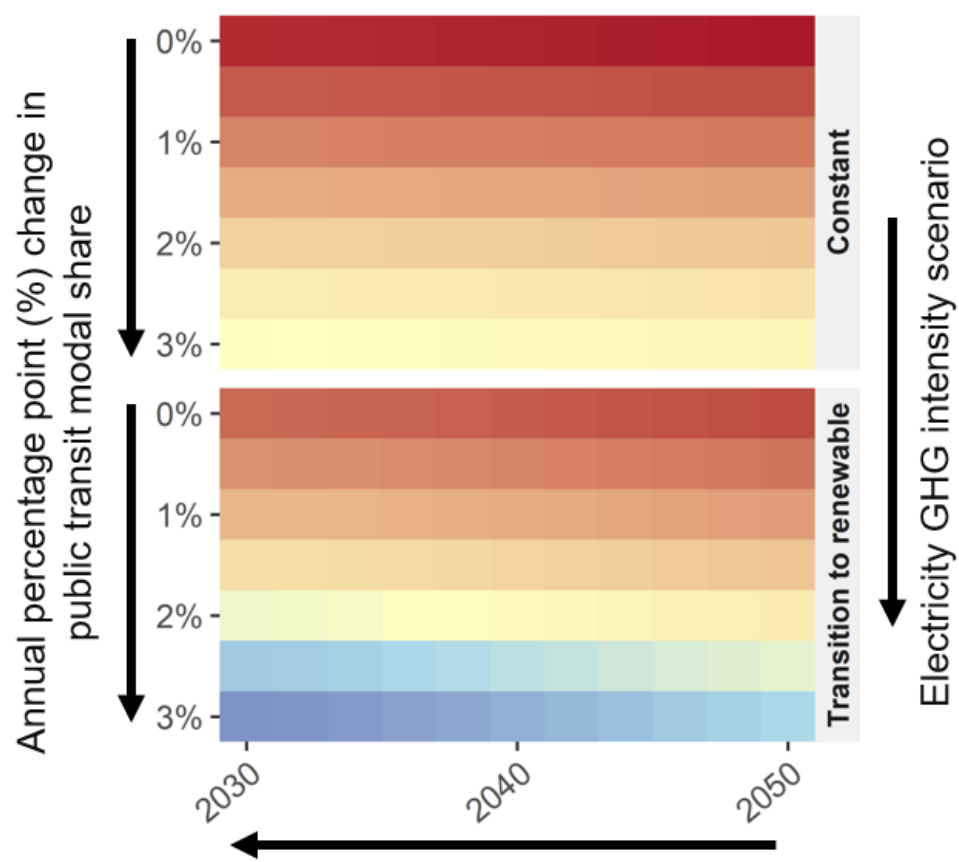

2018-2050 cumulative GHG emissions

(Mt $\mathrm{CO}_{2}$ eq.)

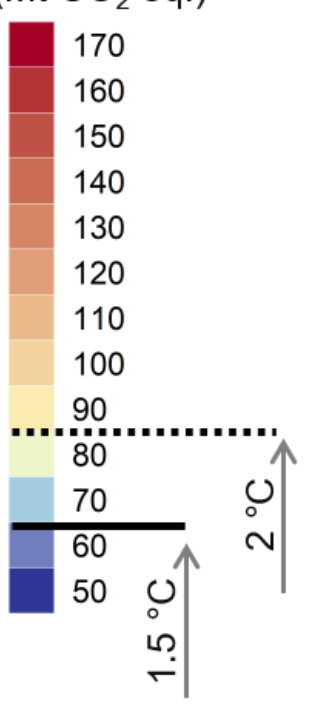

Public transit electrification target year

Figure 23: Cumulative GHG emissions for multiple prospective scenarios of public transit deployment and electrification

\section{Recommendations to apply the CURTAIL model}

The aim of this study is to develop a novel model, the CURTAIL (Climate change constrained URban passenger TrAnsport Integrated Life cycle assessment) model and apply it to a case study of Singapore. The CURTAIL model assesses the life cycle GHG emissions of urban passenger land transport and outlines the set of mitigation strategies that are consistent with $1.5^{\circ} \mathrm{C}$ and $2{ }^{\circ} \mathrm{C}$ global warming targets. In this section, we offer recommendations to apply the CURTAIL model to any specific case study with the following procedure.

1. Goal and scope definition. First and foremost, clear analytical, geographical and temporal scopes are defined. The overarching goal of the study is clearly established: the assessment of current policies or of different mitigation pathways for a given city, or the comparison of different city and their strategies. A clear geographical scope is necessary, especially that city boundaries are often disputed (e.g., are close suburban areas included?). In addition, the environmental assessment boundary is appropriately defined following the overarching goal. For example, if public transit or active mobility infrastructures are central pieces of the assessment, infrastructure emissions should be accounted for. Finally, the scope of the assessment clearly determines the modes of transport included.

2. Historical input data collection. Each city is different and collecting data may be a challenge. In Table 21, we list the important inputs to collect and provide recommendations on how or where to collect them. It is unfortunately impossible for us to make an exhaustive list of agencies, operators or sources for all these data. 
Table 21: Recommendations to collect inputs

\begin{tabular}{|c|c|c|}
\hline & Input & Note \\
\hline \multirow{4}{*}{ 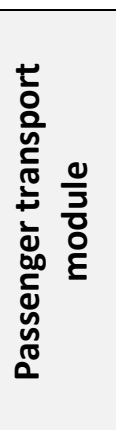 } & $\begin{array}{l}\text { Total motorized } \\
\text { transport activity }\end{array}$ & \multirow{2}{*}{$\begin{array}{l}\text { Historical data can be found from local agencies (e.g., transport services } \\
\text { or ministry of transportation) or local transport operators (e.g., } \\
\text { transport network operators or owners of buses, taxis and rail services). } \\
\text { Using Equation 1, the collected data can be passenger and vehicle } \\
\text { activities, and/or ridership and trip length information. }\end{array}$} \\
\hline & Modal share & \\
\hline & Load factors & \multirow{2}{*}{$\begin{array}{l}\text { In the absence of local data, data at national scale can be used. It is } \\
\text { however important to note that load factors, vehicle occupancy and } \\
\text { vehicle usage may vary between cities (e.g., depending on infrastructure } \\
\text { accessibility, traffic density) even within a country. }\end{array}$} \\
\hline & $\begin{array}{l}\text { Distance travelled by } \\
\text { vehicle }\end{array}$ & \\
\hline \multirow{3}{*}{ 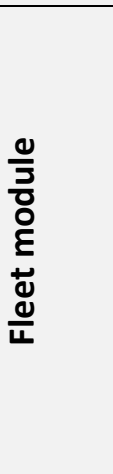 } & $\begin{array}{l}\text { Technology market } \\
\text { share }\end{array}$ & \multirow{2}{*}{$\begin{array}{l}\text { Historical data can derive from local agencies or sales data by } \\
\text { manufacturer. Data can also be approximated from national data. } \\
\text { However, fuel consumption should be carefully examined. Fuel } \\
\text { economy datasets use driving test results and can vary between regions. } \\
\text { In addition, special conditions (e.g., tropical weather, mountainous } \\
\text { area, dense traffic) can affect the average on-road vehicle fuel } \\
\text { consumption of a given city. }\end{array}$} \\
\hline & $\begin{array}{l}\text { Average fuel } \\
\text { consumption by } \\
\text { mode, technology and } \\
\text { production-year }\end{array}$ & \\
\hline & Surv & $\begin{array}{l}\text { ery often, survival rates are not directly available but can be estimated } \\
\text { om vehicle population by age. If no special policies are in place in the } \\
\text { udy city, national data are good approximations. }\end{array}$ \\
\hline & Emi & $\begin{array}{l}\text { Depending on the scope of the study, emission factors can derive from } \\
\text { literature, LCA studies, or existing models (e.g., GREET). Emission factors } \\
\text { should cover all stages outlined in the environmental boundary of the } \\
\text { case study. A special care should be given to energy carriers (e.g., } \\
\text { electricity, hydrogen, biofuels) as they can drastically shift emission } \\
\text { sources and are context-specific. }\end{array}$ \\
\hline \multirow{2}{*}{ 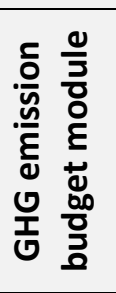 } & $\begin{array}{l}\text { Global and regional } \\
\text { GHG emission } \\
\text { pathways }\end{array}$ & $\begin{array}{l}\text { The same datasets used in this study can be utilized to derive global and } \\
\text { regional GHG emission pathways }{ }^{61} \text {. }\end{array}$ \\
\hline & Population & $\begin{array}{l}\text { National population data can derive from the United Nations Population } \\
\text { Prospects data }{ }^{75} \text {. Urban population data can derive from demographic } \\
\text { data within the country. }\end{array}$ \\
\hline
\end{tabular}

3. Model development with historical data. Once historical data have been collected, a first version of the model is constructed. It initiates the dynamics of the different modules and is the basis of prospective assessments. This first model development also provides ground for an initial analysis of historical GHG emission of urban passenger transport. It starts an iterative procedure between the previous steps to refine the goal and scope of the study and the required data.

4. Mitigation levers definition. Each city has a specific set of resources and political directions. It is important to define the appropriate mitigation levers to be assessed in the study. For example, if the city has a clear agenda to promote car-sharing, then appropriate levers should be defined that reflect potential changes in vehicle ownership, load factors and distance travelled by one vehicle. Then, once the mitigation levers have been established, prospective scenarios are developed to represent worst-case, business-as-usual and ambitious political target scenarios for each mitigation lever. 
5. Model development with prospective scenarios. The model is expanded to enable prospective assessment based on the previously defined scenarios. Then, the dynamics of the optimization procedure is constructed to obtain the combination of mitigation strategies that are consistent with ambitious climate targets.

6. Analysis and interpretation. Finally, results and figures are generated, and analyses performed. It is recommended to show cumulative GHG emissions with multiple mitigation variable and associated values to exhibit the depth of the required mitigations. This last step also provides an opportunity to adjust all previous steps in order to build a consistent study.

\section{References}

(1) Milovanoff, A.; Minet, L.; Cheah, L.; Posen, I. D.; Maclean, H. L.; Balasubramanian, R. The Climate change constrained URban passenger TrAnsport Integrated Life cycle assessment (CURTAIL) model https://doi.org/10.5281/zenodo.4490301. https://doi.org/10.5281/zenodo.4490301.

(2) Land Transport Authority. Public Transport Utilisation - Average Daily Public Transport Ridership https://data.gov.sg/dataset/public-transport-utilisation-average-public-transport-ridership (accessed Jan 31, 2020).

(3) Land Transport Authority. Public Transport Capacity - Average Daily Distance Travelled and Bus Routes in Operation https://data.gov.sg/dataset/public-transport-capacity-average-daily-kmtravelled-and-bus-routes-in-operation (accessed Jan 31, 2020).

(4) Land Transport Authority. Public Transport Utilisation - Average Trip Distance https://data.gov.sg/dataset/public-transport-utilisation-average-trip-distance (accessed Jan 31, 2020).

(5) Land Transport Authority. Annual Motor Vehicle Population by Vehicle Type https://www.mytransport.sg/content/mytransport/home/dataMall/static-data.html (accessed Jan 31, 2020).

(6) Land Transport Authority. Annual Mileage for Private Motor Vehicles https://data.gov.sg/dataset/annual-mileage-for-private-motor-vehicles (accessed Jan 31, 2020).

(7) Fwa, T. F.; Chua, G. K. Passenger Car Travel Characteristics in Singapore. IATSS Res. 2007, 31 (2), 48-55. https://doi.org/10.1016/S0386-1112(14)60222-3.

(8) Henao, A.; Marshall, W. E. The Impact of Ride-Hailing on Vehicle Miles Traveled. Transportation (Amst). 2019, 46 (6), 2173-2194. https://doi.org/10.1007/s11116-018-9923-2.

(9) School Bus Solutions. Students and Trips Daily https://schoolbus.solutions/.

(10) Tan, C. Drivers No Longer Going the Distance. The Straits Times. 2017.

(11) Land Transport Authority. Annual Bus Population by Passenger Capacity.

(12) Land Transport Authority. Annual Age Distribution of Cars https://www.mytransport.sg/content/mytransport/home/dataMall/static-data.html (accessed Jan 31, 2020).

(13) Land Transport Authority. Annual Age Distribution of Motorcycles https://www.mytransport.sg/content/mytransport/home/dataMall/static-data.html (accessed Jan 31, 2020). 
(14) Land Transport Authority. Annual Age Distribution of Buses https://www.mytransport.sg/content/mytransport/home/dataMall/static-data.html (accessed Jan 31, 2020).

(15) Land Transport Authority. Annual Motor Vehicle Population by Type of Fuel Used https://www.mytransport.sg/content/mytransport/home/dataMall/static-data.html (accessed Jan 31, 2020).

(16) Zheng, J.; Zhou, Y.; Yu, R.; Zhao, D.; Lu, Z.; Zhang, P. Survival Rate of China Passenger Vehicles: A Data-Driven Approach. Energy Policy 2019, 129 (April 2018), 587-597.

https://doi.org/10.1016/j.enpol.2019.02.037.

(17) Greene, D. L.; Chen, C. K. E. Scrappage and Survival Rates of Passenger Cars and Light Trucks in the U.S., 1966-1977. Transp. Res. Part A Gen. 1981, 15 (5), 383-389.

https://doi.org/10.1016/0191-2607(81)90144-8.

(18) Wei, W.; Cheah, L. Singapore Road Vehicle Fleet Evolution BT - Complex Systems Design \& Management Asia; Cardin, M.-A., Krob, D., Lui, P. C., Tan, Y. H., Wood, K., Eds.; Springer International Publishing: Cham, 2015; pp 55-71.

(19) Singapore National Environmental Agency. Greenhouse Gas (GHG) Emissions Measurement and Reporting Guidelines https://www.nea.gov.sg/docs/default-source/our-services/climatechange/m-r-appendix-(ver-14-feb-2018).pdf.

(20) Koossalapeerom, T.; Satiennam, T.; Satiennam, W.; Leelapatra, W.; Seedam, A.; Rakpukdee, T. Comparative Study of Real-World Driving Cycles, Energy Consumption, and CO2 Emissions of Electric and Gasoline Motorcycles Driving in a Congested Urban Corridor. Sustain. Cities Soc. 2019, 45 (December 2018), 619-627. https://doi.org/10.1016/j.scs.2018.12.031.

(21) Land Transport Authority. Fuel Economy data of cars and light goods vehicles approved for registration in Singapore vrl.Ita.gov.sg/Ita/vrl/action/pubfunc?ID=FuelCostCalculator (accessed Jan 10, 2021).

(22) Singapore National Environmental Agency. Singapore To Accept Emission Results From The Worldwide Harmonised Light-Duty Vehicles Test Procedure (WLTP) For Type Approval Of New Vehicles And Vehicular Emissions Scheme. 2018.

(23) Land Transport Authority. Annual New Registration of Cars by Make https://www.mytransport.sg/content/mytransport/home/dataMall/static-data.html (accessed Feb 5, 2020).

(24) International Energy Agency. Oil Information 2019.

(25) Element Energy Limited. Quantifying the Impact of Real-World Driving on Total CO2 Emissions from UK Cars and Vans; 2015.

(26) International Energy Agency. Fuel Economy in Major Car Markets: Technology and Policy Drivers 2005-2017; 2019.

(27) Bradley, T. H.; Quinn, C. W. Analysis of Plug-in Hybrid Electric Vehicle Utility Factors. J. Power Sources 2010, 195 (16), 5399-5408. https://doi.org/10.1016/j.jpowsour.2010.02.082.

(28) Zhang, S.; Wu, Y.; Liu, H.; Huang, R.; Yang, L.; Li, Z.; Fu, L.; Hao, J. Real-World Fuel Consumption 
and CO2 Emissions of Urban Public Buses in Beijing. Appl. Energy 2014, 113, 1645-1655.

https://doi.org/10.1016/j.apenergy.2013.09.017.

(29) BYD Singapore. Electric bus K9 Technical Specs sg.byd.com/k9/ (accessed Jan 10, 2021).

(30) SMRT Corporation Ltd. Annual Report 2016; 2016.

(31) SMRT Corporation Ltd. Sustainability Report 2016; 2016.

(32) Davis, S. C.; Boundy, R. G. Transportation Energy Data Book Edition 37; 2019.

(33) U.S. Department of Energy. Fuel Economy Guide Model Year 2018; 2018.

(34) Johnson, V. H. Fuel Used for Vehicle Air Conditioning: A State-by-State Thermal Comfort-Based Approach. SAE Tech. Pap. 2002, No. 724. https://doi.org/10.4271/2002-01-1957.

(35) U.S. Environmental Protection Agency. The 2020 EPA Automotive Trends Report; 2021.

(36) Yuksel, T.; Michalek, J. J. Effects of Regional Temperature on Electric Vehicle Efficiency, Range, and Emissions in the United States. Environ. Sci. Technol. 2015, 49 (6), 3974-3980.

https://doi.org/10.1021/es505621s.

(37) Hao, X.; Wang, H.; Lin, Z.; Ouyang, M. Seasonal Effects on Electric Vehicle Energy Consumption and Driving Range: A Case Study on Personal, Taxi, and Ridesharing Vehicles. J. Clean. Prod. 2019, 249, 119403. https://doi.org/10.1016/j.jclepro.2019.119403.

(38) Gao, Z.; Lin, Z.; LaClair, T. J.; Liu, C.; Li, J.-M.; Birky, A. K.; Ward, J. Battery Capacity and Recharging Needs for Electric Buses in City Transit Service. Energy 2017, 122, 588-600.

https://doi.org/10.1016/j.energy.2017.01.101.

(39) Zhou, B.; Wu, Y.; Zhou, B.; Wang, R.; Ke, W.; Zhang, S.; Hao, J. Real-World Performance of Battery Electric Buses and Their Life-Cycle Benefits with Respect to Energy Consumption and Carbon Dioxide Emissions. Energy 2016, 96, 603-613. https://doi.org/10.1016/j.energy.2015.12.041.

(40) Stocker, T. F.; Qin, D.; Plattner, G. K.; Tignor, M. M. B.; Allen, S. K.; Boschung, J.; Nauels, A.; Xia, Y.; Bex, V.; Midgley, P. M. Climate Change 2013: The Physical Science Basis. Working Group I Contribution to the Fifth Assessment Report of the Intergovernmental Panel on Climate Change. Cambridge Univ. Press 2013.

(41) Intergovernmental Panel On Climate Change. Volume 2 Energy - Chapter 3 Mobile Combustion. In 2006 IPCC Guidelines for National Greenhouse Gas Inventories; 2006; pp 1-78.

(42) Nam, E. K.; Jensen, T. E.; Wallington, T. J. Methane Emissions from Vehicles. Environ. Sci. Technol. 2004, 38 (7), 2005-2010. https://doi.org/10.1021/es034837g.

(43) Becker, K. H.; Lörzer, J. C.; Kurtenbach, R.; Wiesen, P.; Jensen, T. E.; Wallington, T. J. Nitrous Oxide (N2O) Emissions from Vehicles. Environ. Sci. Technol. 1999, 33 (22), 4134-4139. https://doi.org/10.1021/es9903330.

(44) Popa, M. E.; Vollmer, M. K.; Jordan, A.; Brand, W. A.; Pathirana, S. L.; Rothe, M.; Röckmann, T. Vehicle Emissions of Greenhouse Gases and Related Tracers from a Tunnel Study: $\mathrm{CO}: \mathrm{CO}$, $\mathrm{N} 2 \mathrm{O}: \mathrm{CH} 4: \mathrm{O} 2$ : Atios, and the Stable Isotopes $13 \mathrm{C}$ and $18 \mathrm{O}$ in $\mathrm{CO} 2$ and CO. Atmos. Chem. Phys. 2014, 14 (4), 2105-2123. https://doi.org/10.5194/acp-14-2105-2014.

(45) Argonne National Laboratory. Greet 2016. 2014. 
(46) Energy Market Authority. Singapore Energy Statistics 2020 www.ema.gov.sg/singapore-energystatistics/ (accessed Jan 10, 2021).

(47) Kannan, R.; Leong, K. C.; Osman, R.; Ho, H. K.; Tso, C. P. Gas Fired Combined Cycle Plant in Singapore: Energy Use, GWP and Cost-a Life Cycle Approach. Energy Convers. Manag. 2005, 46 (13-14), 2145-2157. https://doi.org/10.1016/j.enconman.2004.10.021.

(48) Wernet, G.; Bauer, C.; Steubing, B.; Reinhard, J.; Moreno-Ruiz, E.; Weidema, B. The Ecoinvent Database Version 3 (Part I): Overview and Methodology. Int. J. Life Cycle Assess. 2016, 21 (9), 1218-1230. https://doi.org/10.1007/s11367-016-1087-8.

(49) Mutel, C. L. Brightway: An Open Source Framework for Life Cycle Assessment. J. Open Source Softw. 2017, 12 (2), 1-2. https://doi.org/10.21105/joss.00236.

(50) Kawamoto, R.; Mochizuki, H.; Moriguchi, Y.; Nakano, T.; Motohashi, M.; Sakai, Y.; Inaba, A. Estimation of $\mathrm{CO} 2$ Emissions of Internal Combustion Engine Vehicle and Battery Electric Vehicle Using LCA. Sustainability 2019, 11 (9), 2690. https://doi.org/10.3390/su11092690.

(51) Kim, H. C.; Wallington, T. J.; Arsenault, R.; Bae, C.; Ahn, S.; Lee, J. Cradle-to-Gate Emissions from a Commercial Electric Vehicle Li-Ion Battery: A Comparative Analysis. Environ. Sci. Technol. 2016, 50 (14), 7715-7722. https://doi.org/10.1021/acs.est.6b00830.

(52) Cars-Data. All technical specs in one car database https://www.cars-data.com/en/.

(53) Volvo. Volvo B5LH Specifications.

(54) Cooney, G.; Hawkins, T. R.; Marriott, J. Life Cycle Assessment of Diesel and Electric Public Transportation Buses. J. Ind. Ecol. 2013, 17 (5), n/a-n/a. https://doi.org/10.1111/jiec.12024.

(55) Singapore National Environmental Agency. Singapore's Fourth National Communication and Third Biennial Update Report; 2018.

(56) United Nations Framework Convention on Climate Change. Adoption of the Paris Agreement; Paris, 2015.

(57) Matthews, H. D.; Gillett, N. P.; Stott, P. A.; Zickfeld, K. The Proportionality of Global Warming to Cumulative Carbon Emissions. Nature 2009, 459 (7248), 829-832.

https://doi.org/10.1038/nature08047.

(58) Meinshausen, M.; Meinshausen, N.; Hare, W.; Raper, S. C. B.; Frieler, K.; Knutti, R.; Frame, D. J.; Allen, M. R. Greenhouse-Gas Emission Targets for Limiting Global Warming to $2^{\circ} \mathrm{C}$. Nature 2009, 458 (7242), 1158-1162. https://doi.org/10.1038/nature08017.

(59) Riahi, K.; van Vuuren, D. P.; Kriegler, E.; Edmonds, J.; O’Neill, B. C.; Fujimori, S.; Bauer, N.; Calvin, K.; Dellink, R.; Fricko, O.; Lutz, W.; Popp, A.; Cuaresma, J. C.; KC, S.; Leimbach, M.; Jiang, L.; Kram, T.; Rao, S.; Emmerling, J.; Ebi, K.; Hasegawa, T.; Havlik, P.; Humpenöder, F.; Da Silva, L. A.; Smith, S.; Stehfest, E.; Bosetti, V.; Eom, J.; Gernaat, D.; Masui, T.; Rogelj, J.; Strefler, J.; Drouet, L.; Krey, V.; Luderer, G.; Harmsen, M.; Takahashi, K.; Baumstark, L.; Doelman, J. C.; Kainuma, M.; Klimont, Z.; Marangoni, G.; Lotze-Campen, H.; Obersteiner, M.; Tabeau, A.; Tavoni, M. The Shared Socioeconomic Pathways and Their Energy, Land Use, and Greenhouse Gas Emissions Implications: An Overview. Glob. Environ. Chang. 2017, 42, 153-168.

https://doi.org/10.1016/j.gloenvcha.2016.05.009. 
(60) Rogelj, J.; Popp, A.; Calvin, K. V.; Luderer, G.; Emmerling, J.; Gernaat, D.; Fujimori, S.; Strefler, J.; Hasegawa, T.; Marangoni, G.; Krey, V.; Kriegler, E.; Riahi, K.; Van Vuuren, D. P.; Doelman, J.; Drouet, L.; Edmonds, J.; Fricko, O.; Harmsen, M.; Havlík, P.; Humpenöder, F.; Stehfest, E.; Tavoni, M. Scenarios towards Limiting Global Mean Temperature Increase below $1.5^{\circ} \mathrm{C}$. Nat. Clim. Chang. 2018, 8 (4), 325-332. https://doi.org/10.1038/s41558-018-0091-3.

(61) Gidden, M. J.; Riahi, K.; Smith, S. J.; Fujimori, S.; Luderer, G.; Kriegler, E.; van Vuuren, D. P.; van den Berg, M.; Feng, L.; Klein, D.; Calvin, K.; Doelman, J. C.; Frank, S.; Fricko, O.; Harmsen, M.; Hasegawa, T.; Havlik, P.; Hilaire, J.; Hoesly, R.; Horing, J.; Popp, A.; Stehfest, E.; Takahashi, K. Global Emissions Pathways under Different Socioeconomic Scenarios for Use in CMIP6: A Dataset of Harmonized Emissions Trajectories through the End of the Century. Geosci. Model Dev. Discuss. 2018, No. November, 1-42. https://doi.org/10.5194/gmd-2018-266.

(62) Clarke, L. E.; Jiang, K.; Akimoto, K.; Babiker, M.; Blanford, G. J.; Fisher-Vanden, K.; Hourcade, J.-C.; Krey, V.; Kriegler, E.; Loschel, A. Assessing Transformation Pathways. In: Climate Change 2014: Mitigation of Climate Change. Contribution of Working Group III to the Fifth Assessment Report of the Intergovernmental Panel on Climate Change; 2015.

(63) Gignac, R.; Matthews, H. D. Allocating a $2{ }^{\circ} \mathrm{C}$ Cumulative Carbon Budget to Countries. Environ. Res. Lett. 2015, 10 (7), 075004. https://doi.org/10.1088/1748-9326/10/7/075004.

(64) Du Pont, Y. R.; Jeffery, M. L.; Gütschow, J.; Christoff, P.; Meinshausen, M. National Contributions for Decarbonizing the World Economy in Line with the G7 Agreement. Environ. Res. Lett. 2016, 11 (5). https://doi.org/10.1088/1748-9326/11/5/054005.

(65) Robiou du Pont, Y.; Jeffery, M. L.; Gütschow, J.; Rogelj, J.; Christoff, P.; Meinshausen, M. Equitable Mitigation to Achieve the Paris Agreement Goals. Nat. Clim. Chang. 2017, 7 (1), 38-43. https://doi.org/10.1038/nclimate3186.

(66) Meyer, A. Contraction \& Convergence: The Global Solution to Climate Change; Green Books, 2000.

(67) International Energy Agency. CO2 Emissions from Fuel Combustion 2019 www.iea.org/reports/co2-emissions-from-fuel-combustion-2019 (accessed Jan 10, 2021).

(68) Le Quéré, C.; Andrew, R. M.; Friedlingstein, P.; Sitch, S.; Hauck, J.; Pongratz, J.; Pickers, P. A.; Korsbakken, J. I.; Peters, G. P.; Canadell, J. G.; Arneth, A.; Arora, V. K.; Barbero, L.; Bastos, A.; Bopp, L.; Chevallier, F.; Chini, L. P.; Ciais, P.; Doney, S. C.; Gkritzalis, T.; Goll, D. S.; Harris, I.; Haverd, V.; Hoffman, F. M.; Hoppema, M.; Houghton, R. A.; Hurtt, G.; llyina, T.; Jain, A. K.; Johannessen, T.; Jones, C. D.; Kato, E.; Keeling, R. F.; Goldewijk, K. K.; Landschützer, P.; Lefèvre, N.; Lienert, S.; Liu, Z.; Lombardozzi, D.; Metzl, N.; Munro, D. R.; Nabel, J. E. M. S.; Nakaoka, S.; Neill, C.; Olsen, A.; Ono, T.; Patra, P.; Peregon, A.; Peters, W.; Peylin, P.; Pfeil, B.; Pierrot, D.; Poulter, B.; Rehder, G.; Resplandy, L.; Robertson, E.; Rocher, M.; Rödenbeck, C.; Schuster, U.; Schwinger, J.; Séférian, R.; Skjelvan, I.; Steinhoff, T.; Sutton, A.; Tans, P. P.; Tian, H.; Tilbrook, B.; Tubiello, F. N.; van der Laan-Luijkx, I. T.; van der Werf, G. R.; Viovy, N.; Walker, A. P.; Wiltshire, A. J.; Wright, R.; Zaehle, S.; Zheng, B. Global Carbon Budget 2018. Earth Syst. Sci. Data 2018, 10 (4), 2141-2194. https://doi.org/10.5194/essd-10-2141-2018.

(69) Hoesly, R. M.; Smith, S. J.; Feng, L.; Klimont, Z.; Janssens-Maenhout, G.; Pitkanen, T.; Seibert, J. J.; Vu, L.; Andres, R. J.; Bolt, R. M.; Bond, T. C.; Dawidowski, L.; Kholod, N.; Kurokawa, J.; Li, M.; Liu, L.; Lu, Z.; Moura, M. C. P.; O’Rourke, P. R.; Zhang, Q. Historical (1750-2014) Anthropogenic 
Emissions of Reactive Gases and Aerosols from the Community Emission Data System (CEDS). Geosci. Model Dev. Discuss. 2017, 1-41. https://doi.org/10.5194/gmd-2017-43.

(70) Climate Action Tracker. Country summary: Singapore https://climateactiontracker.org/countries/singapore/ (accessed Jan 10, 2021).

(71) Kriegler, E.; Bauer, N.; Popp, A.; Humpenöder, F.; Leimbach, M.; Strefler, J.; Baumstark, L.; Bodirsky, B. L.; Hilaire, J.; Klein, D.; Mouratiadou, I.; Weindl, I.; Bertram, C.; Dietrich, J.-P.; Luderer, G.; Pehl, M.; Pietzcker, R.; Piontek, F.; Lotze-Campen, H.; Biewald, A.; Bonsch, M.; Giannousakis, A.; Kreidenweis, U.; Müller, C.; Rolinski, S.; Schultes, A.; Schwanitz, J.; Stevanovic, M.; Calvin, K.; Emmerling, J.; Fujimori, S.; Edenhofer, O. Fossil-Fueled Development (SSP5): An Energy and Resource Intensive Scenario for the 21st Century. Glob. Environ. Chang. 2017, 42, 297-315. https://doi.org/10.1016/j.gloenvcha.2016.05.015.

(72) Fricko, O.; Havlik, P.; Rogelj, J.; Klimont, Z.; Gusti, M.; Johnson, N.; Kolp, P.; Strubegger, M.; Valin, H.; Amann, M.; Ermolieva, T.; Forsell, N.; Herrero, M.; Heyes, C.; Kindermann, G.; Krey, V.; McCollum, D. L.; Obersteiner, M.; Pachauri, S.; Rao, S.; Schmid, E.; Schoepp, W.; Riahi, K. The Marker Quantification of the Shared Socioeconomic Pathway 2: A Middle-of-the-Road Scenario for the 21st Century. Glob. Environ. Chang. 2017, 42, 251-267.

https://doi.org/10.1016/j.gloenvcha.2016.06.004.

(73) Calvin, K.; Patel, P.; Clarke, L.; Asrar, G.; Bond-Lamberty, B.; Yiyun Cui, R.; Di Vittorio, A.; Dorheim, K.; Edmonds, J.; Hartin, C.; Hejazi, M.; Horowitz, R.; Iyer, G.; Kyle, P.; Kim, S.; Link, R.; Mcjeon, H.; Smith, S. J.; Snyder, A.; Waldhoff, S.; Wise, M. GCAM v5.1: Representing the Linkages between Energy, Water, Land, Climate, and Economic Systems. Geosci. Model Dev. 2019, 12 (2), 677-698. https://doi.org/10.5194/gmd-12-677-2019.

(74) Dalkmann, H.; Brannigan, C. Urban Transport and Climate Change, Module 5e: Sustainable Transport, a Sourcebook for Policy-Makers in Developing Cities. GTZ Glob. Fed. Eschborn, Ger. Minist. Econ. Coop. Dev. 2007.

(75) United Nations. World Population Prospects 2019 population.un.org/wpp/ (accessed Jan 10, 2021).

(76) Diao, M. Towards Sustainable Urban Transport in Singapore: Policy Instruments and Mobility Trends. Transp. Policy 2019, 81 (November 2016), 320-330.

https://doi.org/10.1016/j.tranpol.2018.05.005.

(77) Government of Singapore. Budget 2020 Speech: Advancing As One Singapore www.singaporebudget.gov.sg/budget_2020/budget-speech (accessed Jan 10, 2021).

(78) Land Transport Authority. Land Transport Master Plan 2040; 2019.

(79) Allen, J. G. Reasons for Commuter Rail Electrification: Early 20th Century and Since 2000. Transp. Res. Rec. 2019, 2673 (7), 227-238. https://doi.org/10.1177/0361198119840621. 